\title{
Copyright
}

by

Katherine Saunders McCalister

2003 
The Dissertation Committee for Katherine Saunders McCalister Certifies that this is the approved version of the following dissertation:

\section{HARDINESS AND SUPPORT AT WORK AS PREDICTORS OF WORK STRESS AND JOB SATISFACTION}

Committee:

Mary Steinhardt, Supervisor

Nell Gottlieb

John Bartholomew

Oscar Mink

Christyn Dolbier 


\title{
HARDINESS AND SUPPORT AT WORK AS PREDICTORS OF WORK STRESS AND JOB SATISFACTION
}

\author{
by \\ KATHERINE SAUNDERS MCCALISTER, B.S., M.A. \\ DISSERTATION \\ Presented to the Faculty of the Graduate School of \\ The University of Texas at Austin \\ in Partial Fulfillment \\ of the Requirements \\ for the Degree of \\ DOCTOR OF EDUCATION
}

THE UNIVERSITY OF TEXAS AT AUSTIN

MAY, 2003 


\section{Dedication}

With gratitude I dedicate this volume to the memory of my mother. Without her

love, support, devotion, and encouragement for the first thirty-one years of my life, I may not have had the consistency to pursue and complete my doctorate. 


\title{
Acknowledgements
}

\author{
I am grateful \\ -to Mark, my husband, for his patience and understanding. \\ -to my family for their ongoing support \\ -to my dear friends and colleagues who have
} provided me with encouragement throughout my doctoral work. 


\section{HARDINESS AND SUPPORT AT WORK AS PREDICTORS OF WORK STRESS AND JOB SATISFACTION}

Publication No.

Katherine Saunders McCalister, Ed.D.

The University of Texas at Austin, 2003

Supervisor: Mary Steinhardt

Both work stress and job satisfaction are important individual factors which directly influence organizational outcomes. In addition to influencing work outcomes, these factors may have a positive impact on an individual's well-being and overall life satisfaction. The person-environment fit model, social exchange theory, and the transactional theory of stress and coping provide the framework in this paper for the discussion of the effect that individual and environmental factors have on work stress and job satisfaction. The present study tests a model predicting work stress and job satisfaction using two available samples: 1) a sample of high-tech employees ( $\mathrm{N}=378)$, and 2) a sample of government agency employees $(\mathrm{N}=745)$. The proposed model investigates the effects of the work environment variables (coworker support and supervisor support) and the 
personality disposition variables (hardiness and negative affect) on the outcome variables of work stress and job satisfaction.

Results of the path analyses indicate that the proposed model fits the data for both the government agency and high-tech samples. The fit indices were calculated after the non-significant pathway (negative affectivity to job satisfaction) was removed to improve the fit of the model. All hypotheses were supported such that the predictor variables of supervisor support, coworker support and hardiness significantly predicted the criterion variables work stress and job satisfaction, above and beyond the variance accounted for by the confounding variable, negative affectivity. A secondary test of multiple group path analysis using nested model comparison was employed to compare whether selected pathways were equal across the two samples. The findings of this secondary analysis re-confirm that the model fits the data for both samples. In addition, a second model (Model 2) was developed, with five pathways constrained to be equal between the high tech and government agency samples. Model 2 was found to be the most parsimonious model, with the best fit to both samples. Overall, the findings from the current study indicate that both the work environment variables (coworker support and supervisor support) and the personality disposition variables (hardiness and negative affect) significantly influence the outcome variables of work stress and job satisfaction. The results of this study suggest that the work environment and individual personality traits may exude protective effects that reduce work stress and increase job satisfaction. 
This study has implications for all professionals who are interested in reducing work stress and enhancing job satisfaction for employees in the work setting. 


\section{Table of Contents}

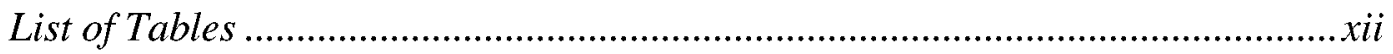

List of Figures..................................................................................

CHAPTER ONE 1

Introduction ................................................................................................ 1

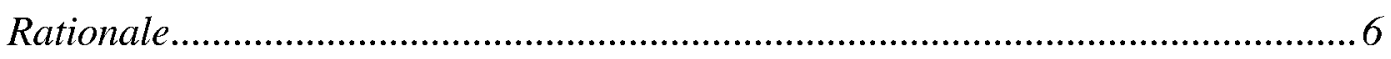

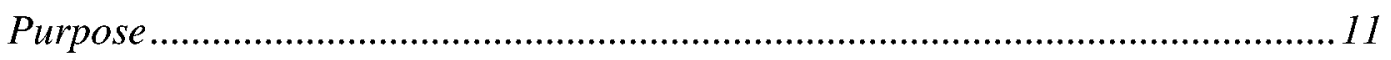

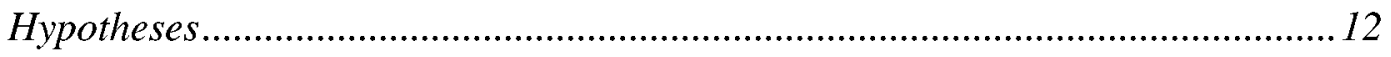

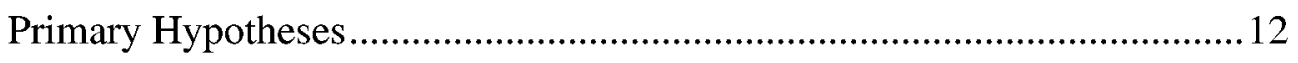

Secondary Hypotheses ....................................................................... 13

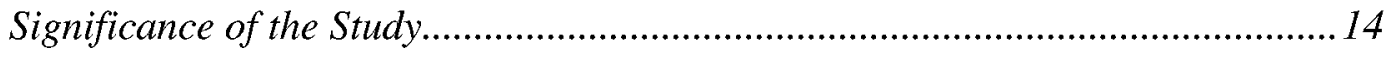

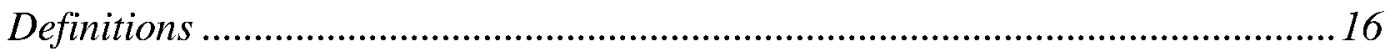

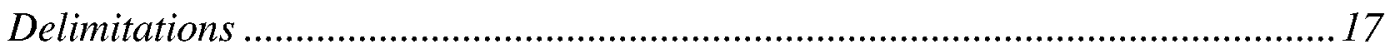

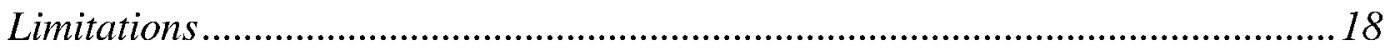

$\begin{array}{lr}\text { CHAPTER TWO } & 20\end{array}$

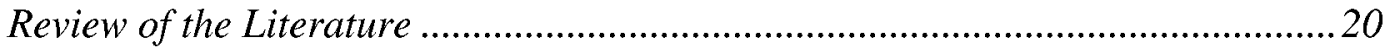

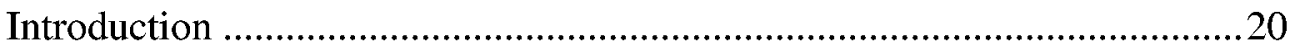

Review of Theoretical Framework ........................................................2 21

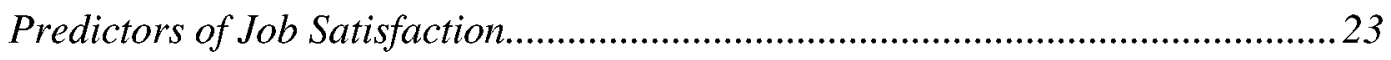

Relationship of Work Stress to Job Satisfaction ......................................23

Support at Work and Job Satisfaction ......................................................25

The Relationship of Coworker Support to Job Satisfaction .......................26

The Relationship of Supervisor Support to Job Satisfaction ......................27 
The Relationship of Hardiness to Job Satisfaction...................................... 29

Predictors of Work Stress.................................................................................... 31

The Relationship of Coworker Support to Work Stress............................ 31

The Relationship of Supervisor Support to Work Stress ........................... 32

The Relationship of Hardiness to Work Stress ......................................... 33

Inclusion of Negative Affectivity in the Model ....................................... 35

Chapter Summary: Review of the Literature ............................................ 37

\begin{tabular}{l} 
CHAPTER THREE \\
\hline 9
\end{tabular}

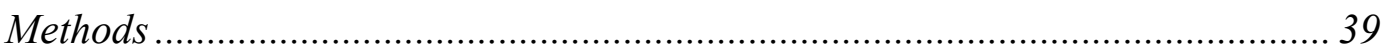

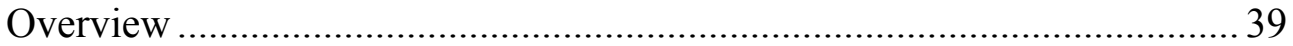

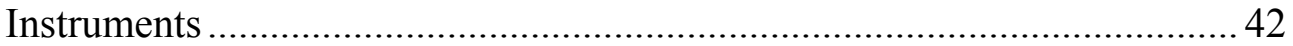

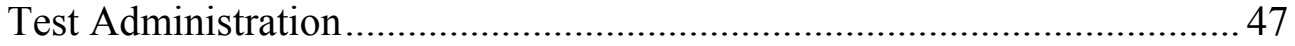

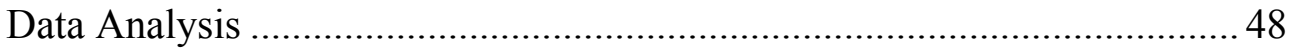

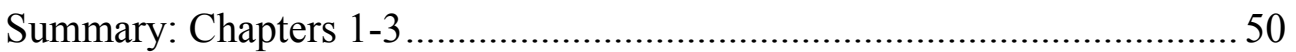

CHAPTER FOUR

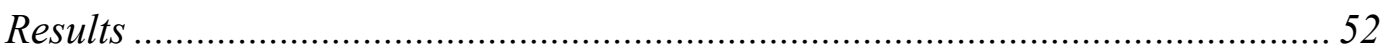

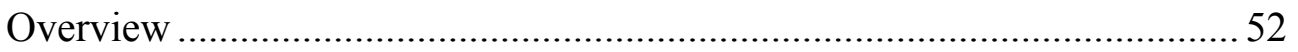

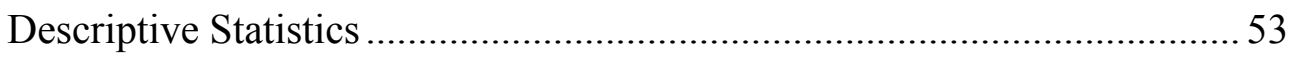

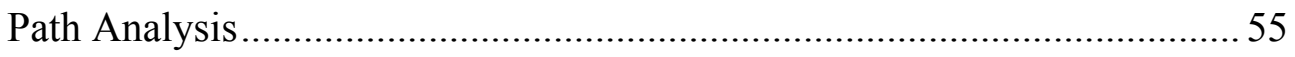

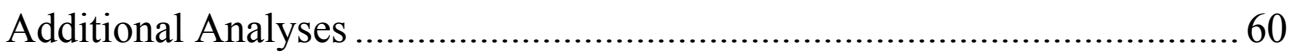

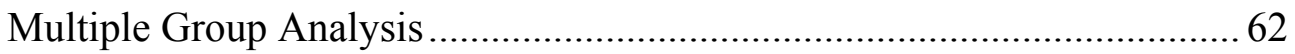

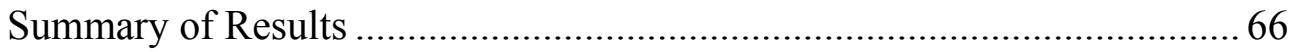

$\begin{array}{ll}\text { CHAPTER FIVE } & 70\end{array}$

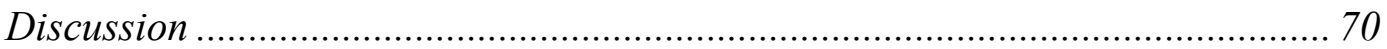

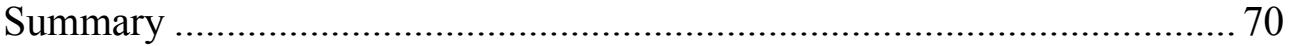

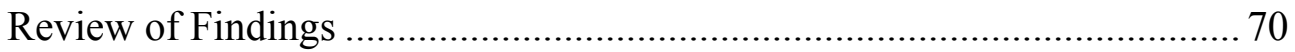

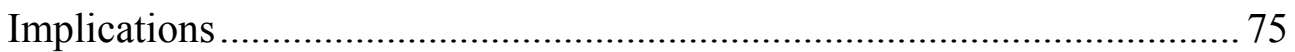


Study Limitations and Recommendations For Future Research .................78

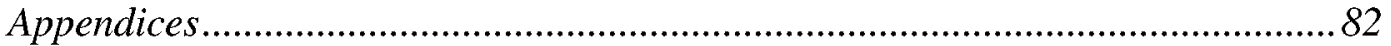

Appendix A: High-Tech Sample Survey ….............................................83

Appendix B: Government Agency Sample Survey ....................................86

Appendix C: High Tech Consent Letter ....................................................90

Appendix D: Government Agency Consent Letter .................................91

Appendix E: Job Satisfaction Single and 15-Item Correlation....................92

Appendix F: Gender Differences........................................................94

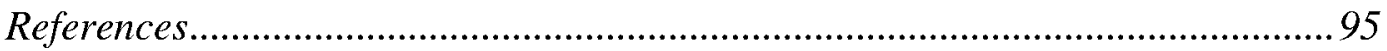

Vita 


\section{List of Tables}

Table 1. Possible Range of Scores, Means, and Standard Deviations for All

Variables in High Tech $(\mathrm{N}=310)$ and Government $(\mathrm{N}=745)$

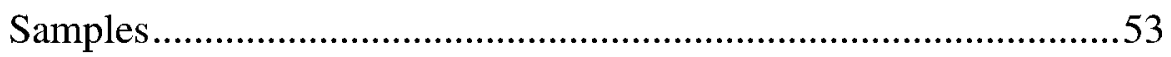

Table 2. High Tech Sample: Correlations among All Variables ..........................57

Table 3. Government Agency Sample: Correlations among All Variables ..........57

Table 4. Path Coefficients in the Final Model: High Tech Sample......................61

Table 5. Path Coefficients in the Final Model: Government Agency Sample ......61

Table 6. Goodness-of-Fit Indices for Final High Tech and Government

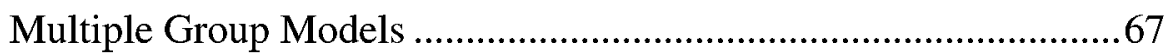

Table 7. Path Coefficients from Multiple Groups Analysis Model 2: High

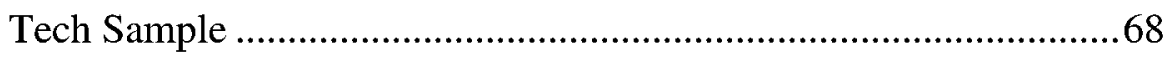

Table 8. Path Coefficients from Multiple Groups Analysis Model 2:

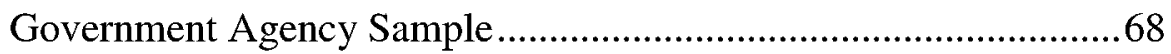




\section{List of Figures}

Figure 1. Person and Environment Transaction Diagram and Work Outcomes .....9

Figure 2. Path Model: Hardiness \& Support at Work as Predictors of Work Stress

\& Job Satisfaction............................................................................ 12

Figure 3. High Tech Path Model (Single Group Analysis) ...............................59

Figure 4. Government Agency Path Model (Single Group Analysis)..................59

Figure 5. Final Model High Tech Sample (Multiple Group-Five Pathways

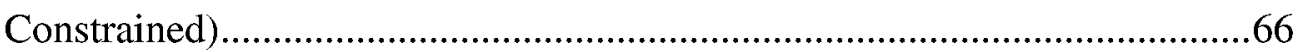

Figure 6. Final Model Government Sample (Multiple Group -Five Pathways

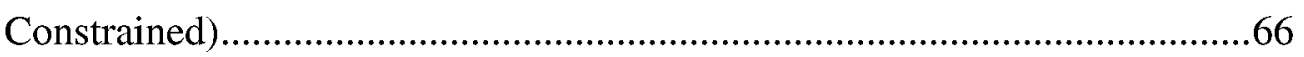




\section{CHAPTER ONE}

\section{Introduction}

The nature of work is changing, driven by rapid advancements in technology, globalization, business deregulation and economic demand for increased operational productivity. These changes can have a negative impact on both individuals and organizations if they result in increased work stress and decreased job satisfaction. Although the nature of work is changing across all organizations, the negative effects of change at work are not experienced equally by all individuals. The current study examines the effects of individual dispositions and environmental variables that may reduce employee work stress and enhance job satisfaction.

Across industries, companies are re-examining ways to streamline production processes to achieve optimal levels of productivity and profits. In the midst of these productivity enhancements, employees may be facing an increasing workload due to greater frequency of electronic communications, additional training required to master new technology and a greater number of diverse customers with the globalization of industry. Commonly employees are given fewer resources to manage their increased workload, such as less time for each project due to increasing responsibilities and less staff assistance due to company downsizing. The discrepancy between workload and resources frequently results in employees spending more time at work. According to the United States (U.S.) Department of Labor (1999a) more than 134 million people are employed in the U.S., and total employment is projected to increase to more than 155 million by 2008 . Employed adults who are caught up in the changing nature of work make up the vast majority of adults, 134 million out of 142 million in Americans (U.S. Department of Labor, 1999a). Although the changes that workers are experiencing on the job can often bring opportunities, frequent change in the workplace can also lead to increased work stress. Feeling "stressed" at work is 
not unusual. However, some employees experience debilitating stress symptoms to the degree that they need to take time off from work to recover. Overall, high levels of work stress can be detrimental to both the employee and the employer.

In the U.S., there has been increasing concern about the impact of stress-related illness and injury on the cost of health care and lost productivity in the workplace. The Health Enhancement Research Organization committee (HERO) conducted a study linking healthcare expenditures to modifiable (lifestyle-related) health risks for a sample of 46,026 employees in six different U.S. companies. The findings from the HERO study indicate that workers who reported high levels of work stress had annual healthcare expenditures averaging 46 percent higher than their counterparts. In addition, participants in the same study who reported high levels of both stress and depression had healthcare expenditures 147 percent higher than those employees who did not report high levels of stress or depression. Results from this study suggest that high levels of occupational stress increase healthcare expenditures and lead to lost productivity (Goetzel et al., 1998). In addition to the HERO study, federal labor statistics attribute a significant amount of lost productivity to occupational stress. In 1997, the U.S. Department of Labor reported 3,418 total occupational stress-related injuries and illnesses annually. The median absence resulting from these conditions was 23 lost days, with more than 40 percent of these cases resulting in 31 or more days of lost productivity (U.S. Department of Labor, 1999b).

The employers' cost of occupational stress-related illnesses and injuries continues to increase along with the rising cost of healthcare. Occupational illnesses and injuries not only increase the operational expenses of the company through medical and lost time expenses, but the cumulative effects of occupational stress can also distract from work through lost productivity. In addition to the effects of occupational stress on the organization, stress can also have a debilitating effect on employee well-being and performance. The impact of occupational stress on the employee is evident in a recent publication by the National Institute for Occupational Safety and Health (NIOSH), Stress at Work (1999). This 
summary of job stress data suggests that 40 percent of surveyed employees believe that their job is "very " or "extremely stressful" and 26 percent of surveyed workers report they are "often or very often burned out/stressed out by their work". Overall, the impact of work stress on employers and employees is substantial. These findings demonstrate the negative and frequent effect of work stress on: 1) increased employee stress-related illness and injury and 2) reduced employer profitability through increased healthcare cost, lost productivity and occupational and non-occupational illness and injury. Companies' concerns about medical costs and lost productivity will continue to increase as the cost of health care and managing businesses across all industries in the U.S. rises.

Another negative effect of work stress for the individual employee is job dissatisfaction. Job dissatisfaction is not uncommon. In the 1999 Gallup News Service Labor Day Poll, less than 50 percent of a randomly selected sample indicated they were "completely satisfied" with their jobs. The polled participants expressed the greatest dissatisfaction with the level of stress at work, job security and pay. Responses from this same sample of workers indicated that 44 percent of the 641 adult workers interviewed described themselves as "workaholics."

Although job satisfaction is a leading indicator of valued work outcomes, it is in and of itself an important business metric. Job dissatisfaction has been identified as one of the adverse outcomes of work stress, such that high levels of work stress correlate to high levels of job dissatisfaction. In a 2001 Gallup News Service Poll, 599 employed adults participated in nationwide telephone survey interviews to assess work stress and job dissatisfaction. Thirty-six percent of the survey respondents reported experiencing high levels of stress on the job. In addition, most participants indicated that stress at work increased their job dissatisfaction. Specifically, job dissatisfaction findings from the Gallup Poll (2001) demonstrated that 33 percent of all workers reported they would be "happier in another job". Overall, these Gallup findings indicate that many employees are not satisfied with their jobs and that high levels of stress at work contribute to job dissatisfaction. 
Job satisfaction is not static. It may change based on a number of different contributing factors (e.g., support at work). Fluctuations in job satisfaction can result in dramatic effects on organizational outcomes. Although job satisfaction is generally thought to be motivated by salary and benefits, a review of the literature indicates different predictors. Research indicates that job satisfaction is influenced by work stress, personality disposition (Judge, Locke, Durham, \& Kluger, 1998; Rush, Schoel, \& Barnard, 1995), coworker support (House, 1981; Kahn, Wolfe, Quinn, Snoek, \& Rosenthal, 1964; Revicki, Whitley, \& Gallery, 1993) and supervisor support (Babin \& Boles, 1996; Beardslee, White, \& Ritcher, 1985; House, 1981; Terry, Nielsen, \& Perchard, 1993). Personality disposition (hardiness and negative affectivity) and the availability of supportive resources act to influence individual perceptions of satisfaction. These factors sometimes make measurement of job satisfaction difficult. Even though it is often difficult to measure, job satisfaction and its determinants are of interest to practitioners in many fields (e.g., human resources management, industrial and organizational psychology, and operations management) due to its association with important business outcomes.

Job dissatisfaction can have a negative impact on the employee as well as the company. In addition to the negative impact job dissatisfaction has on an employee at work, a spillover effect is seen between satisfaction at work and satisfaction with other aspects of an individual's life, such as marriage and overall life satisfaction. It appears that this relationship is stronger depending on the centrality (value placed) of work to an individual's life (Evans, Pellizzari, Culbert, \& Metzen, 1993; Judge \& Watanabe, 1993; Ray \& Miller, 1994; Wright, Bennett, \& Dun, 1999). For many individuals, their jobs are an important part of their life. For these individuals, job satisfaction impacts work but also satisfaction with life outside of work.

Employee dissatisfaction can influence important organizational outcomes as well. The large amount of research examining the various dimensions and predictors of job satisfaction is based on the premise that satisfied workers, at all organizational levels, are 
important contributors to an organization's effectiveness and success in the marketplace (Sauter \& Murphy, 1995). In contrast, dissatisfied workers are thought to contribute less to the organization due to decreased effort and reduced organizational commitment. Reduced commitment (Williams \& Hazer, 1986) and increased employee withdrawal behaviors are thought to play a role in lowering organizational performance through lost time and productivity (Hackett, 1989; Henne \& Locke, 1985; Locke, 1992; Mobley, 1977). Withdrawal behaviors, such as lack of attention on the job, or absence, are defined as the variety of behaviors that are intended to place physical or psychological distance between employees and adverse work environments (Hackett \& Guion, 1985; Rosse \& Hulin, 1985; Sagie, 1998). The outcomes of reduced commitment or increased employee withdrawal behaviors appear to be associated with job dissatisfaction regardless of whether dissatisfaction is verbalized or is an unexpressed concern at work. Consequently, those organizations that have more satisfied employees are likely to have employment advantages (better retention and recruitment) as compared to competitors with less satisfied employees. Job satisfaction is a major focus in business research due to its direct effect on the individual worker, the worker's overall life satisfaction, and impact on important organizational outcomes.

Taken as a whole, the importance of work stress and job satisfaction to both individuals and employers is undeniable. Work stress and job dissatisfaction are both prevalent in the work force, affecting millions of employees and their employers each year. Work stress is inversely associated with job satisfaction, such that higher levels of work stress are related to lower levels of job satisfaction. Excessive levels of work stress can lead to increased illness, increased absence, decreased job satisfaction and even reduced productivity. Employers are impacted by work stress through increased healthcare costs, loss of worker productivity, and the costs of worker replacement and training. Additionally, decreased job satisfaction may lead to decreased life satisfaction for employees, increased employee withdrawal behaviors, and decreased employee commitment which have a 
negative impact on organizational outcomes. This study applies a path analysis design to examine the influence of individual and environmental predictors of work stress and job satisfaction in two samples, a government employee sample and a high-tech employee sample from private industry. The following rationale will introduce the theoretical framework and conceptual support for the current study and the proposed path model.

\section{Rationale}

This study examines the individual resources of dispositional hardiness, and the work environment resources of supervisor and coworker support as variables that impact work stress and job satisfaction. The predictor variable of dispositional hardiness is a stress resistant character trait. The work environment predictor variables of supervisor support and coworker support are identified as the perceived availability of social support resources from supervisors or coworkers at work. The proposed model suggests that hardiness and support at work from supervisors and coworkers directly impact work stress and job satisfaction. The transactional model of stress and coping (Lazarus \& Folkman, 1984) provides the structural framework for the proposed model pictured in Figure 2. The proposed structural model illustrates a process framework, in which an individual's reactions to stressful situations and their evaluation of the available support resources influence perceived work stress and job satisfaction.

The person-environment fit model and the social exchange theory further describe the details of the processes by which this transaction occurs for each of the outcome variables within the framework of the transactional theory (Mak \& Mueller, 2000). The personenvironment fit approach to work stress acknowledges the relationships between potentially stressful situations and individual differences in response to stress (French, Caplan, \& Harrison, 1982; Lazarus \& Folkman, 1984). The model in this study is based in part on the

premise that stress results when the values, motives and needs of an individual are not met by 
the environment (Mackie, Holahan, \& Gottlieb, 2001). Conversely, stress may result if the demands of a work environment exceed the ability of the individual to meet them.

The social exchange theory (Blau, 1964) is also based on a similar exchange process between the person and the work environment and indicates that a lack of fit between the needs of the individual and the requirements of their job may lead to work stress and job satisfaction. The social exchange theory specifically addresses whether individuals feel justly rewarded in their relationships with their employer and if employees are satisfied with their job and willing to reciprocate with desired work behaviors (Janssen, 2000). Some researchers suggest that job satisfaction is a result of this transactional process between the individual and his/her work environment or that the relationship between the worker and the work environment directly influences job satisfaction (Blau, 1964; Janssen, 2000). Thus, the person-environment fit model and the social exchange theory provide the framework for understanding the relationship of dispositional hardiness and support at work to work stress and job satisfaction.

One of the interesting features of the current study is, although similar environmental demands or pressures produce stress in a substantial number of people, variations in perceptions and sensitivity to events influence each individual's vulnerability to stress (Lazarus \& Folkman, 1984). If the factors which influence an individuals' vulnerability to stress can be identified, then efforts can be made to reduce one's perceived stress. NIOSH (1999) defines work stress as the harmful and emotional response that occurs when the requirements of the job do not match the individual capabilities, resources, or needs of the worker. NIOSH distinguishes between challenge and stress on the job by inferring that challenge occurs when an event energizes a person psychologically and physically, motivating that person to learn and master new skills. When we meet the challenge, we feel relaxed and satisfied. On the other hand, chronic work stress typically stems from job demands or challenges that individuals feel they do not have the resources to meet. 
Within the proposed framework of the transactional model of stress, stress at work doesn't always have a negative impact on employee and business outcomes. Some research suggests that reasonable levels of work stress can actually provide challenge and opportunity for growth, depending on an individual's perception of the situation and the resources that person perceives are available to assist him or her in dealing with the stress (Karasek \& Theorell, 1990; Schaefer \& Moos, 1992). Lazarus (1966) proposed that an individual's personality disposition and factors in the work environment can play an important role in defining an individual's perception of stress. In their book, Stress, Appraisal and Coping, Lazarus and Folkman (1984) suggest that dispositional personality and work support factors may provide a protective function for an individual who is experiencing stress. The current study focuses on this premise.

The process of evaluating the demands (or stressors), while considering individual and work environment resources (French, et al., 1982), is referred to as the personenvironment fit model and is the conceptual basis for the transactional theory of stress and coping (previously discussed). The relationships among the variables in this study are examined in the context of the person-environment fit model as illustrated in Figure 1. Within the framework of the transactional model of stress and coping, work stress and job dissatisfaction are illustrated as the results of a poor fit between the person and his/her work environment. This transactional model suggests that a person's evaluation of stress takes into consideration the availability of internal resources, such as dispositional hardiness, as well as environmental resources, such as social support from supervisors and coworkers. The individual's perception of the availability and strength of these resources influences his/her perceived vulnerability or resistance in given stressful circumstances. The outcome of this person-environment evaluation process determines the person's perception of stress and satisfaction. This evaluation process is ongoing and may occur whenever an individual perceives a situation or series of daily hassles as stressful. 
Figure 1. Person and Environment Transaction Diagram and Work Outcomes

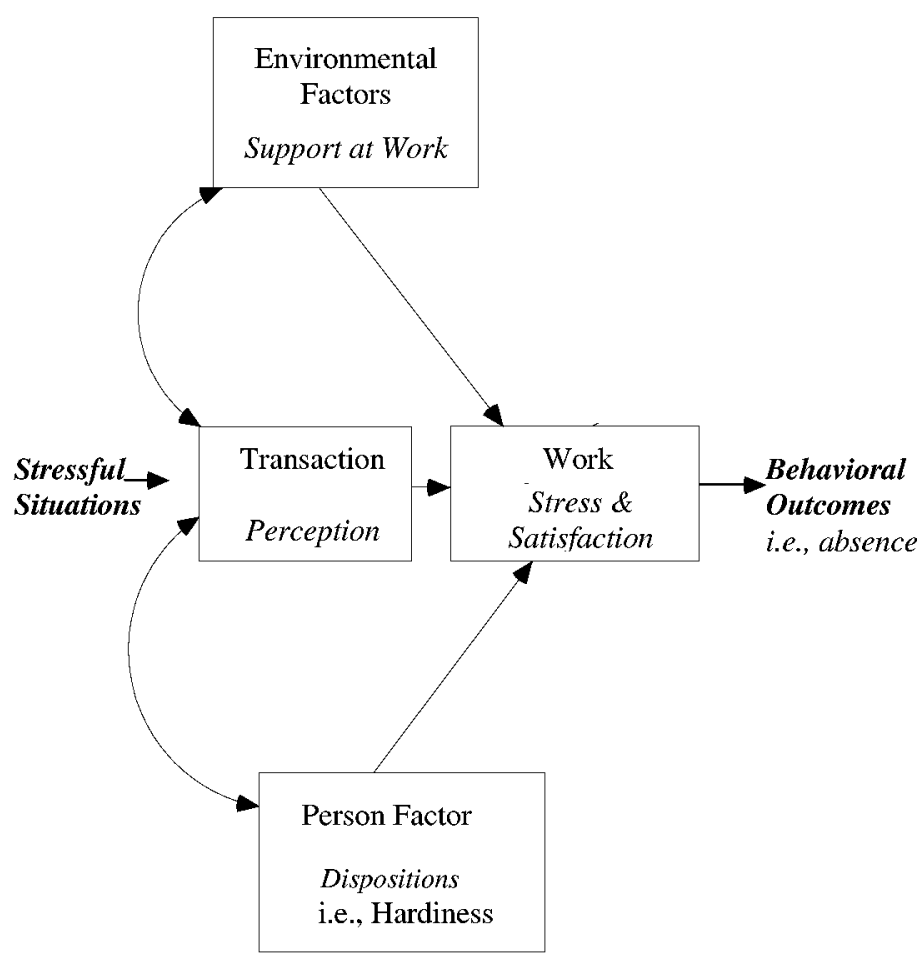

Despite the research based on the person-environment fit model (French, et al., 1982), many work-site stress interventions in the U.S. have focused on person-oriented treatments or "worker-oriented approaches" (Kompier, Geurts, Grundemann, Vink, \& Smulders, 1998). Traditional worksite "stress management" training in corporations over the past 20 years has focused on providing specific skills to recognize stress when the workers experience it and take steps to reduce the negative psychological and physical effects of stress. These types of stress management interventions may assist individuals in dealing with the symptoms of stress; however, stress responses occur as a result of an individual first perceiving a situation as stressful. This traditional approach to stress management trains the worker how to cope more effectively with stress at work, but doesn't address the individual's perception of the situation or the environmental cause of the stress. 
A more effective intervention would combine this traditional approach (focused on reducing symptoms of work stress) with efforts to enhance the individual's stress-resistant resources. These stress-resistant resources can be found in both the work environment and in the individual's disposition. Recent research has begun to establish the effectiveness of cognitive behavioral interventions which can help participants modify perceptions of how they process stressful situations (Kompier et al., 1998; Murphy, 2002). For example, stress management interventions may be most effective when they "attend to work stress at (both) the organizational and the individual levels" (Murphy, 2002, p.398).

Each worker may view their work situation differently, based on life experiences and personality traits. Negative affect is a personality trait that refers to the extent to which an individual generally experiences various negative feelings and emotions (Watson, Clark, \& Tellegen, 1988). Negative affect has been implicated as a disposition that influences an individual's perception of stressful situations. Given that negative affectivity influences an individual's perception of a stressful situation, it is included in the path model (Figure 2) to account for the contributions it makes to the criterion variables, work stress and job satisfaction, and its correlation with the other predictor variables. This study examines the contributing effects of support at work from supervisor and coworkers (external factors) as well as individual dispositions (internal factors), such as hardiness and negative affectivity, on the outcomes of perceived work stress and job satisfaction.

As indicated previously, job satisfaction is an important organizational metric in and of itself (Henne \& Locke, 1985). Organizations measure job satisfaction primarily because of its presumed impact on business goals and the effect on company revenue (e.g., cost of turnover, absence and lost productivity). Job satisfaction has been associated with enhanced worker productivity (Goetzel et al., 1998) and reduced absence, errors, and decreased employee turnover (Hackett, 1989; Sagie, 1998). Higher levels of work stress or lower levels of job satisfaction can lead to employee behaviors that can be detrimental to employers and the business community. Henne and Locke (1985) suggest that job satisfaction is a result of 
the perception that an individual's job experiences are fulfilling his/her perceived job values. This research provides additional support for the social exchange process model for job satisfaction, which suggests that job satisfaction is a result of a transactional process involving an individual's effort at work and their perception of the work environment (Blau, 1964; Janssen, 2000).

The conceptual model proposed and tested in this study is based on a review of the research that supports the relationships illustrated in Figure 2. This model seeks to replicate the relationships between the outcome variables of work stress and job satisfaction found in the review of literature. In addition, the study examines the effects of the personality disposition variables, hardiness and negative affectivity and the work environment variables of coworker and supervisor support, on work stress and job satisfaction. The conceptual model, illustrated in Figure 2, is applied to test the predicted relationships described in the hypotheses to follow.

\section{Purpose}

Based on the person-environment fit model, the present study tests a model predicting work stress and job satisfaction on two available samples: 1) a sample of high-tech employees $(\mathrm{N}=378)$ and 2$)$ a sample of government agency employees $(\mathrm{N}=747)$. This model explores the influence of work environment resources (coworker support and supervisor support) and dispositional personality traits (hardiness and negative affectivity) on the outcome variables of work stress and job satisfaction, while accounting for the contribution of negative affectivity to all variables. 
Figure 2.

Path Model: Hardiness \& Support at Work as Predictors of Work Stress \& Job Satisfaction

$$
\text { Predictor Variables Criterion Variables }
$$

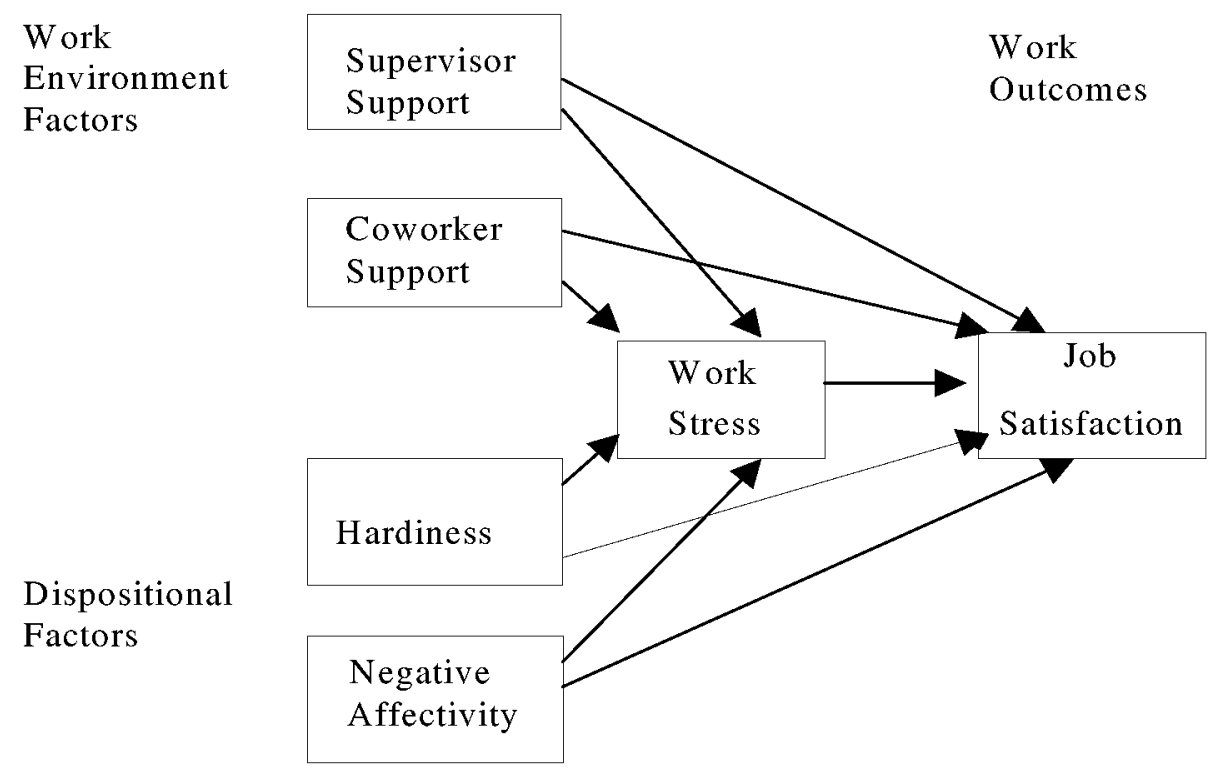

\section{Hypotheses}

The model (illustrated in Figure 2) was hypothesized to fit both the high-tech and the government agency employee data sets.

\section{PRIMARY HYPOTHESES}

H1. The predictor variables of supervisor support, coworker support and hardiness account for a substantial amount of variance in the criterion variable, work stress. 
H2. The predictor variables of work stress, supervisor support, coworker support, and hardiness account for a substantial amount of variance in the criterion variable, job satisfaction.

H3. The predictor variables of supervisor support, coworker support and hardiness significantly predict the criterion variables of work stress and job satisfaction and account for variance above and beyond that of negative affectivity in the model.

\section{SECONDARY HYPOTHESES}

The researcher anticipated the analysis to yield the following path relationships:

H4. A negative relationship exists between work stress and job satisfaction.

H5. A positive relationship exists between supervisor support and job satisfaction.

H6. A positive relationship exists between coworker support and job satisfaction.

H7. A positive relationship exists between hardiness and job satisfaction.

H8. A negative relationship exists between supervisor support and work stress.

H9. A negative relationship exists between coworker support and work stress.

H10. A negative relationship exists between hardiness and work stress.

Negative affectivity is included in the model as a confounding variable, not as a variable of interest. It is expected to have an inverse relationship with each of the predictor variables, a positive relationship with work stress, and a negative relationship with job satisfaction. The proposed relationships suggest direct associations between the predictor and criterion variables; however, the proposed direct effects may take into account any potential indirect effects and intercorrelations between the variables. For example, if supervisor support is directly related to work stress and work stress is directly related to job satisfaction, then part of the raw effect of supervisor support on job satisfaction could be due to the indirect effect of supervisor support on job satisfaction through reduced work stress. After controlling for the intercorrelations and indirect relationships, the researcher expected the model to yield the direct paths indicated in the hypotheses. The relationships illustrated in the model are presented in the next chapter. 


\section{Significance of the Study}

The findings of the current study are important and add to the related research in the health, human resources, organizational development and business literature. First, Rush et al. (1995) recommend that future investigations consider social support relationships at work as a predictor in path models predicting work stress and job satisfaction. This study includes social support measures for both supervisor and coworker support, as they relate to the outcome variables of work stress and job satisfaction.

Second, although the measures chosen for work stress, social support and job satisfaction are general measures (not used to evaluate particular facets), they are, however, specific to the work domain. These general measures (work stress, social support and job satisfaction) were chosen for their direct applicability to the workplace. The measures of work stress, social support and job satisfaction are very similar to the survey tools many corporations use to evaluate their organizational climates and assess employee satisfaction with work programs and services. Therefore, findings from this study are likely to be relevant to worksite settings.

Third, the proposed model was tested on both high-tech and government agency data sets to examine the external validity of the model. By testing the goodness of fit of the proposed model on two independent samples of working employees, it is possible to determine whether the results indicate that the model can be generalized to two different work samples.

Fourth, the focus of this paper was to examine the positive effects of individual and environmental factors on work stress and job satisfaction as outlined in the personenvironmental fit model, while controlling for the influence of negative affectivity. If the proposed model indicates that support in the work environment and dispositional hardiness account for a substantial amount of the variance in work stress and job satisfaction. These contributing variables could be targeted for future work site interventions. 
Fifth, it is well accepted that working conditions can play a primary role in contributing to work stress and job satisfaction. Consequently, focusing solely on individual characteristics without considering work environment factors limits the opportunity for effective interventions since such an approach only considers half of the means for reducing stress and enhancing job satisfaction. In order for health and human resource practitioners to understand how they can best reduce work stress and enhance job satisfaction at the worksite it is important to consider both the employee and work environment factors which impact these variables. Individual factors, such as the disposition of hardiness, and environmental factors, such as supervisor and coworker support, impact employees' interpretations of satisfaction with their jobs and general stress at work. Although personality dispositions like hardiness are difficult to change, they can be enhanced. In addition, supervisors and coworkers can be trained and offered incentives to provide support (e.g., work team training) and create a more supportive work environment. If a work situation is perceived as less threatening by a worker, his or her stress response is minimized. This study explores the unique contributions of individual and work environment protective factors and how they impact perceived work stress and job satisfaction. Practitioners should focus worksite interventions on the factors that provide the greatest opportunity to reduce individual and organizational stress. If employees are less stressed at work, they will be more satisfied with their jobs and more productive at work (Kompier et al., 1998; Murphy, 2002).

Finally, since the average American spends a great deal of time working, the work domain is ideal for the exploration of the relationship between social support in the work environment, dispositional hardiness and their unique and collective effects on the work outcomes of stress and job satisfaction. These variables are of interest to employers and employees since they can impact employee health and job satisfaction, as well as the health and productivity of the work organization.

In summary, there are many ways that the current study can add to related research in several disciplines. The choice of measures includes work domain measures that are general 
and similar to surveys currently used to assess organizational health in many corporations. In addition, the model is tested on two different worksite samples; therefore, the findings of this study may generalize to other worksite settings. The current study should provide direction for human resource personnel, business operations leaders and worksite health promotion professionals to implement future, comprehensive stress and satisfaction interventions in the workplace. The proposed study will accomplish two overall goals. It will further the current research in this area and enhance the application of existing research to the worksite setting.

\section{Definitions}

Coworker Support is the instrumental and emotional support received from coworkers at work (Karasek \& Theorell, 1990).

Supervisor Support is the instrumental and emotional support received from supervisors at work (Karasek \& Theorell, 1990).

Hardiness is a personality disposition that describes an individual who possesses three closely related qualities: challenge, commitment, and control (Maddi \& Kobasa, 1984). Specifically, these qualities refer to the tendency to perceive change as a challenge, to maintain a sense of purpose and deep commitment to the people and activities in which one is involved and to perceive a sense of personal control in handling life's events and activities (Bartone, Ursano, Wright, \& Ingraham, 1989).

Perceived Work Stress is a general measure of the level of stress at work (Cohen, Kamarck, \& Mermelstein, 1983; Mackie, et al., 2001). This measure reflects an individual's perception of general stress or perceived hassles at work.

Job Satisfaction is a pleasurable or positive emotional state resulting from the perception of one's job experiences as fulfilling important job values (Henne \& Locke, 1985). Overall job satisfaction is defined as satisfaction with one's job as a whole (Warr, Cook, \& Wall, 1979). 
Negative Affectivity is the extent to which an individual generally experiences various negative feelings and emotions (Watson, et al., 1988).

\section{Delimitations}

Characteristics of the convenient study population inherently delimit the findings of the study in several ways. The high-tech sample is made up of employees who are based in either Austin, Texas, or Santa Clara, California. This sample includes professionals in various jobs: material handling, purchasing, engineering and supplier management. The high tech sample is primarily male due to the technical nature of the work done in this industry and this sample is generally younger than the government sample. The government agency sample is based in Austin, Texas. This sample includes a variety of job categories ranging from accounting, finance, purchasing, and health and social services. The government agency has slightly more females than males. Both samples contain ethnic diversity; however the government sample is slightly more diverse than the high tech sample. Findings from the proposed study can only be generalized to populations at like work settings, with similar job types and demographics.

The study design and selection processes used for data collection by both of the organizations may also delimit the findings of the study in several ways. The researcher acquired consent (see Appendices $\mathrm{C}$ and D) from both the high-tech company and the government agency to use already existing data sets. The selection process conducted by both organizations was based on convenience, with the high-tech sample coming from one division and the government agency from volunteers across the site. Therefore the lack of homogeneity of either sample could potentially impact the study outcomes and the applicability of the findings. One condition that will assist the primary researcher is the large size of both samples. The larger the sample the greater the likelihood of a representative sample with adequate variation. 


\section{Limitations}

Due to the nature of the work site setting and the use of already existing data sets, there are limitations in the current study design. For example, both samples may have particularly supportive supervisors and coworkers. This factor may influence the findings and limit the generalization of the results to other work settings with less supportive supervisors. In addition, participants may have been suspicious or concerned that management in the organization would see their responses during data collection. To minimize employee concern for confidentiality, the organizations informed all potential participants of the precautions taken to maintain confidentiality of individual surveys prior to the data collection. Participants were informed that their survey responses would only be analyzed and presented in aggregate form, access to data storage would be limited, and only aggregate data analysis would be reported back to organizational management.

Causality cannot be inferred from the findings of this study due to the cross-sectional nature of the study design. It is possible that outside variables, not included in the study could influence or account for relationships demonstrated in the study findings. One such variable, negative affectivity has been identified in the literature as a potential nuisance variable in stress research. Negative affectivity is included in the data analysis to control for its effects in the model.

The use of selected measures in this study may limit the generalization of the findings. First, the use of a general measure of work stress may limit the interpretation of findings to application of general stress measures at similar work site settings. Second, the use of general measures of work stress, supervisor, and coworker support does not infer any conclusion for specific types of work stress (e.g., role conflict, role ambiguity) or social support (e.g., emotional versus instrumental support). Findings from this study should only be generalized to overall work stress, social support at work and job satisfaction. The 
general measures of work stress and support were chosen for their ease of application to the work setting. Third, the use of a single-item job satisfaction measure may affect the reliability or validity of the measurement. However, support exists for use of a single-item job satisfaction measure as an effective tool for assessing overall job satisfaction (Nagy, 2002; Scarpello \& Campbell, 1983; Wanous, Reichers, \& Hudy, 1997). Results of these three studies (including a 1997 meta-analysis) indicate that a single-item job satisfaction measure compares favorably to several published multiple-item general job satisfaction scales. In addition to the single-item measure, the government agency sample also has job satisfaction data from a fifteen-item job satisfaction survey. Both samples (high-tech and government) share the common single item, overall job satisfaction question that can be used for comparison and cross-validation of the model between samples. Finally, if the model fits both data sets and explains a similar amount of variance for both samples with the planned job satisfaction item, than this issue is less of a concern for the researcher.

Other limitations may influence the study findings such as self-report data and possible historical effects (e.g., participants' past experiences associated with work surveys). These are difficult issues to control for in a work site setting. However, each of the sample sizes will exceed three hundred participants. This larger sample size helps to control for some limitations by reducing the influence individual responses have on the overall sample distributions. 


\section{CHAPTER TWO}

\section{Review of the Literature}

\section{INTRODUCTION}

This chapter provides a review of related literature supporting the path model illustrated in Chapter One. There are three main sections and nine subsections in this chapter with each subsection identified by a subtitle. Each subtitle represents a selected pathway between one of the path model's predictor variables (e.g., hardiness, supervisor support or coworker support) and one of the two criterion variables: job satisfaction or work stress. The first main section begins with a brief review of the theoretical framework supporting the model, followed by a discussion of relevant literature supporting the relationship between the two criterion variables. The second main section addresses the relationship between the predictor variables of hardiness and support at work from coworkers and supervisors to the outcome variable of job satisfaction. The third main section reviews the relationships between the predictor variables, hardiness, supervisor support and coworker support at work, and the outcome variable of work stress. The chapter ends with a summary of the importance of the predictor variables, the protective effects they have on mitigating work stress and job dissatisfaction, and their impact on individual and organizational outcomes. Considering the extensive amount of variation in the conceptualization and measurement of the variables from the proposed model in the work stress and job satisfaction literature, this review of empirical research is not meant to be exhaustive. Instead, the purpose of this chapter is, first, to present an overview of general relationships between predictor and criterion variables and, second, to provide specific examples of research studies that utilize similar variable measures and provide support for the pathways in the proposed model. 


\section{REVIEW OF THEORETICAL FRAMEWORK}

Work stress is often a result of incompatibility between the person and the environment, i.e., when the relationship between the demands of the job and the abilities of the individual to meet these demands are not equivalent. The transactional theory of stress and coping provides the structural framework for researchers to examine the environmental and personal protective factors which enable an individual to manage successfully the daily hassles and stressful events he or she may experience (Lazarus \& Folkman, 1984). The presence or absence of these factors may partially explain the differences in perceptions, attitudes and behaviors of various individuals in similar, potentially stressful situations. Lazarus \& Folkman (1984) suggest that an individual's past experiences, current levels of perceived stress, and expectations about future stressful events all influence the amount of stress one feels at any given moment. For example, an event itself may not be perceived as threatening; however, a person's interpretation of a given situation, their perception of the availability of support at work, and their perceived ability determine the work stress and job satisfaction they experience. Work stress can result from an individual's perception of the relationship between the person and the environment. French et al. (1982) describe the interactive nature of this relationship as The Person-Environment Fit Model. This model illustrates the functions of relationships within the framework of the Transactional Theory of Stress and Coping (Lazarus \& Folkman, 1984).

Similarly, job satisfaction has been described as a function of the person-environment relationship which may result in job dissatisfaction (Janssen, 2000). A related model, which describes the person-environment transaction for job satisfaction, is called the Social Exchange Theory (Heaney \& Israel, 1990). Organizational theorists and researchers describe the social exchange theory as being a transactional model like the Person-Environment Fit 
(PE Fit) process model. Social Exchange Theory (SE Theory) provides a conceptual basis for understanding the relationship between an individual and that individual's work environment. Specifically, SE Theory explains the development and maintenance of interpersonal relationships at work that can influence an employee's perceptions of the work environment (Blau, 1964; Eisenberger, Cummings, Armeli, \& Lynch, 1997). The SE Theory presumes that an employee's view of employment is a reciprocal exchange relationship. Employees respond favorably to positive treatment and intention of others at work. This response to positive treatment at work directly influences job satisfaction (Blau, 1964; Janssen, 2000).

The individual's perception of available personal and work environment resources influences his/her evaluation of stress and job satisfaction. In a study examining the impact of work environment perceptions on individual outcomes, such as overall job satisfaction, James and James (1989) determined that people respond to work environments in terms of their perceptions. Specifically, job satisfaction is influenced by the degree to which individuals perceive themselves as benefiting as opposed to being harmed by their environment.

The SE and PE Fit models illustrate the process in which work environment resources, such as support from coworkers and supervisors, and personal factors, such as hardiness, influence one's perception of work stress and job satisfaction. Both the SE Theory and PE Fit Model conceptually describe the transactional framework in which an individual's internal resources and environmental support resources act to diminish the effects of demands, stressors, threats or risks in a given situation. These internal (personality dispositions) and external resources (social support at work) can provide resistance against work stress and job dissatisfaction. 


\section{Predictors of Job Satisfaction}

\section{RELATIONSHIP OF WORK STRESS TO JOB SATISFACTION}

Overall job satisfaction has been found to be closely related to work stress (Berwick, 1992; Fogarty, et al., 1999; Rout, 1999). Some research studies suggest a reciprocal relationship between work stress or strain and job satisfaction. However, many of these studies are not designed to enable determination of the direction of predictive relationships between variables (Bateman \& Strasser, 1983). Multivariate and advanced statistical techniques that predict directional relationships, such as path analysis, have indicated a directional relationship predicting that higher levels of work stress increase tension and dissatisfaction with the job (Jackson \& Schuler, 1985; Rush et al., 1995; Ulleberg \& Rundmo, 1997). The current study incorporates path analysis testing methodology and infers that work stress predicts job satisfaction.

Although the link between work stress and job satisfaction is well established in empirical research, few studies have used general measures of work stress and overall job satisfaction similar to the instruments chosen for the current study. Some researchers refer to general stresses as "daily hassles." Lazarus and Folkman (1984) suggest that, even though these daily hassles are less dramatic than the major stressful life events frequently measured in stress research it is possible that the general stresses employees experience on an ongoing basis might be an important area of investigation. This paper suggests that research examining general stressors is useful, because of the prevalence of general hassles in the lives of most working adults, and because of the lack of research on general work stress and the daily hassles of working life. Work stress and job satisfaction have been conceptualized in numerous ways in other research studies. The following paragraph will discuss several 
studies that have applied similar methods and measures, that demonstrate findings supporting the pathway from work stress to job satisfaction in the proposed model.

General measures of work stress have an inverse relationship to overall job satisfaction (Cummins, 1989, 1990; Fogarty et al., 1999; Hills \& Norvell, 1991; Poulin \& Walter, 1992; Steinhardt, Dolbier, Gottlieb, \& McCalister, in press; Ulleberg \& Rundmo, 1997; Wong, 2000). In a multivariate study examining the determinants of job satisfaction, results demonstrated that a general measure of work stress was significantly related to a global measure of job dissatisfaction [ $\mathrm{r}=-.44$ at $\mathrm{p}>.01]$ (Cummins, 1989). Work stress was identified as a significant predictor of job satisfaction in a structural equation model (Rush et al., 1995). The results of this study demonstrated that work stress was inversely related to job satisfaction and was a moderate predictor of job satisfaction. In addition, the findings from Fogarty et al. (1999) lend further support for the relationship between stress at work and job satisfaction $(r=-.46)$, with stress demonstrating a direct negative path to job satisfaction. Finally, a third path analysis study reported similar findings from a sample of offshore oil and gas platform workers (Ulleberg \& Rundmo, 1997). The results indicated that work stress predicted job dissatisfaction and strain. In the discussion, the authors recommended that health promotion practitioners focus their future efforts on improving job satisfaction as a means of improving overall employee well-being. The anticipated results of this study would build on the current findings for the general measures demonstrated in the literature cited above. Specifically, a general measure of work stress is expected to be negatively related to job satisfaction and a predictor of the general measure of job satisfaction.

Additional evidence for the inverse relationship between work stress and job satisfaction is demonstrated for specific work stress measures, such as role conflict, role ambiguity, and role stress (Abdel-Halim, 1982; Beardslee et al., 1985; Terry et al., 1993). In 
early research on work stress and job satisfaction, Kahn and colleagues (1964) found that men experiencing role ambiguity and role conflict (specific work-related stressors) reported lower job-satisfaction and higher job-related tension. In two multivariate analysis studies conducted on samples of physicians, specific types of work stress measures (time pressures/interruptions at work, working environment/communication and career/goal achievement) were found to be predictive of high levels of job dissatisfaction (Cooper, Rout, \& Faragher, 1989; Rout, 1999).

In summary, research indicates that both specific and general types of work related stress are inversely related to job satisfaction. These findings demonstrate the relationship of work stress to job satisfaction, and the related empirical research provides the foundation for the hypothesized pathway of work stress predicting job satisfaction (Figure 2).

\section{SUPPORT AT WORK AND JOB SATISFACTION}

Support at work can have a positive impact on job satisfaction (Babin \& Boles, 1996; House, 1981; Judge \& Watanabe, 1993; Terry et al., 1993). Social support at work refers to overall levels of helpful social support available on the job from coworkers or supervisors (House, 1981). Social support at work can act as a sustaining factor in the work environment, thus reducing the amount of stress an employee may experience at work and directly influencing job satisfaction. In a study exploring social support and work outcomes, the authors suggest that social relationships at work can enhance or diminish an individual's capacity for managing stress (Karasek, Triantis, \& Chaudhry, 1982; Viswesvaran, Sanchez, \& Fisher, 1999). Individuals who have good social support will be less impacted by the environmental demands and stressful situations they face on the job. Specifically employees who have supportive coworkers and supervisors may experience a protective effect against 
work stressors, such as a reduction of interpersonal pressures and tensions, which can contribute to enhanced job satisfaction by fulfilling work motivations or through affiliation (House, 1981). In addition, people's social network linkages may help them interpret events and problems in a more positive and constructive light (Thoits, 1983). In conclusion, social support at work from both coworkers and supervisors can act as a protective factor in the work environment, reducing the amount of stress that an employee experiences at work and increasing job satisfaction.

\section{THE RELATIONSHIP OF COWORKER SUPPORT TO JOB SATISFACTION}

Coworker support is significantly related to job satisfaction in that higher levels of coworker support are related to higher levels of job satisfaction (Ducharme \& Martin, 2000; House, 1981; Poulin \& Walter, 1992). Thoits (1983) suggests that the provision of support is likely to be more effective when received from people who are similar to the support recipients and who share similar stress experiences. Coworkers frequently experience similar situations at work and can provide and receive support through sharing these stressful experiences with each other. In a study of newly-graduated nurses in their first six-months of employment, Fisher (1985) found significant direct effects for both coworker and supervisor support on job satisfaction. In a second study examining the effects of support at work (using the same measures applied in the current study) lack of coworker support was directly related to general job dissatisfaction (Karasek et al., 1982). Conversely, in a multivariate study using a sample of government agency employees, lack of coworker support was directly related to job dissatisfaction (Seers, McGee, Serey \& Graen, 1983). In summation, although there is some variation in the findings, the majority of the studies indicates that coworker support is positively related and a predictor of overall job satisfaction.

Specific measures of support at work have also been found to predict job satisfaction (Abdel-Halim, 1982; Himle, Jayaratne, \& Thyness, 1989; Martin \& Hunt, 1980; Schaubroeck 
\& Fink, 1998). Himle et al. (1989) found that a specific measure of emotional support from both supervisors and coworkers predicted job satisfaction. This finding is consistent with other research demonstrating that emotional support is the type of support presumed to have the strongest effect on work stress and job satisfaction (House, 1981). In a recent multivariate (regression) study, two specific measures of coworker support were found to have a significant and positive impact on job satisfaction (Ducharme \& Martin, 2000). Although social support from coworkers enhanced worker job satisfaction in this study, support did not reduce (buffer) the negative effects of work stress on job satisfaction. Additionally, in a path analytic study investigating process models that predict work related outcomes, a group cohesiveness measure, similar to the coworker support measure in the current study, demonstrated a main effect on job satisfaction (Martin \& Hunt, 1980). Finally, results of a multivariate study conducted on a sample of low- to mid-level managers in a Midwest manufacturing company indicated that coworker and supervisor support at work were positively related to job satisfaction (Abdel-Halim, 1982). In short, a substantial amount of research supports the overall effects of coworker support on job satisfaction, both for general and specific measures of coworker support.

\section{THE RELATIONSHIP OF SUPERVISOR SUPPORT TO JOB SATISFACTION}

Supervisor support can act as a situational or work environment resource and can have a direct and positive effect on job satisfaction (Babin \& Boles, 1996; Cummins, 1990; House, 1981; Schirmer \& Lopez, 2001; Terry, et al., 1993). Although support from both coworkers and supervisors at work exhibits enhancing effects on employee job satisfaction, the effect of supervisor support typically has the stronger relationship to job satisfaction (House, 1981; Karasek et al., 1982; Schirmer \& Lopez, 2001). Research indicates that the

presence of a supportive supervisor can have a positive impact on employees' perceptions of their jobs and directly reduce work stress by acting as a stress resistant/protective factor 
(Abdel-Halim, 1982; Davis-Sacks, Jayaratne, \& Chess, 1985; House, 1981; Ulleberg \& Rundmo, 1997). Additional support exists for the indirect effect of supervisor support on job satisfaction through work stress (Abdel-Halim, 1982; Himle et al., 1989).

Supervisor support has been directly related to overall job satisfaction, in that higher levels of supervisor support are related to higher levels of job satisfaction (Beehr, King, \& King, 1990; Moyle, 1998; Poulin \& Walter, 1992; Schirmer \& Lopez, 2001). Results from a path analysis study on a sample of retail employees demonstrated that employee perceptions of supervisor support directly increased job satisfaction and reduced work stress, using specific measures of role conflict and role ambiguity (Babin \& Boles, 1996). In a research study conducted by Moyle (1998), managerial support was found to influence job satisfaction both directly and indirectly through specific measures of work stress in a sample of food retail managers. In the discussion of the findings from her study, Moyle suggested that, in addition to the positive effect of supervisor support on job satisfaction, the study results also indicated that employee well-being can be enhanced by managerial support.

In addition to the general measures of supervisor support, specific measures of supervisor support also demonstrate positive relationships with job satisfaction. In a multivariate study conducted on a sample of business administration students, researchers found that support from supervisors was positively associated with job satisfaction for individuals who were categorized as having an external locus of control (Cummins, 1989). In a second multivariate study, researchers examined survey responses from 153 public sector employees. The study results indicated that supervisor support distinctively predicted job satisfaction and psychological well-being (Terry et al., 1993). A substantial amount of literature exists to suggest that supervisor support at work can positively impact employee job satisfaction. The findings on the relationship of coworker and supervisor support suggest that both variables have a direct impact on job satisfaction. Additional support exists for the indirect effect of supervisor support on job satisfaction through work stress (AbdelHalim, 1982; Himle, Jayaratne, \& Thyness, 1989). Collectively, these results suggest that 
enhancing support in the work environment may influence employees' job satisfaction indirectly, by reducing job stress, and directly by leading to more positive perceptions of their work environment.

\section{THE RELATIONSHIP OF HARDINESS TO JOB SATISFACTION}

In addition to external factors in the work environment, individuals possess internal resources, such as the personality disposition of hardiness, which can positively affect job satisfaction. Research links personality dispositions to job satisfaction and overall life satisfaction (Evans et al., 1993; Judge et al., 1998). Hardiness is one of the personality dispositions in Figure hypothesized to have a positive impact on job satisfaction. Hardiness is defined as a collection of personality characteristics that function as a resistant resource when an individual is facing change and stressful situations (Kobasa, Maddi, \& Kahn, 1982). The personality characteristics of hardy individuals include a) the tendency to perceive change as a challenge and an expected part of life which can lead to growth; b) the commitment, or desire to actively contribute to one's life course; c) and control, which is the belief that one is capable of influencing important life circumstances (Kobasa, 1982). The personality characteristics that make up psychological hardiness help to protect individuals when they are facing stressful situations and typically lead to a reduction in perceived stress at work and a less critical evaluation of one's personal satisfaction with a job (Berwick, 1992; Rush et al., 1995).

Hardiness appears to have a positive effect on job satisfaction (Judge et al., 1998). Henne and Locke (1985) suggest that one way to reduce job dissatisfaction is to change an individual's perception of the job situation. For example, if one perceives a stressful work situation as threatening, he/she may be less satisfied with their job experience. If, however, the individual perceives a stressful situation at work as a challenge (one of the qualities of the 
hardiness personality), then he/she is less likely to experience dissatisfaction which may result from feelings of stress at work. In addition the individual who feels challenged is more likely to handle the situation effectively as opposed to an individual who feels threatened or stressed. Hardiness personality dispositions are typically associated with higher levels of positive affect and job satisfaction (Fisher, 1985). This suggestion supports the personenvironment fit and social exchange processes in which an individual's job values are perceived as being fulfilled and the employee is more satisfied with his/her job. Conversely, if job values are frustrated (not fulfilled), the employee will experience frustration and dissatisfaction with his/her job.

In the specific domain of the work environment, hardiness is inversely related to and a predictor of job satisfaction (Manning, Williams, \& Wolfe, 1988). In a study investigating variables which influence work stress, hardiness and job satisfaction were positively correlated $(\mathrm{r}=.47)$. In a sample of student affairs administrators (Berwick, 1992), both variables were also significantly related to work stress. In a path analysis study by Rush et al. (1995), a direct path from hardiness to job satisfaction was found to be significant in the final structural equation model. This significant pathway indicated that hardiness had direct effects on increasing job satisfaction in addition to directly reducing stress. Adding this direct path from hardiness to satisfaction improved the fit of the model with its outcome variables of stress, job satisfaction and withdrawal intentions. The results of this study demonstrated that hardy individuals experienced higher satisfaction and less stress than nonhardy individuals. Collectively, these findings support the suggestion that the hardiness construct may have direct effects on satisfaction as well as stress (Kobasa, Maddi, \& Kahn, 1982). Kobasa et al. also suggest that hardy individuals may be more resistant to feelings of stress and report higher levels of subjective well-being. The present study proposes both a 
direct effect of hardiness on job satisfaction as well as an indirect effect on job satisfaction through reduced work stress.

\section{Predictors of Work Stress}

\section{THE RELATIONSHIP OF COWORKER SUPPORT TO WORK STRESS}

The support that an employee receives from coworkers can provide an important mechanism that affects how he/she responds to stress (Abdel-Halim, 1982; Winnubst, Marcelissen, \& Kleber, 1982). Most studies report significant, direct or indirect effects of support on reduced work stress; still some studies do not find any significant effects (Beehr, Jex, Stacy, \& Murray, 2000, French et al., 1982; House, 1981; Revicki, et al., 1993). Overall, the findings of research on the relationship of coworker support to work stress are mixed. The variability in the findings from these studies is in part due to the lack of consistent and clear operational definitions of support across studies in current research. In the present study, coworker support has been conceptualized as the degree of instrumental, informational and emotional integration between fellow workers (Karasek \& Theorell, 1990). Few research studies to date have examined the relationship between coworker support and general work stress. Coworkers who share common work experiences and similar responsibilities can often increase each other's instrumental support (providing mutual support to accomplish work tasks) and emotional support (providing positive interactions and trust toward each other) (Karasek \& Theorell, 1990). This study explores the beneficial association represented by the pathway between perceived coworker support at work and general stress at work, as illustrated in Figure 2.

Although few studies have used general work stress measures, several studies have found significant relationships between coworker support and specific types of work stressors. Kahn and colleagues (1964) suggest that the quality of interpersonal relationships and social climate in the workplace might affect an individual's response to a specific work 
stress (role stress). Results from another study underscored significant effects of emotional support on specific types of work stress (role ambiguity, role conflict, workload and burnout) in Norwegian and U.S. human service workers (Himle et al., 1989). In this study, emotional support from coworkers was associated with lower levels of work stress, less burnout, and fewer mental health problems. According to the authors, interpersonal relationships can influence the emotional and behavioral consequences of various types of work stress. The finding that coworker support reduces specific types of work stress is logical since coworkers do experience similar types of stress at work; and typically employees in similar job situations know how to support each other when experiencing similar stresses in the work place (House, 1981). Overall, the effects of coworker support on alleviating specific types of work stress are supported in the literature; however, this study expands the current literature by examining the relationships of work support using a general work stress measure.

\section{THE RELATIONSHIP OF SUPERVISOR SUPPORT TO WORK STRESS}

Many studies have demonstrated that coworker support reduces employee stress; however, the presence of support at work from supervisors typically exerts an even stronger effect than support from coworkers. The protective effects of supervisor support have been shown to lessen work stress for subordinates (Beehr, King \& King, 1990; Cummins, 1990; Davis-Sacks et al., 1985; Terry et al., 1993; Winnubst et al., 1982). However, only a few of these studies have examined this relationship using a general work stress measure as this study proposes. In a study examining the effects of supervisor support on work stress, it was observed that supervisor support mitigated the impact of general stress (Beardslee et al., 1985). A recent research study applying path analysis techniques found a significant relationship between higher scores of supervisor support resulting in lower general work stress in a random sample of working former East German citizens (Dormann \& Zapf, 1999). Finally, findings from a hierarchical regression analysis indicate that supervisor support was related to general work stress, with higher levels of supervisor support directly predicting 
lower levels of work stress (Schirmer \& Lopez, 2000). In conclusion, the studies that have examined the relationship of supervisor support to general stress have indicated that supervisor support may provide a positive and protective relationship for individuals experiencing stress.

Numerous studies using specific work stress measures have demonstrated significant and beneficial relationships with supervisor support at work. Emotional support by supervisors has been associated with lower levels of specific types of work stress and fewer mental health problems (Himle et al., 1989). Terry et al. (1993) reported a positive effect of supervisor support on specific measures of work stress (role ambiguity, role conflict, underutilization of skills, and quantitative work overload). Those experiencing work stress also reported decreased confidence in superiors and the organization. A supportive work environment, indicated by the employees' perception of adequate work support, can protect against stress by providing opportunities for individuals to explore different coping options and enhance employee efficacy (Holohan \& Moos, 1986). A recent study reinforced this finding, suggesting that informational support supervisors reduced stress (emotional distress) (Cheuk \& Wong, 2000). This study examined the influence of supervisor support and job stress on kindergarten principals in Hong Kong. Collectively, research using both general and specific measures of work stress indicates that support at work from supervisors is inversely related to work stress.

\section{THE RELATIONSHIP OF HARDINESS TO WORK STRESS}

The individual protective effect of hardiness against work stress is supported in stress-related research. Although a relationship exists between stress and illness, not everyone who experiences similar stressful situations suffers from the negative effects of stress (Thoits, 1983). Kobasa et al. (1982) describe hardiness as an internal factor that acts

as a resistant resource in the encounter with stressful events, thus permitting hardy individuals to avoid some of the negative effects of stress. Maddi \& Kobasa (1984) suggest 
that hardy individuals adjust more readily to change and stressful life circumstances by perceiving change as an opportunity or challenge for growth rather than a threat. In addition, hardy individuals are deeply committed to the people and activities with whom they are involved. Finally, rather than feeling helpless or victimized, these individuals perceive a sense of personal control in handling life's events and activities (Maddi \& Kobasa, 1984). These qualities provide hardy individuals with the ability to successfully deal with stress and change.

Many researchers suggest that the personality trait of hardiness is inversely related to lower levels of work stress (Berwick, 1992; Bartone et al., 1989; Evans et al., 1993; Kobasa et al., 1982; Langemo, 1990). Hardiness has been found to relate to general measures of work stress. Collins (1996) found that full-time hospital staff nurses with higher levels of hardiness had less work stress and a lower incidence of burnout. Collins' research supports the initial findings of Kobasa et al. (1982), that individuals with a high level of hardiness experienced less stress. In later studies, researchers suggest that hardy individuals possessed the ability to transform negative stressors into growth or to mitigate the effects of work stress (Carver, 1998; Maddi \& Kobasa, 1984; Schaefer \& Moos, 1992). In a study predicting worker outcomes regarding general job tension, job satisfaction, and health in a sample of 469 employees from two different organizations, hardy individuals reported higher levels of job satisfaction and reduced tension at work (Manning et al., 1988). In the same study, the researchers found that hardiness was related to work and life stress. This research indicates that a relationship exists between hardiness and general work stress as is suggested by the pathway from hardiness to work stress in the current study.

The relationship between hardiness and work stress is evident in several studies using more specific measures of stress. Langemo (1990) reported that lower hardiness scores were related to higher scores on specific work stress measures such as emotional exhaustion, depersonalization, and personal accomplishment scales in female nurse educators. Langemo's findings suggest that the assessment individuals make of environmental support 
factors and personal resources acts to determine the amplitude of stress experienced. A recent exploratory study also found that hardiness was negatively linked to employees' perceptions of work-specific stressors in a sample of nurses at a medium-sized hospital (Turnipseed, 1999). Overall, the presence of higher levels of psychological hardiness appears to be useful for reducing one's perception of the magnitude of stress at work. In addition to reducing stress, hardiness has a positive influence on an individual's well-being and on the type of coping methods he/she may choose to use when facing stressful situations (Lambert \& Lambert, 1999). Other studies indicate that hardy individuals are more likely to seek out social support to help them manage stressful situations. The presence of social support can have a positive influence on reducing one's perception of stress (Bartone et al.,1989). Overall, research using both general and specific measures of work stress suggests that hardiness may act as a stress-resistant factor, reducing the effects of stress at work.

\section{INCLUSION OF NEGATIVE AFFECTIVITY IN THE MODEL}

Negative affectivity refers to the extent to which an individual generally experiences various negative feelings and emotions (Watson et al., 1988). Negative affectivity is included in the path model to account for its correlation with the other predictor variables and the contributions it makes to the criterion variables, work stress and job satisfaction. Some researchers suggest that negative affectivity may act as a confounding variable in self-report data (Brief et al., 1988). These authors specifically indicate that negative affectivity should be controlled for in stress research. Work stress and negative affectivity are often found to be moderately to highly correlated; for example, in a recent study examining the relationships of negative affectivity on work stress, negative affectivity was positively associated with work stress $(\mathrm{r}=.58$, at $\mathrm{p}<.001)$ (Wong, et al., 2000). Given the strong relationship of work stress and negative affectivity, it is not prudent to assume that variance explained in work stress, by work stress or related variables is exactly as it appears, without controlling for negative affectivity. 
In addition to the association of negative affectivity to work stress, a few studies indicate that negative affectivity influences job satisfaction (Ducharme \& Martin, 2000: Levin \& Stokes, 1989). Some research suggests that job dissatisfaction is an outcome of negative affectivity toward one's job (Necowitz \& Roznowski, 1994), while other studies suggest that negative affectivity may be related to satisfaction through stress or strain (Fisher, 2000; Fogarty et al., 1999). In one of these studies, a hierarchical regression analysis, Necowitz \& Roznowski (1994) replicated earlier findings (Brief et al., 1988; Levin \& Stokes, 1989) which indicated that negative affectivity explained a substantial amount of the variance in job satisfaction $(6 \%$ at $\mathrm{p}<.05)$ after the variance accounted for by other work environment variables typically associated with job satisfaction had already been calculated. Overall, the literature on negative affectivity suggests that individuals with high levels of negative affectivity may be more likely to experience substantial levels of distress and dissatisfaction over time across different situations. However, the relationship of negative affectivity to work stress is more consistent in the research than the relationship of negative affectivity to job satisfaction. The results of the current study should provide clarification to the previously inconsistent findings in the literature for the relationship of negative affectivity and job satisfaction.

Beyond its role as a confounding factor, negative affectivity has also been implicated as a nuisance variable in hardiness research (Bartone et al., 1989; Watson \& Pennebaker, 1989), and it has been negatively associated with specific types of support at work (House, 1981; Wong et al., 2000). The use of path analysis in this study permits the determination of the amount of variance that negative affectivity contributes to work stress and job satisfaction. To determine the variance explained by negative affectivity, the model is run without negative affectivity and then the same analysis is conducted with negative affectivity. The change in variance accounted for in work stress and job satisfaction is compared to determine the effect of negative affectivity on the outcome variables in the 
model (see Chapter $4, \mathrm{R}^{2}$ change). The model takes into account the relationship of negative affectivity with each predictor variable and their collective effects on the criterion variables.

\section{CHAPTER SUMMARY: REVIEW OF THE LITERATURE}

The purpose of this chapter was to provide an overview of the literature supporting each of the pathways of the model in the current study. This literature review highlights some of the studies that have used measures and designs similar to the current study. The inverse relationship between work stress and job satisfaction is well documented in the research. The personality disposition of hardiness and the work environment factors of supervisor support and coworker support are all inversely related to work stress and positively related to job satisfaction. Negative affectivity is included in the model to capture its influence as a nuisance variable. In summary, the impact of the predictor variables on the model's criterion variables of work stress and job satisfaction is well supported by the literature presented in this chapter.

The overall purpose of this study was to test a conceptual model that represents the relationships indicated above by using path analysis. Path analysis enables the testing of direct effects of the predictor variables (i.e., hardiness, supervisor support, coworker support, and negative affectivity) on work stress and job satisfaction. This study also examines the direct effect of work stress on job satisfaction and the indirect effects of the predictor variables on job satisfaction through work stress. Moreover, path analysis takes into account the interrelations among the predictor variables, determining the unique contribution of each variable to work stress and job satisfaction.

The findings from this study may have important implications for employee health and satisfaction as well as organizational productivity and retention. The work-site setting offers practical opportunities for the investigation of what factors impact work stress and job satisfaction. This study provides a foundation for future intervention studies designed to 
reduce work stress and increase job satisfaction. By enhancing an individual's internal and external resources, such as support at work, and providing tools for individuals to enhance their ability to manage change, work site practitioners can have a positive impact on organizational health and productivity. 


\section{CHAPTER THREE}

\section{Methods}

\section{OVERVIEW}

This study examines how hardiness and work environment factors contribute to work stress and job satisfaction for employees at a high-tech company and at a government agency. The researcher was granted access to two existing data sets. Participants in these samples include employees from a high-tech company $(\mathrm{N}=378)$ and employees from a state government agency $(\mathrm{N}=745)$. The employer administered the surveys. The participating employees from both organizations completed a survey assessing individual levels of perceived supervisor and coworker support at work, hardiness, negative affectivity, work stress and job satisfaction. Path analysis was used to test the fit of the proposed model in the two data sets. In this chapter the researcher presents the variables, the descriptions of both the government and high-tech data samples and the study design that were used to test the hypothesized structural equation model.

\section{Participants}

\section{High-Tech Sample}

The participants in this sample were full-time employees from the materials management division of a high-tech capital equipment and service-supply company. This high-tech company employs approximately 10,000 workers in North America. At the time of the data collection, participants in this study sample were in one company division, with 420 employees based in Austin, Texas and Santa Clara, California. 378 employees were recruited to participate in the current study. This convenience sample was comprised of $79.9 \%$ males and $20.1 \%$ females with a mean age of $40.1 \pm 9.7$ years. The sample consisted of 73.2\% White, 15.5\% Asian/Pacific, 7.7\% Hispanic, 3.1\% African American, and .5\% 
American Indian. The demographic information for the high-tech company sample is based upon a smaller sample of 194 participant for whom the demographic information was available and complete. This demographic sample is considered to be representative of the larger sample population.

\section{Government Agency Sample}

The participants in this sample were employees from two divisions of a state government agency, the Department of Human Services (DHS). This government agency employs approximately 15,470 employees in Texas, with 1,500 employees based in Austin, Texas, at the agency headquarters. 745 employees in these two government agency divisions were recruited to participate in the current study. The government agency sample was comprised of $26 \%$ males and $74 \%$ females with a mean age of $44.2 \pm 9.4$ years. The sample consisted of $63.5 \%$ White, $2.1 \%$ Asian/Pacific, 20.4\% Hispanic, 13.8\% African American, and $.02 \%$ American Indian. The demographic information for the government agency sample is based upon a smaller sample of 658 participants for whom demographic information was available and complete. The participants for whom demographic information was not available are assumed to be similar to the larger group.

\section{Similarities and Differences: High-Tech and Government Agency Samples}

Differences between the two organizations became apparent during examination of descriptive statistics. First, the high tech company sample is predominantly male, and the government agency is predominantly female. Second, the companies varied in ethnicity such that the high tech company had a greater number of Asian/Pacific employees, whereas the government agency had larger numbers of Hispanic and African American employees. In addition, a difference was seen with the average education level of employees. $72.9 \%$ of the high tech employees completed a college degree compared to only $44.2 \%$ of the government employees. Finally, a difference was evident in the average length of service for employees 
between the high tech sample $(3.9 \pm 3.2$ years $)$ compared to government agency sample $(13.2$ \pm 9.2 years)

Although all organizations experience change, change in the workplace may be perceived differently based on the culture of the organization and the expectations in a specific industry. In this respect, the work environments of the high-tech and government agency samples differ considerably. The high-tech company culture encourages and expects change based on technological advancements in the industry. This situation is illustrated by the company's business objective of "effectively adapting to change". On the other hand, employees at the government agency cited the "stability of the work environment" as a primary factor influencing their intent to stay with the organization. On the whole, the differences between the two work environments are noteworthy, and this fact should add to the external validity of the study findings. Additional comparisons between the samples will be reported after the demographic data are analyzed. The data for both the high-tech company and the government agency were collected within the same three-month period in July-September of 2001.

\section{Study Design}

This study employed a cross-sectional design using existing organizational survey data from a high-tech company and a government agency. The purpose of the study was to examine the effect of two employee personality dispositions (hardiness and negative affectivity), as well as the impact of two work environmental resources (coworker and supervisor support) on the outcome variables of work stress and job satisfaction. The researcher acquired consent from the high tech company and the government agency to use the data samples for this study. 


\section{INSTRUMENTS}

\section{Coworker Support}

Coworker support is defined as the instrumental and emotional support received from coworkers, based on the worker's perception (Karasek \& Theorell, 1990). Coworker support has been identified as being helpful when an individual is confronted with stressful work or life events. In this study coworker support was measured using Karasek's 5-item Coworker Support Scale (Karasek \& Theorell, 1990). This scale has been shown to have high internal consistency (Cronbach's alpha ranging from .80 to .84) (Karasek \& Theorell, 1990). The internal consistency for this scale in the current study was consistent with previously reported Cronbach's alphas, (high tech sample $\alpha=.81$ and government agency sample $\alpha=.86$ ). Participants were asked to complete five items, on a 4-point Likert scale ranging from "strongly disagree" to "strongly agree". Sample items include such statements as: "People I work with are helpful in getting the job done," "People I work with are friendly," and "People I work with take a personal interest in me." The combined sum of the items yields a composite coworker support score with a minimum possible of 5 and a maximum possible of 20.

\section{Supervisor Support}

Supervisor support is defined as the instrumental and emotional support received from supervisors at work, based on the worker's perception (Karasek \& Theorell, 1990). In this study Karasek's 4-item Supervisor Support Scale is used. This supervisor support scale has been shown to have high internal consistency (Cronbach's alpha ranging from .80 to .84) (Karasek \& Theorell, 1990). The internal consistency for this scale in the current study was consistent with previously reported Cronbach's alphas, (high tech sample $\alpha=.88$ and government agency sample $\alpha=.89$ ). Participants were asked to complete four items on a 4point Likert scale ranging from "strongly disagree" to "strongly agree". Sample items include: "My supervisor is successful in getting people to work together," and "My supervisor 
is concerned about the welfare of those under him/her." The combined sum of the items yields an overall supervisor support score with a minimum possible of 4 and a maximum possible of 16.

\section{Hardiness}

Hardiness is defined as three separate but closely related subscales assessing three dispositional qualities: challenge, commitment, and control (Maddi \& Kobasa, 1984). The 30-item Dispositional Resilience Scale [DRS] (Bartone et al., 1989) was chosen as the measure of hardiness in this study due to this measure's ability to measure the presence of hardiness tendencies as opposed to the absence of these qualities. The DRS is reputed to partially control for negative affectivity. In addition, the DRS can be formulated into three factors consistent with the original hardiness scale, or it can be used as a unitary scale (Bartone et al., 1989). Participants were asked to indicate the extent to which statements on the DRS were true in general on a 4-point Likert scale ranging (0-3) from "not true at all" to "completely true". Sample items include: "Changes in routine are interesting to me," "I often wake up eager to take up my life wherever it left off," and "Most of my life gets spent doing things that are worthwhile". The DRS has been shown to have high internal consistency (Cronbach's alpha of .85) (Bartone et al., 1989). The internal consistency for this scale in the current study was acceptable (high tech sample $\alpha=.81$ and government agency sample $\alpha=$ .75). For the specific interest of this study, the DRS will be used as a unitary measure (representing the single scale of dispositional hardiness instead of the three subscales). The combined sum of the items yields a composite dispositional hardiness score with a minimum possible of 0 and a maximum possible of 90 .

\section{Perceived Work Stress}

Perceived work stress was measured using the Perceived Work Stress Scale (PWS) (Mackie et al., 2001). The PWS measures perceptions of general work-related stress and has shown criterion validity in predicting work stress, correlating with the subscales of the 
Generic Job Questionnaire developed by the NIOSH (Hurrell \& McLaney, 1988). The PWS is a general measure containing seven items that assess the overall level of perceived stress experienced by an individual at work during the last month. These items were adapted from the Perceived Stress Scale (Cohen et al., 1983). The scale has been shown to be reliable, demonstrating internal consistencies ranging from .82 to .88 (Mackie et al., 2001). The internal consistency for this scale in the current study was consistent with previously reported Cronbach's alphas, (high tech sample $\alpha=.87$ and government agency sample $\alpha=.89$ ). Participants were asked to indicate how often the feelings and thoughts indicated in the PWS had occurred in the last month on a 5-point Likert scale ranging from "very often" to "never". Sample items from the survey include: "How often have you felt you had too much stress at work?" and "How often have you had to deal with irritating hassles at work?" The combined sum of the items yields a work stress score with a range of a minimum of 7 and a maximum of 35 .

The Perceived Work Stress Scale was chosen as a general, but domain specific measure. Cohen and Williamson (1988) present support for the use of a general stress measure. First, the authors suggest that a general stress measure can provide information about the process through which objective stressors influence such desired outcomes as health, stress, or job satisfaction. Second, a general measure can be used to investigate the role of perceived stress (at work) in situations where objective stress measures are too difficult to measure (Cohen \& Williamson, 1988). In this study, the participant's perception of overall stress in the work environment and the relationship of stress and general job satisfaction are the primary interests of the researcher.

\section{Job Satisfaction}

\section{High-Tech Sample}

Job satisfaction in this sample was assessed using a 1-item overall job satisfaction measure. Overall job satisfaction is defined as the degree of satisfaction employees feel about 
their present job as a whole. The overall job satisfaction measure was taken from the job satisfaction subscale of the Perceived Intrinsic Job Characteristics [PIJC] scale (Warr et al., 1979). This single-item measure was chosen from the 16 -item subscale due to its ability to measure overall job satisfaction and due to space limitations on the company surveys. Participants were asked to answer the question "Taking everything into consideration, how do you feel about your job as a whole?" indicating their degree of satisfaction with their present job. Responses for the single-item scale are posted on a 7-point Likert scale, ranging from "extremely dissatisfied" to "extremely satisfied". The range of job satisfaction scores on the single-item scale is a minimum of 1 and a maximum of 7 . Support exists for use of a single-item job satisfaction measure as an effective tool for assessing overall job satisfaction (Nagy, 2002; Scarpello \& Campbell, 1983; Wanous et al., 1997). Results of these three studies (including a 1997 meta-analysis) indicate that a single-item job satisfaction measure compares favorably to several published multiple-item general job satisfaction scales.

\section{Government Agency Sample}

Job satisfaction in the government sample was measured using both the single-item scale and a longer (15-item) version of Warr, Cook and Wall's (1979) Job Satisfaction Scale of the PIJC scale. The single-item scale (described previously) was the common scale used in both the high-tech and government agency samples. The 15-item scale measures total job satisfaction from a variety of different facets, using two sub-scales: intrinsic job satisfaction and extrinsic job satisfaction. Participants were asked to answer questions such as "How satisfied are you with the physical conditions of your present job?" and "How satisfied are you with the amount of responsibility you are given in your present job?" The participants' responses to these questions indicate their degree of satisfaction with the various aspects of their present job. Responses for the 15-item scale are posted on a 7-point Likert scale, ranging from "extremely dissatisfied" to "extremely satisfied". The range of job satisfaction scores on the 15-item scales is a minimum of 15 and a maximum of 105 . Test-retest reliability for total job satisfaction with a six-month time interval is shown to be .63. The 15- 
item PIJC is shown to have good internal consistency (Cronbach's alpha ranging from .85.88) (Warr et al., 1979). The internal consistency for this scale in the government agency sample in the current study was consistent with previously reported Cronbach's alphas, $(\alpha=$ $.92)$.

\section{Negative Affectivity}

Negative affectivity is defined as the extent to which an individual generally experiences various negative feelings and emotions (Watson et al., 1988). Negative affectivity was included in the model to control for possible confounding effects on the criterion variables, work stress and job satisfaction. The path analysis design takes into account the relationship of negative affectivity with each predictor variable and their collective effects on the criterion variables. Ten items measuring negative affectivity from the Positive and Negative Affect Schedule (PANAS), a 20-item questionnaire, were used to assess the extent to which an individual generally experiences various negative feelings and emotions. Sample items from the negative affectivity subscale include:"Distressed," "Hostile," "Irritable," "Upset". Participants were asked to answer the questions indicating the extent to which they generally feel the various emotions. The PANAS is scored on a 5point Likert scale, ranging from "very slightly or not at all" to "extremely". The range of negative affectivity scores on the ten-item scale is a minimum of 10 and a maximum of 50 . The negative affectivity subscale has been shown to have an acceptably high internal consistency (Cronbach's alpha ranging from .84 to .87) (Watson et al., 1988). Negative affectivity was included in this study to control for its effect on the criterion variables of interest. In addition to negative affect's association with work stress and job satisfaction, it has also been cited in the literature for its correlations with the other variables in this study: hardiness, work stress, job satisfaction, and support at work (from supervisors and coworkers) (Bartone et al., 1989; Brief et al., 1988; Fisher, 2000; House, 1981; Necowitz \& Roznowski, 1994; Wong et al., 2000;). 


\section{TEST ADMINISTRATION}

\section{High-Tech Sample}

\section{High-Tech Pilot Study Assessing Effectiveness of Electronic Survey}

The high-tech company conducted a pilot study to assess the effectiveness of an online survey. The online data collection format was preferred by the organization since it significantly reduces the survey administration time. This pilot study used an on-line abbreviated survey in a convenience sample of employees. Participants were recruited from the Human Resources Management Division ( $\mathrm{N}=151)$ to complete the online survey. The pilot survey was administered via electronic mail. This survey process yielded a 96 percent response rate with expected ranges and means on all variables. The pilot study determined that this data collection process was reliable and efficient, given the high prevalence of computer usage by the participants in the high-tech sample.

All employees in the materials division of this high-tech company $(\mathrm{N}=420)$ received a letter through email from a management representative requesting them to complete an electronic survey containing questions assessing scores on the variables listed above (see Appendix A for a copy of the survey). The email explained that the survey assesses levels of hardiness, support at work, work stress, and job satisfaction. All participants completed the electronic survey within two weeks of receiving the letter. The survey administered by the high-tech company took approximately twenty minutes to complete and was taken electronically at a computer in the employees' work area.

All data that the researcher was given access to were kept confidential, and participants were not identified by name. Demographic data were extracted using the personnel database to obtain the most complete descriptive data. Following final data collection and analysis, the researcher provided an aggregate report to division management at the high-tech company. 
The researcher was given permission to use the existing survey data by a representative of the high-tech company (see Appendix $\mathrm{C}$ for a copy of the permission letter). The researcher obtained The University of Texas Institutional Review Board (IRB) approval for using the already existing data set from the high tech company.

\section{Government Agency Sample}

All employees in two designated local divisions of the state government agency, The Department of Human Services (DHS) and The Department of Protective and Regulatory Services (PRS), $(n=1,500)$ received an email from a management representative requesting them to complete a survey containing questions assessing scores on the variables listed above (see Appendix B for a copy of the survey). The email explained that the survey assessed levels of hardiness, support at work, work stress, and job satisfaction and requested employees to complete the survey at designated dates and times within a two-week period. The survey was administered to employees in a designated quiet environment near the employees' work areas and took approximately forty minutes to complete.

All data were kept confidential, and participants were not identified by name. Access to the data files was limited to ensure confidentiality. Demographic data were extracted using the agency's personnel database to obtain the most complete descriptive data. The researcher was given permission to use the government agency-owned survey data by an agency representative (see Appendix D for the permission letter). Approval was obtained from the University of Texas' Institutional Review Board (IRB) for using the already existing data set from the government agency.

\section{DATA ANALYSIS}

Descriptive statistics including means and standard deviations were calculated for all variables on both samples. Bonferonni adjustments were employed to correct for the analysis of multiple means. Separate Chi-square analyses and t-tests within-groups were used to evaluate whether significant differences exist in the data sets based on group membership. 
Effect sizes were also used to assess the practical significance of group differences. The group differences for gender, age, education, ethnicity, and tenure are reported in Chapter 4 study results. In addition, Pearson product-moment correlation coefficients were calculated to examine the relationships among all variables in both samples. The investigator used the Statistical Package for the Social Sciences (SPSS) software program version 10.0 (Nie, Hull, Jenkins, Steinbrenner \& Bent, 1974) for descriptive statistics and Chi-square analyses.

A path analysis was conducted to test the goodness of fit of the proposed model of the relationships between the predictor variables of hardiness, negative affectivity, coworker support, and supervisor support and the criterion variables of work stress and job satisfaction in both samples. The path analysis also tested the proposed relationship of work stress and the criterion variable job satisfaction. The path analysis was performed using Analysis of Moment Structures (AMOS) statistical software version 4.0 (Arbuckle, 1995).

The Goodness of Fit Indices (GFI) for the path analysis were examined using the ChiSquare Test, the Tucker-Lewis Index (TLI), the Comparative Fit Index (CFI), the Normed Fit Index (NFI) and the Root Mean Square Error of Approximation (RMSEA) fit indices (lower and upper confidence intervals). The Chi-square statistic provides a test of whether the model fits the data if $p>.05$, i.e., the null hypothesis is rejected and the proposed model is accepted as fitting the data. The structural null hypothesis proposes that there are no relationships between the predictor and criterion variables (Bentler \& Bonett, 1980; Bentler \& Chou, 1987). The TLI, CFI, and NFI are all similar. The TLI, CFI, and the NFI compare the absolute fit of the specified model to the absolute fit of the null or independence model (model which assumes no relationships between variables). The greater the discrepancy between the overall fit of the two models, the larger the values of these descriptive statistics. These indices range from 0 to 1 , where 0 represents the goodness of fit associated with the null model (which suggests that all the variables are uncorrelated) and 1 represents the goodness of fit associated with a saturated model (rejecting the null hypothesis). The greater the discrepancy between the independence model and the hypothesized model, the larger the 
values of the descriptive indices and the better the model describes the data. Values of over .90 on the TFI, CFI, and NFI indicate a good fit between the model and the data (Hoyle, 1995). Other researchers recommend RMSEA values below .06 and TLI values of .95 or higher (Bentler \& Chou, 1987). RMSEA compares the fit of the hypothesized model to the saturated (or perfectly-fitted) model. The lower the RMSEA, the less discrepancy there is between the hypothesized model and the perfectly-fitted model; hence the better the fit. The more conservative fit indices of .95 for TLI, CFI, and NFI, as well as RMSEA values below .06 and Chi-square of $\mathrm{p}>.05$, will be utilized for analysis of model fit in this study (specifically for testing hypotheses $\mathrm{H} 1, \mathrm{H} 2$, and $\mathrm{H} 3$ ). Critical ratios for each model pathway were used to assess the strength and significance of the relationships between the predictor and criterion variables. Critical ratio values that exceed the threshold of \pm 1.96 , with a $p$ value -.05 indicate significant associations between the predictor and criterion variables. A second analysis, using multiple group path analysis with nested models comparison, was then conducted to explore the similarities and differences in the model parameters between samples. The change in $\mathrm{R}^{2}$ also explored between a model with negative affectivity as the sole predictor of work stress and job satisfaction versus the proposed model with hardiness, supervisor support, coworker support and negative affectivity. These analyses were included to assess the additional amount of variance accounted for by all the predictor variables over and beyond the predictive effects of negative affectivity on the criterion variables. Additional details of these analyses are described in Chapter 4.

\section{SUMMARY: CHAPTERS 1-3}

The nature of work is changing, but the negative effects of change at work are not experienced equally by all individuals. The current study is explored within the framework of the transactional theory of stress and coping and uses the processes described by the person-environment fit model and the social exchange theory to explain how support at work 
and hardiness predict work stress and job satisfaction. Negative affectivity was included in the model to account for the inter-correlation it has with the other predictor variables and the variance it contributes to the two criterion variables. The present study tests a model predicting work stress and job satisfaction on two available samples: 1) a sample of high-tech employees and 2) a sample of government agency employees. This model (illustrated in Figure 2) explores the influence of two work environment resources (coworker support and supervisor support), negative affectivity and hardiness on the outcome variables of work stress and job satisfaction. Secondary analyses were conducted to clarify variable relationships and identify similar variable relationships between samples. The researcher has been granted access to two existing data sets. Participants in these samples include employees from a high-tech company $(\mathrm{N}=310)$ and employees from two divisions of a state government agency $(\mathrm{N}=745)$. Path analysis was used to test the fit of the proposed model on the two data sets. The proposed model (illustrated in Figure 2) was hypothesized to fit both the high-tech and the government agency data sets. 


\section{CHAPTER FOUR}

\section{Results}

\section{OVERVIEW}

Seven hundred forty-five government agency employee surveys and three hundred ten high-tech employee surveys were included in this study. Each of the participant's surveys was assigned a code number for identification, composite scores were calculated for all variables, and the data analyses outlined previously were calculated. Prior to the path analysis using Analysis of Moment Structures (AMOS), a preliminary data analysis was performed to assess the distribution of the ranges on all variables. Descriptive statistics including frequency distributions, means and standard deviations were calculated for all variables in both samples. Further statistical analysis methods were applied to ensure that the assumptions for structural equation modeling were considered (i.e., the normality of the data distributions on all variables). In addition, Pearson product-moment correlation coefficients were calculated to examine the linear relationships among all the variables in both samples. T-tests, Chi-square tests were conducted and effect sizes calculated to identify differences between the samples on all variables.

A path analysis was conducted to test the goodness of fit of the proposed path model in both samples. In the proposed model, the two outcome (or criterion) variables of interest were work stress and job satisfaction. The predictor variables were the personality variables (dispositional hardiness and negative affectivity) and the work environment variables (coworker and supervisor support). Work stress was also a predictor variable for job satisfaction. The model illustrated in Figure 2 (see Chapter 1) was hypothesized based on the literature review. Each predictor variable (the personality variables of hardiness and negative 
affectivity and the work environment variables of supervisor support and coworker support) had a direct path to each criterion variable (work stress and job satisfaction). In addition, work stress had a direct path to job satisfaction (suggesting that work stress also predicted job satisfaction, and that the predictor variables may influence job satisfaction indirectly by lessening job stress).

\section{DESCRIPTIVE STATISTICS}

The possible range of scores, means, and standard deviations for all variables in the high tech and government agency samples are shown in Table 1. The means of all the variables were similar to means that are typically published for these variables. The mean differences and the effect size (ES) or measure of practical significance between mean differences are discussed in the group differences section following Table 1.

Table 1. Possible Range of Scores, Means, and Standard Deviations for All Variables in High Tech (N=310) and Government $(\mathrm{N}=745)$ Samples

\section{High tech sample Govt. Sample}

\begin{tabular}{lccccc} 
Variable & $\begin{array}{l}\text { Possible } \\
\text { Range }\end{array}$ & M & SD & M & SD \\
\hline *Hardiness & $0-90$ & 62.8 & 8.0 & 61.3 & 7.4 \\
*Negative Affectivity & $10-50$ & 15.7 & 4.9 & 17.7 & 6.4 \\
Supervisor Support & $4-16$ & 12.5 & 2.4 & 12.5 & 2.7 \\
Coworker Support & $5-20$ & 15.8 & 2.3 & 15.7 & 2.7 \\
Work Stress & $7-35$ & 20.9 & 5.0 & 20.4 & 5.7 \\
*Job Satisfaction & $1-7$ & 5.1 & 1.3 & 5.3 & 1.2 \\
\hline
\end{tabular}

*Indicates significant difference in the variables between samples 
(Bonferroni adjusted $\underline{p}<.008$ )

\section{Group differences}

Chi-square analyses were conducted and significant differences were found between the high tech and government agency samples on the following demographic variables: gender $\left(\underline{X^{2}}=239.6, \underline{p}<.001\right)$, education (achieving a college degree) $\left(\underline{X^{2}}=88.7, \underline{p}<.001\right)$, and ethnicity $\left(\underline{X^{2}}=155.3, \underline{p}<.001\right)$. T-tests were conducted, and the groups were found to be significantly different in length of service $(t=22.2, \underline{p}=.001)$; however, age was not significantly different between samples $(\underline{t}=6.4, \underline{p}=.380)$. In addition, significant statistical differences between the samples were found for the following variables: hardiness $(t=-2.7$, $\underline{p}=.007$, government $\underline{M}=61.3$ and high tech $\underline{M}=62.8, \mathrm{ES}=.19)$, negative affectivity $(\underline{t}=4.9$, $\underline{p}=.001$, government $\underline{M}=17.7$ and high tech $\underline{M}=15.7, \mathrm{ES}=.33)$, and job satisfaction $(\underline{t}=2.7$, $\underline{p}=.007$, government $\underline{M}=5.3$ and high tech $\underline{M}=5.1, \mathrm{ES}=.19)$. Researchers often use effect size as a measure of practical significance when examining mean differences. Effect sizes are generally categorized as small, moderate and large, with recommended indices of .20, .50 , and .80 respectively, when independent sample means are being compared (Cohen, 1992). Although significant mean differences between the two samples were found for the variables hardiness, negative affectivity, and job satisfaction, the practical significance of these findings was small to moderate.

\section{Correlations}

Pearson product-moment correlations among the variables for both the high tech and government samples are shown in Tables 2 and 3, respectively. As hypothesized, higher scores on job satisfaction were associated with higher scores on hardiness, supervisor support, and coworker support as well as lower scores on negative affectivity. Lower scores on work stress were associated with higher scores on job satisfaction as predicted. Also, as hypothesized, higher scores on hardiness, supervisor support, coworker support and lower 
scores on negative affectivity were associated with lower scores on work stress. It is important to note that there are significant intercorrelations among the predictor variables. These intercorrelations are typically small to moderate in this study and path analysis statistical techniques address multicollinearity problems.

Consistent with the literature review, the results of this study indicate that a significant, small to moderate Pearson Product Moment Correlations were found between negative affectivity and work stress in both the high tech $(r=.44)$ and the government agency samples $(r=.37)$. Also as suggested by previous research, the relationship between work stress and negative affectivity is stronger than the relationship of negative affectivity to job satisfaction (high tech $\underline{\mathrm{r}}=-.17$, and government agency $\underline{\mathrm{r}}=-.23$ ). In addition, moderate associations were found between negative affectivity and hardiness in both samples (high tech $\underline{r}=-.38$ and government agency $\underline{r}=-.43$ ). These findings support the inclusion of negative affectivity in the proposed model.

\section{Path ANALysis}

Path analysis was conducted using AMOS statistical software version 4.0 (Arbuckle, 1995). The path analysis was performed separately on each sample (single group analysis). Each predictor variable (the dispositional variables of hardiness and negative affectivity and the work environment variables of supervisor support and coworker support) had a direct path to each criterion variable (work stress and job satisfaction). Additionally, work stress had a direct path to job satisfaction suggesting that work stress also predicted job satisfaction (and that the dispositional and work environment predictors of work stress influence job satisfaction indirectly via job stress). The proposed model was saturated since each variable (hardiness, supervisor support, coworker support, negative affectivity, work stress, and job satisfaction) in the model had an associated path drawn to all other variables. No free parameters or degrees of freedom remained; therefore, a Chi-square test of the overall goodness of model fit could not be calculated. While a Chi-square test could not be conducted on the saturated model, the critical ratios for each pathway (strength of the 
relationships between the predictor and criterion variables) could be calculated. Therefore, the model was tested on both samples to assess the critical ratios for each path between predictor and criterion variables. In both samples, all of the critical ratios were significant (exceeding \pm 1.96 with a $\mathrm{p}<.05$ ), except for the path from negative affectivity to job satisfaction. The insignificance of this path was not surprising due to the lack of consistent theoretical support found for the relationship between negative affect and job satisfaction in the literature. Therefore this path was deleted for both theoretical and empirical reasons to produce a more parsimonious model, and the model was re-evaluated, as an unsaturated model. 

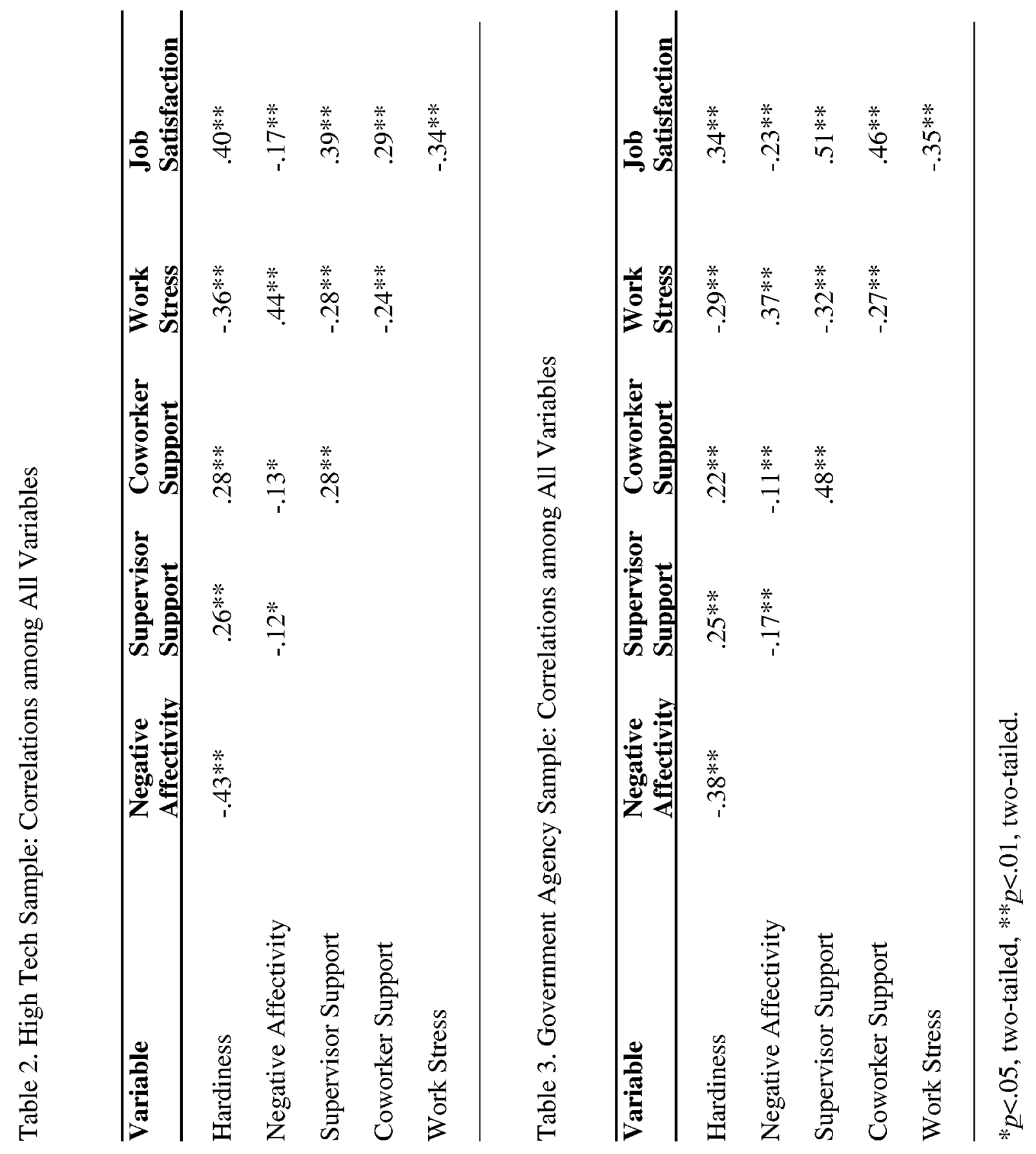

in 
After removing the non-significant path from negative affectivity to job satisfaction, the model was no longer saturated and a $\mathrm{X}^{2}$ value could be calculated. Results of the path analysis support this revised model for both the high tech and the government agency data samples. The model overall fit indices indicated non-significant Chi-square values (exceeding $\underline{p}=.05$ ), $\underline{X}^{2}=1.42$, $\underline{p}=.23$ for the high tech sample $(\mathrm{N}=310)$ and $\underline{X}^{2}=1.80, \underline{p}=.18$ for the government agency sample $(\mathrm{N}=745)$. These fit indices indicate that the model fit the data for both the high tech and the government agency samples. The predictors accounted for a substantial amount of variance in work stress $\left(\underline{R}^{2}=.28\right.$ for the high tech sample and $\underline{R}^{2}=.23$ for the government agency). In addition, the predictors accounted for a significant amount of the variance in job satisfaction ( $\underline{R}^{2}=.28$ for the high tech sample and $\underline{R}^{2}=.37$ for the government agency). All of the indices of the descriptive goodness of fit tests exceeded .95 , and were less than .06 for RMSEA (NFI=1.00, $\mathrm{CFI}=1.00, \mathrm{TLI}=.999, \mathrm{RMSEA}=.04$ for the high tech sample; and NFI=1.00, CFI=1.00, TLI=.999, RMSEA=.03 for the government agency sample). See Chapter 3 for a detailed explanation of fit indices. The results of the single group analysis indicate a good fit between the final model and the data for both samples. Tables 4 and 5 depict the various pathways from the predictors to the criterion variables, the unstandardized and standardized estimates, standard error, the critical ratios of the paths and the $\mathrm{p}$ values for the variables in both samples. Results of the path analysis supported the proposed hypotheses and the final model pictured in Figures 3 and 4, for the high tech and the government agency samples, respectively. Additional analyses, including the $\underline{R}^{2}$ change associated with controlling for negative affectivity and the exploration of the effects of gender differences on the variable relationships illustrated in the proposed model were conducted as secondary analyses in this study. The results of these analyses are described in the "Additional Analyses" section below. 
Figure 3. High Tech Path Model (Single Group Analysis)

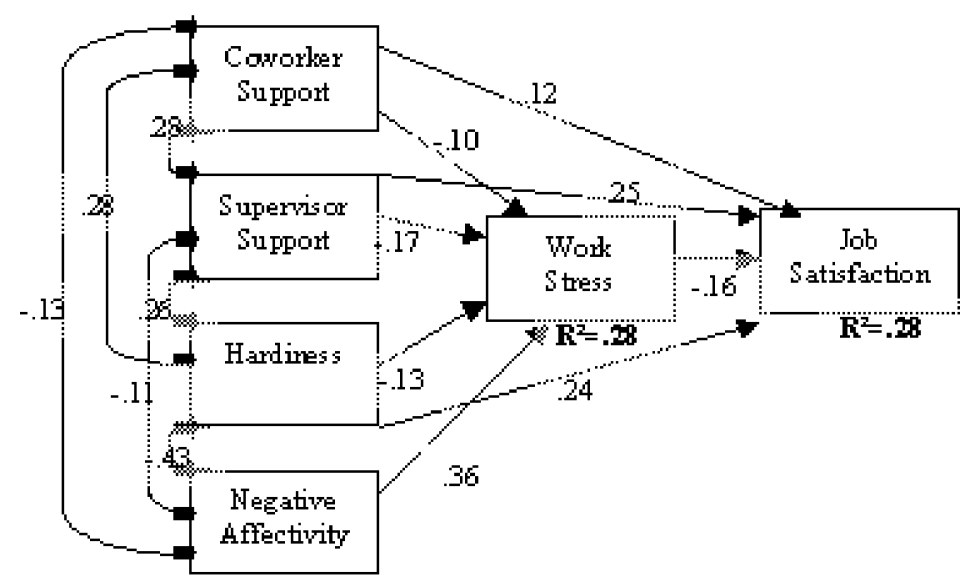

Figure 4. Government Agency Path Model (Single Group Analysis)

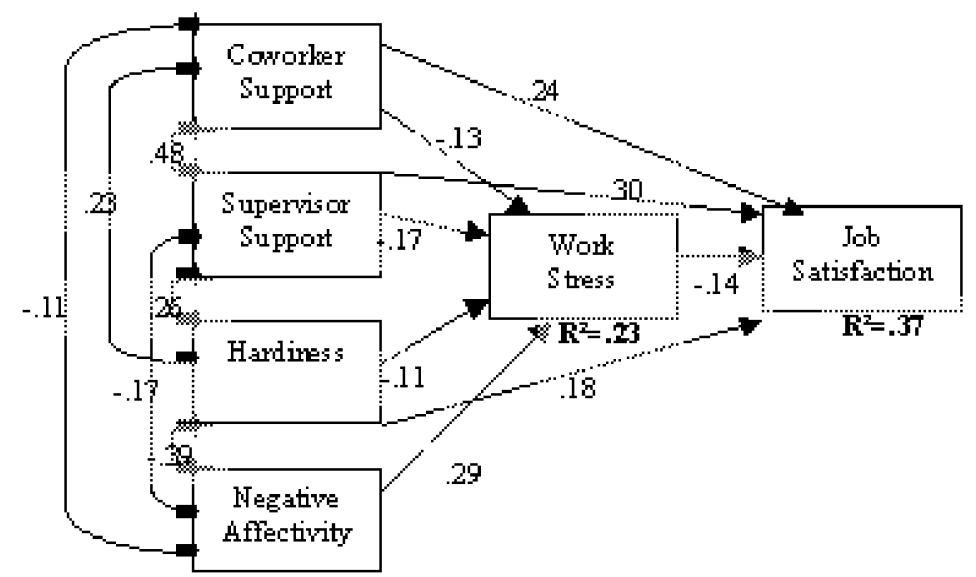




\section{ADDITIONAL ANALYSES}

\section{$R^{2}$ Change}

A specific data analysis procedure was followed in an effort to determine how much the predictors contributed to the criterion variables above and beyond the nuisance factor of negative affectivity. Path analysis is sometimes described as a series of multiple regression equations, with all equations fitted to the model simultaneously. Therefore, the basic principles of hierarchical regression were applied to this path analysis in order to determine the unique contributions each variable made and the $\mathrm{R}^{2}$ change (increased variance accounted for) in the criterion variables of work stress and job satisfaction above and beyond negative affectivity. Since negative affectivity is implicated as a nuisance/confounding variable in the stress literature, the model was first run with negative affectivity as the only predictor variable, with pathways to work stress and job satisfaction. Although no Chi-square test could be calculated due to the saturated nature of the model, the critical ratios were significant and the $\mathrm{R}^{2}$ values were calculated. The $\mathrm{R}^{2}$ for work stress was $\underline{R}^{2}=.20$ for the high tech sample and $\underline{R}^{2}=.14$ for the government agency sample. The $\mathrm{R}^{2}$ for job satisfaction was $\underline{R}^{2}=.12$ for the high tech sample and $\underline{R}^{2}=.13$ for the government agency. Although negative affectivity accounts for a large amount of the variance in work stress, the addition of the other predictor variables (hardiness, supervisor support, and coworker support) resulted in an additional $8 \%$ increase in the $\mathrm{R}^{2}$ for the high tech sample. The addition of the same predictor variables for the government agency resulted in a $9 \%$ increase in the $R^{2}$ for work stress for the government agency sample. The $R^{2}$ change in job satisfaction also increased substantially, $16 \%$ in the high tech sample and $24 \%$ in the government agency sample with the addition of the other predictor variables in both samples. 

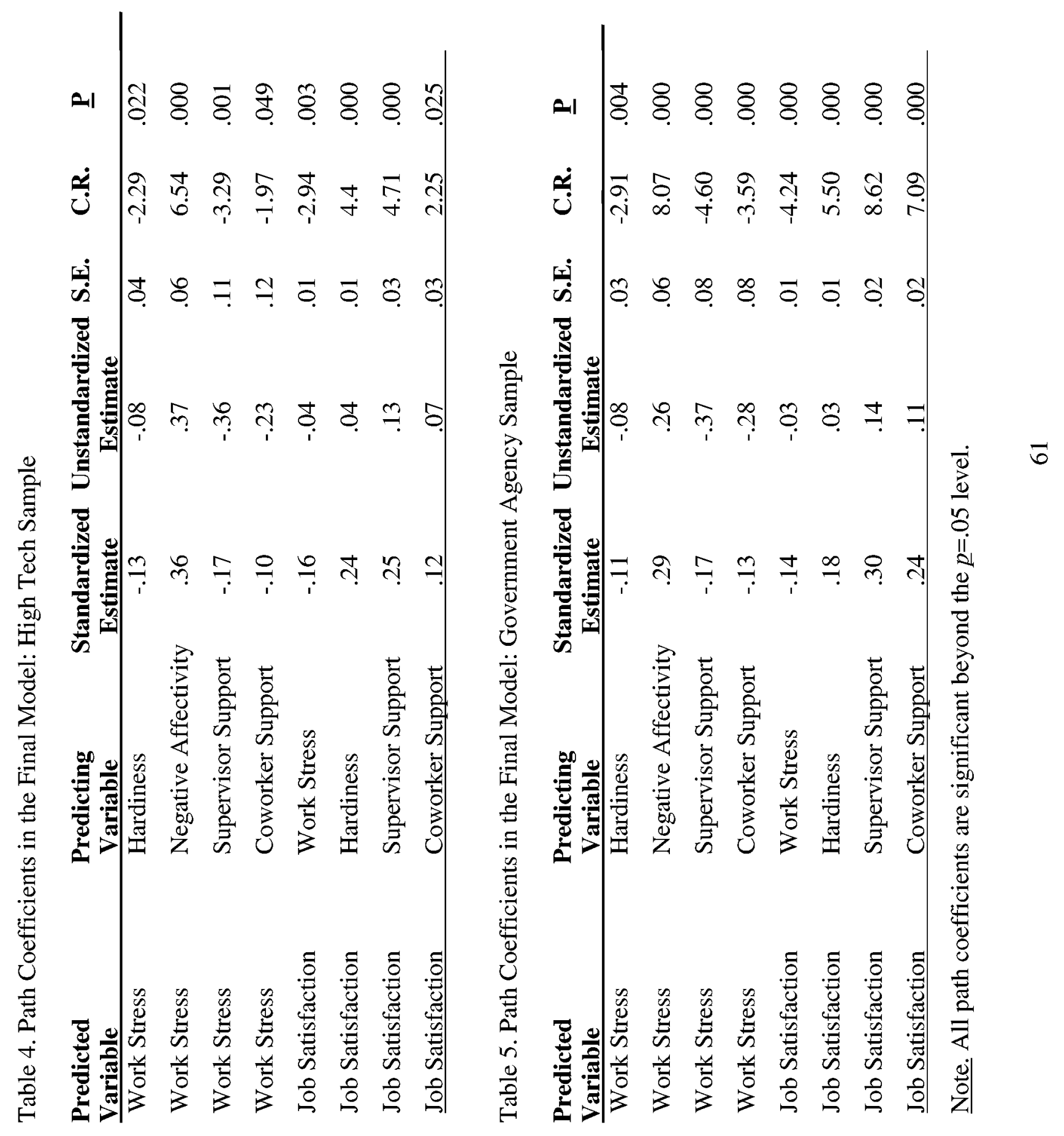
The findings of this analysis confirm research hypothesis three: that the predictor variables of hardiness, coworker support, and supervisor support account for a substantial amount of variance in the criterion variables of work stress and overall job satisfaction above and beyond the nuisance factor of negative affectivity.

\section{MULTIPLE GROUP ANALYSIS}

Based on the findings of the single group path analysis, a multiple group path analysis was conducted. Multiple group analyses are typically employed to investigate whether group (i.e., sample) membership influences the relationships between the variables specified in the model being tested (Kline, 1998). Model parameters refer to the strengths of associations between variables, and paths are the predicted relationships illustrated by arrows between the variables in the models. Since the model fit the data for both the high tech and government agency samples separately, additional statistical tests of multiple group path analysis were applied to estimate whether the model fit differed by gender or if model parameters were similar across both the samples simultaneously. Two types of multiple group analyses were conducted and described below. The first analysis was conducted on a collapsed data set containing both samples, exploring the effects of gender differences on the proposed model relationships, and the second analysis tested the similarities in variable relationships across both samples.

\section{Testing for Gender Effects}

Due to the gender composition differences between samples and the general interest in the effects of gender on several of the variables included in this analysis, (i.e., support), a multiple groups analysis was conducted to determine whether gender significantly influenced the variables under study in this model (see Appendix F). Since both data sets had unequal numbers of male and female participants the analysis was conducted on a collapsed data set which included both government and high tech male and female samples. The model fit the data for both the combined samples of males and females. However, the significance of the pathways varied for two of the critical paths between the groups. For the combined sample of males 
$(\mathrm{N}=399)$, the pathway from coworker support to work stress was not significant (critical ratio = $1.22, p=.22)$, and, for the combined sample of females $(\mathrm{N}=551)$, the pathway from hardiness to work stress was not significant (critical ratio $=-1.78, \underline{p=.08}$ ). Although these pathways were not significant (at $\underline{p}=.05$ level) in the gender specific multiple group analyses, the strengths of these pathways were approaching significance. In addition, hardiness and coworker support appear to be of some practical significance in predicting work stress. Overall, no gender specific trends appeared to be important in the gender multiple groups analysis. See Appendix F for additional details and output data.

\section{Nested Models Comparison}

Since the model fit the data for both the high tech and government agency samples and several of the pathways appeared similar in strength of association, a statistical test of nested models comparison analysis was conducted to compare whether selected pathways/ model parameters were equal (similar) across the two samples. In order to conduct this analysis, a technique known as nested models' comparison was employed. Multiple group path analysis using nested models comparison is frequently used to investigate whether a sample group's membership effects the relationships or pathways specified in the model. Initially, a multiple group analysis (simultaneous single group analyses on both the high tech and government agency data samples) was conducted on the previously confirmed path model (pictured in Figures 3 and 4). The previously confirmed single group model contained only free parameters; therefore no equal constraints were placed on any of the pathways between the two samples. This unconstrained model is referred to as Model 1. The results of the multiple group analysis on the initially unconstrained model re-confirmed that Model 1 fit the data for both samples. The overall fit indices for the multiple group analysis indicated non-significant Chi-square values (exceeding $\underline{p}=.05$ ), $\underline{X}^{2}=3.2, \underline{p}=.20$, with 2 degrees of freedom for Model 1. The non-significant Chi-square value confirms the previous single group analyses findings that the model fits the data similarly for both samples. 
To achieve the most parsimonious model fit for both samples, a second model with pathway constraints (Model 2 with five cross-group equalities or pathways set equal) was investigated to determine whether sample differences impact the relationships specified using a nested models' comparison analysis. Nested models analysis permits the comparison of one model to one or more slightly different models, such as an unconstrained model to a model with several pathways constrained to be equal. Nested models comparison is useful for two primary purposes in this study: first, to determine the most parsimonious fit of the model for both samples, and second to investigate whether model pathways and critical ratios were similar enough to be generalized between samples.

The second model (Model 2) was tested with the unstandardized coefficients constrained to be equal between groups (pooling the estimates between samples) for five pathways (hardiness to work stress, supervisor support to work stress, work stress to job satisfaction, hardiness to job satisfaction and supervisor support to job satisfaction). Although researchers sometimes prefer to analyze data based on standardized estimates, there is a strong preference in the Structural Equation Modeling (SEM) literature for use of unstandardized estimates. Most SEM estimation procedures assume analysis of unstandardized variables, and this is preferable in multiple group analysis where samples differ in their variabilities (Klein, 1998). Five pathways in Model 2 were constrained to be equal between the groups based on empirical findings, specifically similar unstandardized coefficients between the samples, as indicated by the results of the single group analysis (see Tables 4 and 5). In addition to the empirical findings of similar relationships between samples in this study, theoretical support for the strength (small to moderate) of relationships found for these five constrained pathways is consistent with previous research has indicated for these same relationships.

Overall fit indices for both models were examined: the simultaneous single group analysis model without any constraints (Model 1), and a second model with five of the unstandardized pathways constrained to be equal (Model 2). Both models were analyzed and 
then compared. The fit indices for Model 1 were compared with Model 2, and the results indicated that the fit of the second model was not appreciably worse than the more complicated Model 1 (used in single group analysis). The overall fit indices for Model 2 included nonsignificant Chi-square values (exceeding $\underline{p}=.05),\left(\underline{X}^{2}=5.8, \underline{p}=.568\right)$, with 7 degrees of freedom (five additional degrees of freedom) compared to the overall Model 1 fit indices, $\left(\underline{X}^{2}=3.2\right.$, $p=.20$ ), with 2 degrees of freedom. The Akaike Information Criterion (AIC) is a measure of fit index which is used in nonhierarchical model comparisons similar to the Chi-square goodness of fit statistic; however it includes a "penalty" for model complexity adjusting for the number of estimated parameters (Byrne, 2001, Klein, 1998). The Browne-Cudeck Criterion (BCC), similar to the AIC, operates as a fit index for model comparisons. Models with fewer degrees of freedom are seen as more complex and less desirable models, and, thus, they are given a penalty through larger $\underline{X^{2}}$ values and by larger AIC and BCC indices (Byrne, 2001; Klein, 1998). Although there are no threshold values for AIC fit, given two nonhierarchical models, the one with the lower AIC and BCC and the greater degrees of freedom is the simpler/preferred model. The AIC and BCC values for Model 1 are 107.22 and 108.96 (respectively) and for Model 2 the values are $\mathrm{AIC}=99.76$ and $\mathrm{BCC}=101.33$ (see Table 6). Finally, the nested models comparison indicated that the difference between Model 1 and Model 2 were non-significant, $(\underline{p}=.77$,

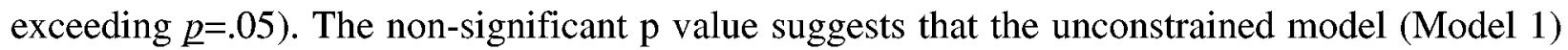
and the constrained pathway model (Model 2) are not too different in their fit. However, Model 2 is the simplest model, with the lowest AIC and BCC indices and the greatest degrees of freedom (7). Therefore this model with the five equally constrained pathways from the predictor to the criterion variables is described as the most parsimonious model resulting from the multiple group nested models comparison. The final path model (Model 2) with path coefficients, correlations, and variances are pictured below for the high tech sample in Figure 5 and the government agency in Figure 6. In addition, Tables 7 and 8 contain the output (including the p-values, standardized and unstandardized estimates) for each pathway in the final model. 
Figure 5. Final Model High Tech Sample (Multiple Group-Five Pathways Constrained)

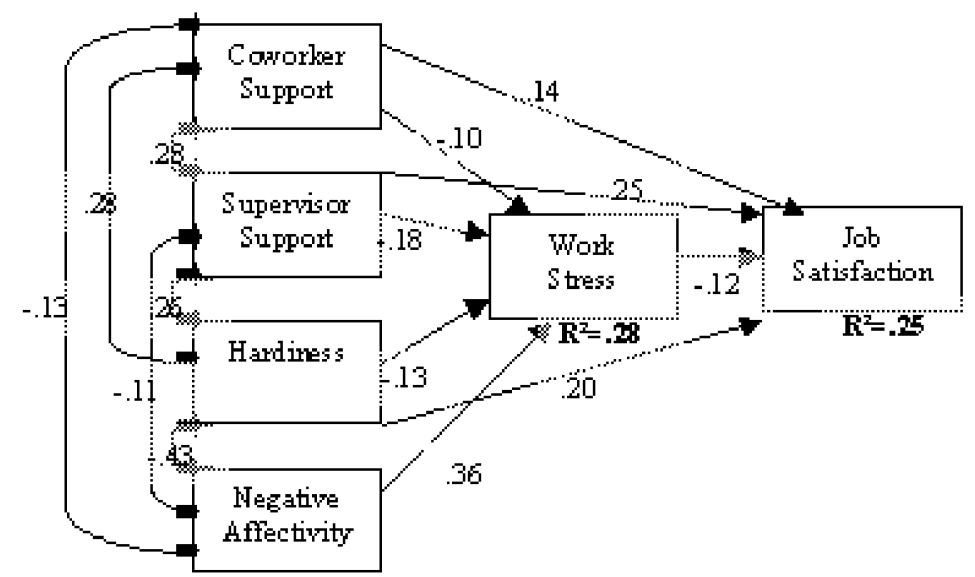

Figure 6. Final Model Government Sample (Multiple Group -Five Pathways Constrained)

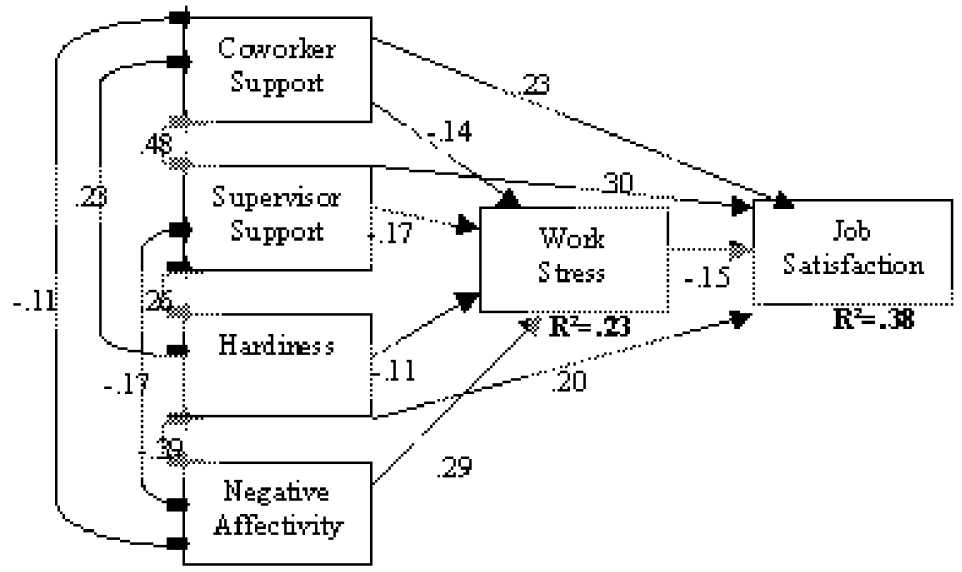

\section{SUMMARY OF RESULTS}

Results of the analyses indicate that the proposed model fit the data for both the government agency and high-tech samples. The fit indices were calculated after the nonsignificant pathway (negative affectivity to job satisfaction) was removed to improve the 


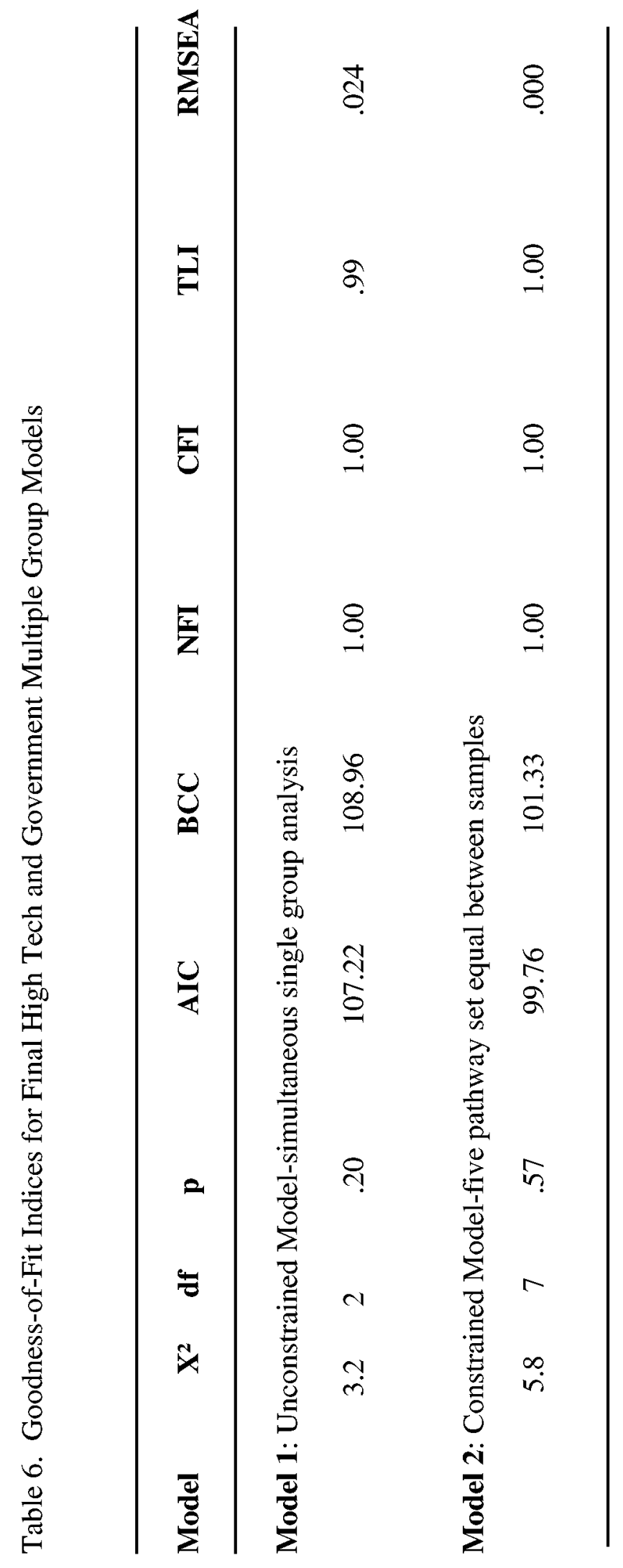




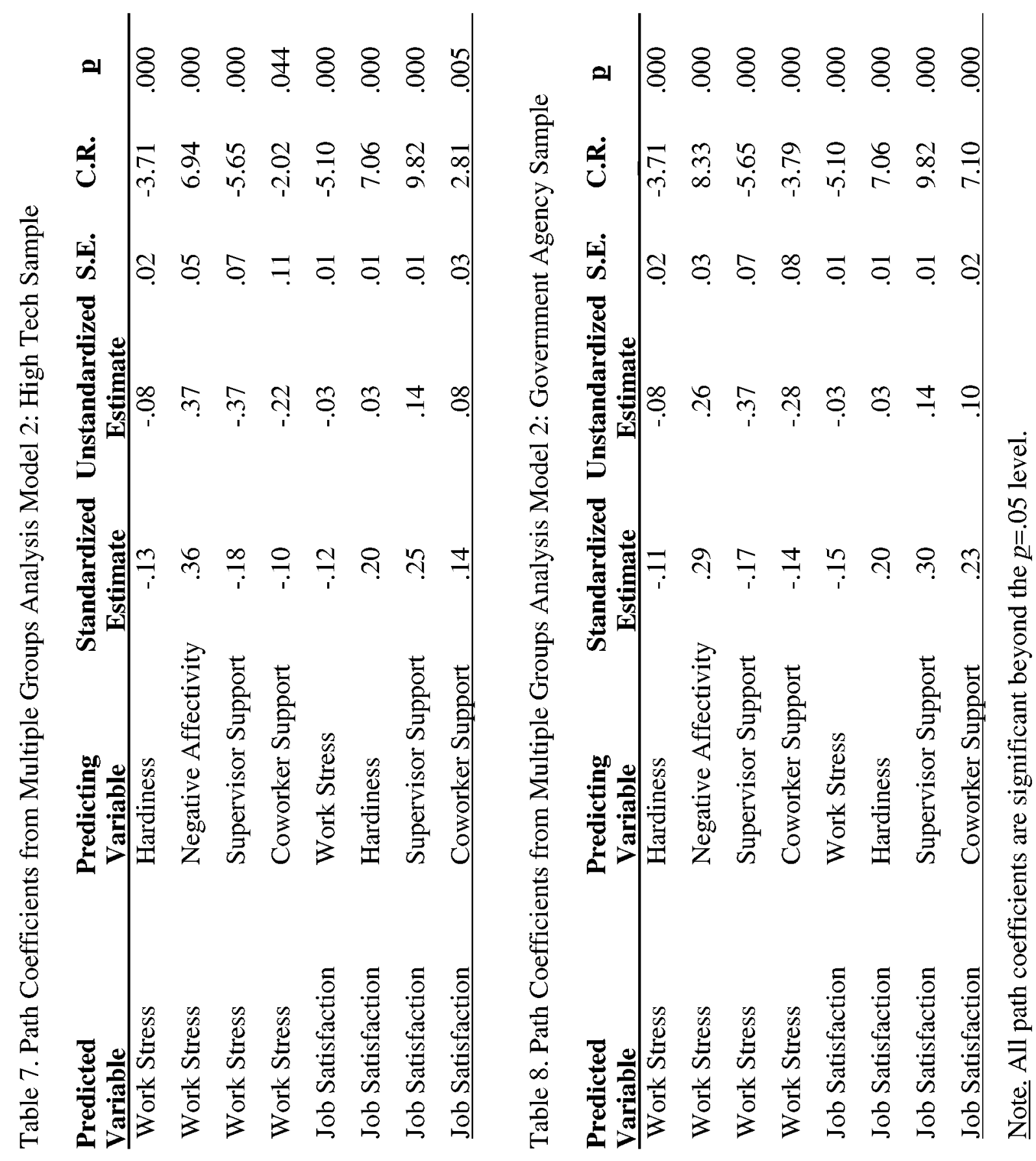


parsimonious fit of the model. Therefore, hypotheses 1 and 2 were supported since the predictor variables account for a substantial amount of variance in the two criterion variables, work stress and job satisfaction. In addition, hypothesis 3 was also supported, in that the predictor variables of supervisor support, coworker support and hardiness significantly predicted the criterion variables work stress and job satisfaction, above and beyond the variance accounted for by the confounding variable negative affectivity. Finally, the proposed relationships suggested in hypotheses 4 through 10 were supported as predicted (see Tables 2 and 3 for correlations among all variables, as well as path coefficients in Figures 3 and 4, and critical ratios of the specified model paths in Tables 4 and 5). In addition to the originally proposed hypotheses (see Chapter One), an additional research question was raised and addressed during the analysis in this study. The question of whether the estimates of the model parameters might be similar or vary between samples was addressed through a multiple group path analysis using nested model comparison to determine how sample group membership effected the relationships specified in the model. The findings of this secondary analysis re-confirm that the model fits the data for both samples similarly. In addition, five pathways, which were set equal between groups in Model 2 (hardiness to work stress, supervisor support to work stress, work stress to job satisfaction, hardiness to job satisfaction and supervisor support to job satisfaction) were essentially equal in strength between the high tech and government agency samples. See Figures 5 and 6 for a diagram of the final model with the path coefficients and Tables 6 and 7 for the critical ration of the specified model paths. The secondary (multiple group analysis with nested model comparison) revealed that Model 2 was the most parsimonious and final model. Discussion and implications of these study findings will follow. 


\section{CHAPTER FIVE}

\section{Discussion}

\section{SUMMARY}

The purpose of this study was to explore the relationships among the individual dispositions of hardiness and negative affectivity and environmental protective factors of coworker and supervisor support on work stress and job satisfaction. A path model of these relationships based on previous research was proposed and tested. A single group path analysis was employed to explore the fit of the model in two data samples, a high tech and a government agency sample. Based on the findings of the initial analyses, multiple group path analyses with nested models' comparisons were conducted comparing the strengths and similarities of the variable relationships between the two data samples. In general, the outcomes of the data analyses provide support for all proposed hypotheses.

The following discussion of the results is divided into three main sections. The first section reviews the descriptive, correlational and path analysis results. Within this section the discussion provides an overview of the key findings from the results of the analyses conducted in the current study. The second section of the discussion interprets important outcomes of the study and their possible implications to research in related fields. The discussion concludes with a review of study limitations and recommendations for future research.

\section{REVIEW OF FINDINGS}

Findings from this study were as predicted for the relationships of all variables to the criterion variables: job satisfaction and work stress. Consistent with previous research, general job satisfaction was inversely related to work stress (Berwick, 1992; Dolbier et al., in press; Rout, 1999), and positively related to hardiness (Evans et al., 1993; Judge et al., 1998). Also 
consistent with the previous research, higher scores on job satisfaction were related to higher scores on supervisor support (Babin \& Boles, 1996; Cummins, 1990; Schirmer \& Lopez, 2001; Terry et al. 1993) and coworker support (Ducharme \& Martin, 2000; House, 1981; Poulin \& Walter, 1992). The findings for work stress were compatible with previous research and hypotheses, indicating that lower scores on work stress were inversely associated with higher scores on hardiness (Berwick, 1992; Bartone et al., 1989; Evans et al., 1993; Langemo, 1990). Lower scores on work stress were also related to higher scores on supervisor support (Beehr, King \& King, 1990; Cummins, 1990; Terry et al., 1993) and higher scores on coworker support (Abdel-Halim, 1982; Winnubst, Marcelissen, \& Kleber, 1982). Overall, the results of variable relationships in the current study reinforce the findings of previous research and extend those results to the general and work domain relevant measures used in the current study.

The relationship of negative affectivity with the other variables in the path model corroborated the proposed hypotheses and previous research. As suggested in the literature review, the nuisance variable negative affectivity was inversely related to job satisfaction (Ducharme \& Martin, 2000; Levin \& Stokes, 1989) and positively related to work stress (Brief et al., 1988; Wong, et al., 2000). Although, negative affectivity was inversely related to job satisfaction in the initial path analysis, this pathway was not significant when all predictor variables were included in the model. The small inverse association between negative affectivity and job satisfaction found in this study is supported by the findings of several previous studies (Ducharme \& Martin, 2000; Necowitz \& Roznowski, 1994).

The correlation and path analysis findings from this study supported previous research suggesting the association of negative affectivity to hardiness disposition and work stress (Brief et al., 1988; Fogarty et al., 1999). The results of the Pearson Product Moment Correlations indicated that negative affectivity was moderately associated with dispositional hardiness and work stress for both samples. A smaller correlation was found for the relationship of negative affectivity to job satisfaction. The weaker correlation is consistent with the path analysis finding 
of a non-significant path between negative affectivity and job satisfaction. The correlation results reiterate the importance of including negative affectivity to capture the influence it has on all variables in the model. Overall, the descriptive results from the current study are consistent with the expected relationships among negative affectivity and the other variables in the model (see Tables 2, 3 and 4).

The results of this study provide clarification to the previously inconsistent findings in the literature for the relationship of negative affectivity and job satisfaction. Some studies have suggested that job satisfaction is closely related to affect or that job satisfaction itself is a measure of affect at work. However, the findings of the current study indicate that the path between negative affectivity to job satisfaction is not significant when hardiness, supervisor and coworker support are included as predictors in the structural equation model. The path analysis results of this study are consistent with some studies that suggested negative affectivity is only weakly related to job satisfaction (Fisher, 2000; Fogarty et al., 1999). This may imply that the relationship of negative affectivity to job satisfaction is weakened by the relationships (intercorrelations) of negative affectivity to the other predictor variables.

Negative affectivity was included in this study as a nuisance variable, following the recommendations from previous work stress, hardiness, and job satisfaction research. When negative affectivity was evaluated using path analysis as the sole predictor of work stress, it accounted for a substantial amount of the variance in both the high tech sample $\left(\underline{R^{2}}=.20\right)$ and the government agency sample $\left(\underline{\mathbf{R}^{2}}=.14\right)$. Negative affectivity was also significantly related to job satisfaction when work stress and negative affectivity were the only predictors of job satisfaction. The variance accounted for in job satisfaction was significant in both the high tech sample $\left(\underline{\mathrm{R}^{2}}=.12\right)$ and the government sample $\left(\underline{\mathrm{R}^{2}}=.13\right)$. However, a important finding from the data analysis indicated that support in the work environment and hardiness personality accounted for a substantial amount of the variance in work stress and job satisfaction (16-20\%) beyond the variance contributed by negative affectivity as predicted. It was also interesting to note that the 
relationship between negative affectivity and work stress was stronger than the pathway from negative affectivity to job satisfaction. Given that the pathway from negative affectivity to job satisfaction was not significant with the addition of the predictor variables of interest, the results suggest that work stress and job satisfaction are significantly influenced by hardiness, supervisor support and coworker support. Negative affect may indirectly influence the criterion variables, through the other predictor variables of interest. If these positive predictor variables directly affect the important work outcome variables of work stress and job satisfaction, support at work and dispositional hardiness could be targeted for future work site interventions.

In summary, the descriptive results were supportive of the proposed relationships suggested in hypotheses 4 through 10. A notable finding from the descriptive outcomes was that the predictor variables with the strongest association were similar for both the high tech and government samples. The variables with the largest correlation to work stress were hardiness, negative affectivity and supervisor support, followed by coworker support. The predictor variables with the strongest correlation to job satisfaction were hardiness, work stress, supervisor support and coworker support. These findings suggested that the relationships between the variables may be similar despite sample differences (described in Chapter 3).

Similar to the descriptive results, the outcomes of the single group path analyses supported the research hypotheses and indicated that the proposed model (Figure 3 and 4) fit the data for both the high tech and government agency samples (see also Tables 3 and 4). The strongest path coefficients for work stress were consistent across samples in the path analysis, and these predictor variables were negative affectivity, and supervisor support. The strongest predictors of job satisfaction were supervisor support, hardiness, and coworker support.

Following the single group path analyses, multiple group path analyses were conducted to extend previous findings by investigating whether group membership (i.e.sample) influenced the relationships between the variables specified in the proposed model. The model was successfully fitted to two subsequent data sets from different work environments. The outcome 
of the multiple group path analyses confirmed that the predictor variables with the strongest association to both criterion variables (work stress and job satisfaction) were consistent across samples. The predictor variables with the greatest path coefficients to work stress were negative affectivity and supervisor support (see Table 3 and 4). The predictor variables with the strongest path coefficients to job satisfaction were supervisor support and coworker support. The commonality in the strength of variable associations between samples suggested that the variable relationships might generalize despite the sample descriptive differences.

A final analysis was conducted to test whether the specific model parameters generalize between sample groups. A nested model comparison was employed for this statistical test. This test was important since the two samples were significantly different on the following variables: hardiness, negative affectivity, and job satisfaction, as well as demographically different, in ethnicity, predominate gender, education and average length of tenure. The nested model comparison enabled the direct comparison of all pathways in the model, permitting the researcher to set similar pathways equal, improving the fit (parsimony) of the model. The unrestricted multiple group model (Model 1) fit both data sets. To distinguish the variation in the strength of specific pathways (path coefficients) as well as the overall fit of the model between samples, a second model (Model 2) with five pathways constrained equal between samples was evaluated. This comparative analysis indicated both samples fit the model similarly, denoted by the improved fit of the model in the multiple group analysis with the several pathways constrained to be equal. The comparative fit indices (see Table 6) suggested that Model 2 was the final and most parsimonious fitting model. This finding further indicated that the strength of the five paths: hardiness to work stress, supervisor support to work stress, work stress to job satisfaction, hardiness to job satisfaction and supervisor support to job satisfaction were essentially equal across samples (see Figures 5 and 6). This result implies that the strength of these five pathways and the amount of variance accounted for by these variable relationships were very similar despite the differences across the two samples. The similar 
strength of these pathways between samples is a key finding of this study. These common results found in both samples enhance the external validity of the model indicating it's ability to generalize to different types of work settings.

\section{IMPLICATIONS}

The results of this study build on the existing research and lead to several implications for practitioners and researchers who are interested in influencing work stress and job satisfaction. First, the inclusion of domain specific social support from supervisor and coworkers as predictors of general work stress and overall job satisfaction is both applicable and important at the work site. Similar to findings of previous work-related social support literature, the strength of the relationship of supervisor support to both criterion variables of work stress and job satisfaction is substantially stronger than the association of coworker support to work stress and job satisfaction (House, 1981; Karasek et al., 1982). This is probably related to the greater amount of influence that supervisors have over issues that increase employee work stress and dissatisfaction. However, coworker support is significantly associated with reduced work stress and increased job satisfaction in both samples. Therefore the effect of this positive relationship should not be disregarded. Taking into consideration the impact of supportive relationships at work in this study, non-supportive supervisors and coworkers should be targeted for interventions to increase employee support from the work environment. Increasing support from supervisors and coworkers may enhance the employee's perception of the work environment by reducing work stress and increasing job satisfaction.

Secondly, the results from this study also reiterate the importance of considering both work environment factors, as well as individual factors for a workplace stress intervention. The strong relationship between support from coworkers and supervisors at work to both work stress and job satisfaction demonstrates that support at work influences important work outcomes. In addition, the path from dispositional hardiness to job satisfaction was significant in both samples. This outcome is supported by results of a previous study by Rush and colleagues, (1995), in 
which hardiness was found to have a direct positive impact on job satisfaction and a similar inverse relationship to work stress. However, the linkage of hardiness to job satisfaction in the current study is contrary to the findings of Fogarty and colleagues, (1999), who indicated that personality variables did not predict job satisfaction. Previous research indicates that the influence of positive personality factors such as hardiness and the perception of support in the work environment has been linked to work stress and job satisfaction (Evans et al., 1993; Judge et al., 1998; Manning et al., 1988). The findings of this study are notable since they replicate some of the previous research outcomes, however, the current study extended the findings by using general instruments (i.e., overall job satisfaction), which are specific to the work domain (i.e., supervisor and coworker support).

Taken as a whole, the findings of this study imply that individuals may experience beneficial or protective effects from hardiness and support at work against situations, events or hassles which often cause work stress and job dissatisfaction. If interventions can be designed to enhance social support at work and enhance individual employee's dispositional hardiness, then organizations can reduce employee work stress and increase employee job satisfaction beyond the conventional salary increases and expensive enrichment of benefit plans with perquisites. If these work environment and individual protective factors can be enhanced, then both the employer and the employee benefit through decreased stress at work, improved quality of life in general, which ultimately influence worker productivity and organizational performance.

Finally, the findings of this study indicate that employees who perceive more support at work from both coworkers and supervisors are more likely to perceive less work stress and greater overall job satisfaction. In addition to impacting the employees' job satisfaction and effectiveness at work, stress often spills over from work to life outside of work. To combat this situation employers can encourage managers and colleagues to plan more positive interaction within work groups. Since the results imply that supervisor support is a strong predictor of work stress and job satisfaction in both samples, it is important to ensure that supervisors are selected, 
trained and prepared appropriately to manage employees before being placed in employee management roles. Effective placement and training of managers may help to reduce work stress and enhance job satisfaction. Since the average American worker spends the majority of their waking time at work, the work domain is ideal for investigation of the positive effects of social support at work, and hardiness on the work outcomes of work stress and job satisfaction.

Overall, the structural model demonstrates that most of the predictors in the model had a direct effect on work stress and job satisfaction. The one path, from negative affectivity to job satisfaction, was not significant when the predictor variables of interest in this study were considered in the model. When evaluated as the sole predictor, negative affectivity significantly predicted work stress and to a lesser extent negative activity and work stress significantly predicted job satisfaction. However, it is important to note that the predictor variables, hardiness, coworker support and supervisor support, all contribute significantly, increasing the amount of variance accounted for in the criterion variables, work stress and job satisfaction. When the model same model was evaluated without negative affectivity, to assess for the influence of the ordering of predictors, the model, and all path critical ratios were significant and the variance accounted for was similar for job satisfaction, and slightly less for work stress. This was expected since double arrows in Figures 3-6 indicate substantial intercorrelations suggesting multicollinearity or shared variance between negative affectivity, and the other predictor variables of interest hardiness, supervisor support and coworker support. Although negative affectivity accounted for very little of the variance in job satisfaction, it accounted for a substantial amount of the variance in work stress. Thus, the variables of interest in this study, hardiness, supervisor support and coworker support all contribute, directly and significantly to the criterion variables, above and beyond the variance shared with the nuisance variable, negative affectivity.

Given the result of the hierarchical analysis assessing $\mathbf{R}^{2}$ change, and that negative affectivity was still a substantial predictor of the variance in work stress, negative affectivity may 
be an important area to consider for work stress interventions. Personality dispositions, such as negative affectivity are difficult to change. However, it may be possible to discuss how negative thoughts and fears of what might happen can cause an individual to feel more stress. Perhaps by pointing out alternative interpretations/evaluation of the situation or event that an individual views as stressful may encourage workers to explore alternative perspectives. These less threatening interpretations are less likely to elicit a stress response. This approach is similar to the cognitive behavioral intervention approach suggested by Kompier and colleagues (1998). This type of intervention could help participants modify perceptions of how they process potentially stressful situations.

\section{STUDY LIMITATIONS AND RECOMMENDATIONS FOR FUTURE RESEARCH}

Due to the dynamic nature of the work site setting and the use of previously existing data sets, there are limitations in the current study design. For example, both samples may have particularly supportive supervisors and coworkers. This factor may influence the findings and limit the generalization of the results to other work settings with less supportive work environments. One recommendation for minimizing the risk of this limitation in future research would be to employ a randomized study design, thus reducing the likelihood of skew or bias in a study sample.

Causality cannot be inferred from the results of the current study due to its cross-sectional nature. It is possible that outside variables, not included in this cross-sectional study design, could influence or account for relationships demonstrated in the study findings. One such variable, negative affectivity, has been identified in the literature as a potential nuisance variable in stress research. Negative affectivity was included in the data analysis to control for its potential effects in the model. Future research could further reduce this limitation by employing a longitudinal study design to track trends over time. A repeated measure intervention study with a control group investigating the effect of some of the work stress and job satisfaction 
interventions proposed in this study would be highly recommended for future research as the preferred method of controlling for unaccounted nuisance variables.

Age and gender were included in the study to assess whether these demographic variables influenced the overall fit of the model to the two data samples. Although small differences were found in the relationships between the variables based on the gender multiple group analysis, the overall model fit was not effected, and still fit the data for both the male and female samples. These findings are similar to previous research on the variables included in the model (Fisher, 2000; Fogarty et al.,1999), where no distinct patterns emerged in based on the demographic variables and the research variables in either sample. Due to the unequal numbers of males and females in both samples, the current study was not well designed to tease out gender-related effects on the variables or the overall path models. It is recommended that future researchers consider designing studies that can better capture and investigate gender effects by including equal sample sizes of both genders.

It is not unusual for employees to be concerned about providing personal information to others at work, based on the fear the information might be shared with others in the organization. To minimize employee concern for confidentiality in the current survey, both organizations informed all potential participants of the various precautions taken prior to the survey administration to maintain confidentiality of individual data. Participants were informed that their survey responses would only be analyzed and presented in aggregate form. In addition, access to data was limited to the research team, and only aggregate data was reported back to organizational management. Informing the participants of the precautions taken during data collection should have reassured them and minimized the risk of this limitation.

The use of general and work domain specific measures in this study may limit the application of these findings. For example, the use of a general stress measure in this study may limit the generalization of these findings to non-specific stress in the work setting. The use of general measures of work stress, supervisor, and coworker support cannot infer any conclusion 
for specific types of work stress (e.g., role conflict, role ambiguity) or social support (e.g., emotional versus instrumental support). Findings from this study should only be generalized to overall work stress, social support at work, and general job satisfaction. However, the general measures of work stress and support utilized in this study were chosen for their ease of application to the work setting and were therefore appropriate for the purpose of the current study.

The use of a single-item job satisfaction measure may affect the reliability or validity of the measurement of job satisfaction in this study. However, support exists for use of a singleitem job satisfaction measure as an effective tool for assessing overall job satisfaction (Nagy, 2002; Scarpello \& Campbell, 1983; Wanous, Reichers, \& Hudy, 1997). Results of these three studies (including a 1997 meta-analysis) indicated that a single-item job satisfaction measure compares favorably to several published multiple-item, general job satisfaction scales. In addition, a significant, strong correlation between the single item and 15-item scales for job satisfaction ( $r=.82)$ was found for the government sample in the current study. This strong correlation indicates a high level of convergent validity and lends additional support to the use of the shorter scale in this study. Surprisingly, when the model was evaluated using the 15 -item job satisfaction measure as the job satisfaction criterion variable no additional variance was accounted for (no change was observed in the $\mathrm{R}^{2}$ for work stress or for job satisfaction). This indicates that no additional variance would be explained in the current model by using the 15item measure instead of the single-item measure

Other limiting factors that may influence the study findings include self-report data, and possible historical effects (e.g., participants' past experiences associated with work surveys). These are difficult issues to control for in a work site setting. However, each of the sample sizes exceeds three hundred participants. This larger sample size helps to minimize this limitation by reducing the influence individual responses have on the overall sample distributions. 
Overall, the findings from this study highlight the importance of individual as well as environmental variables in reducing stress and improving job satisfaction at work. Employers should consider environmental support and hardiness as integral components of a workplace strategy to impact employee stress and job satisfaction. These findings may provide additional direction for occupational health, human resources personnel, business operations leaders, and work site health promotion professionals when considering interventions to reduce work stress and increase job satisfaction for employees. Similar to the previous research presented by Rush and colleagues (1995), the findings of this study suggest that the influence of dispositional personality traits, such as positive affect, be investigated in future studies.

In addition, health promotion practitioners need to understand the importance of considering both the individual and the availability of support in the work environment when planning potential stress interventions at the work site. Most U.S. workplace health promotion stress interventions focus on the individual experiencing stress, but often fail to address the cause of the stress. However, both employees and employers must take responsibility for minimizing the controllable aspects of stress in the workplace. An integrative approach to workplace health promotion requires more than the traditional, individual directed focus, it should also address environmental, organizational, and social factors which influence stress at work, employee morale and job satisfaction. This approach, has been referred to as the Integrative Workplace Health Management (WHM) model has already been adopted and proven successful outside of the U.S. by researchers and practitioners in Canada, Australia, some parts of Europe and Asia (Chu \& Dwyer, 2002).

The results from this study build on the person-environment fit theory by highlighting some of the important individual and work environment protective factors that may reduce work stress to enhance job satisfaction. Overall, this study advances the current research and introduces several possible options for future intervention studies exploring the reduction of work stress and enhancement of job satisfaction in work site settings. 
Appendices 


\section{APPENDIX A: HIGH-TECH SAMPLE SURVEY}

Employee

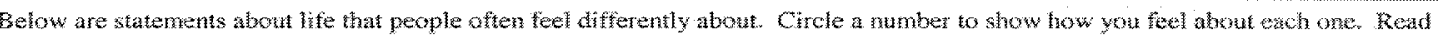

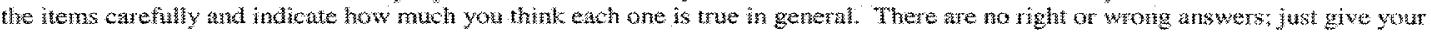
own hones opinions.

(Dispositional Kesulfence/Hardúness -DRS)

\begin{tabular}{|c|c|c|c|c|c|}
\hline \multicolumn{6}{|c|}{ (Dispositional Resulfence/Harduness -DRS) } \\
\hline & & $\begin{array}{l}\text { Noy } \\
\text { AR. }\end{array}$ & 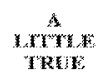 & $\begin{array}{l}\text { grrex: } \\
\text { Trers }\end{array}$ & 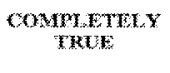 \\
\hline 1. & 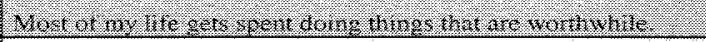 & 0 & 1 & 2 & 3 \\
\hline 2. & Dlanning ahead can help avoud most future problems. & 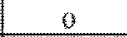 & 1 & 2 & 3 \\
\hline 1. & 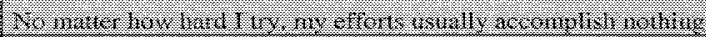 & (1) & 1 & .. & 3 \\
\hline 4. & I tor Whe to make changes in roy exerytay schedule. & 0 & 圭 & 2 & 3 \\
\hline 3. & 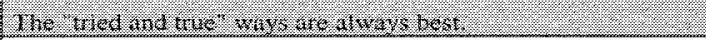 & 0 & 1. & 3 & 13 \\
\hline 6. & 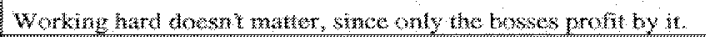 & 0 & 1 & 2 & 3 \\
\hline 1. & 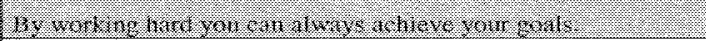 & 0 & 3 & 2. & 1 \\
\hline 8. & Mos of what hapens in hife is jus mean bo be & 0 & 1 & 2 & 3 \\
\hline 13. & 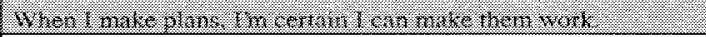 & 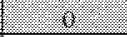 & 诰 & 1 & . \\
\hline 10. & It's excitho to learn sonethang about nyself & 0 & 1 & 2 & 3 \\
\hline$\sqrt{1}$ & 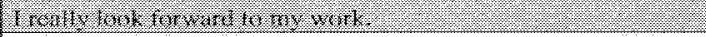 & a & 1 & 1 & 玨 \\
\hline 12 & 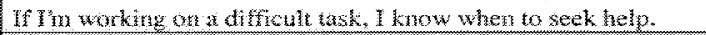 & 0 & 1 & 2 & 3 \\
\hline 11 & 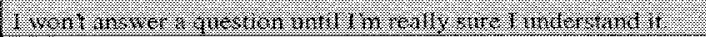 & 1 & 1 & 3 & 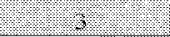 \\
\hline 14 & llike a lot of variety in my work. & 0 & 1 & 2 & 3 \\
\hline 13 & 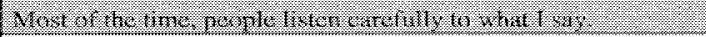 & 18 & 1 & 2 & 1 \\
\hline 16. & Thinkins of yourset as a bee person just leads to frustraton & 0 & 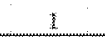 & 2 & 3 \\
\hline 13 & 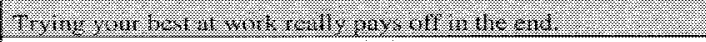 & 1 & 1 & 2 & 1 \\
\hline 18 & My mistakes are ensullly very dinceule to correct & $\theta$ & 1 & 2 & 3 \\
\hline 10. & 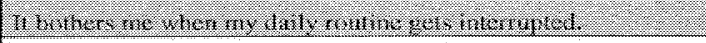 & 1 & & .2 & (1) \\
\hline 20 & 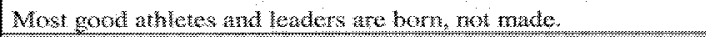 & 0 & 1 & 2 & 3 \\
\hline 21. & 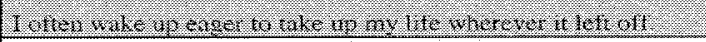 & 9 & I &. & 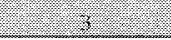 \\
\hline 22. & Lots of times, I dont reakly kmow my own mind. & 0 & 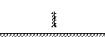 & 2 & 3 \\
\hline 13. & 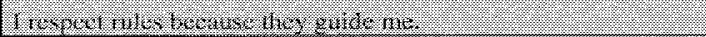 & 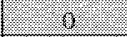 & 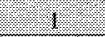 & 3 & 3 \\
\hline 24. & The & 0 & 1 & 2 & 3 \\
\hline 23 & 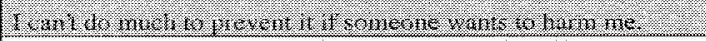 & 1 & & 2 & 3 \\
\hline 26. & Changes in rowans are hueresting to me & 0 & 1 & 2 & 3 \\
\hline 27: & 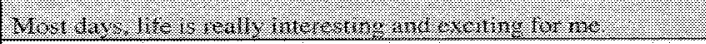 & (6) & 1 & 2 & 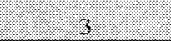 \\
\hline 28 & Its hard to magine anyone getring exeited abou workng. & 定 & 1 & 2 & 3 \\
\hline tit? & 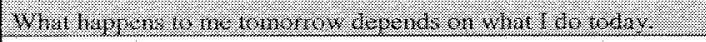 & (1) & 1. & 1 & 3 \\
\hline 30 . & Orinaty wok is just too boring to be worth duing. & 0 & 1 & 2 & 3 \\
\hline
\end{tabular}




\begin{tabular}{|c|c|c|c|c|c|c|}
\hline \multicolumn{7}{|c|}{ (Nogatine Affec) } \\
\hline 1.2 & 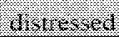 & . & 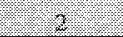 & 3 & : & 3 \\
\hline 2. & topeset & 1 & 2 & 3 & 4 & 5 \\
\hline 3. & 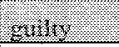 & I. & 1.0 .0$. & $\sqrt{-3}$, & 1. & 5 \\
\hline 4. & scared & 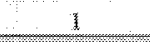 & 2 & 3 & 4 & 5 \\
\hline 1. & 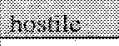 & 1. & 2 & 3 & . & (2: \\
\hline 6. & irritable & 1 & 2 & 3 & 4 & 5 \\
\hline 1. & 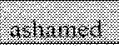 & 1.3 & 2 & . & 1 & .5 \\
\hline 8 & merwous & 1 & 2 & 3 & 4 & 5 \\
\hline 10 & $\operatorname{lin} x=1$ & 1 & 2 & 3 & 1 & . \\
\hline 10. & arrato & 1 & 2 & 3 & 4 & 5 \\
\hline
\end{tabular}

\section{(Work Stress)}

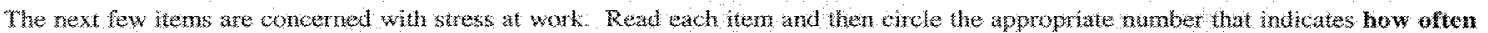
you have experienced the following at work diring the lost month:

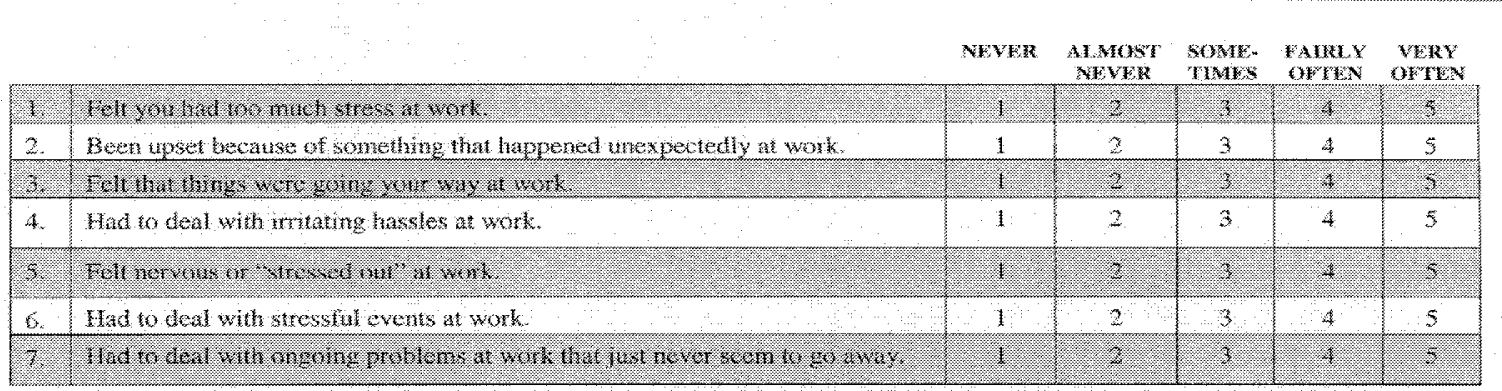




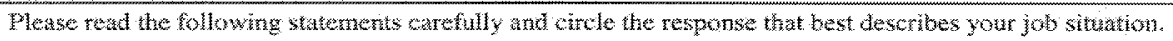

(Supervisor Support w 4 \& Coworker Support $45-9$ )

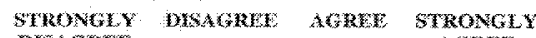
MASTRE:

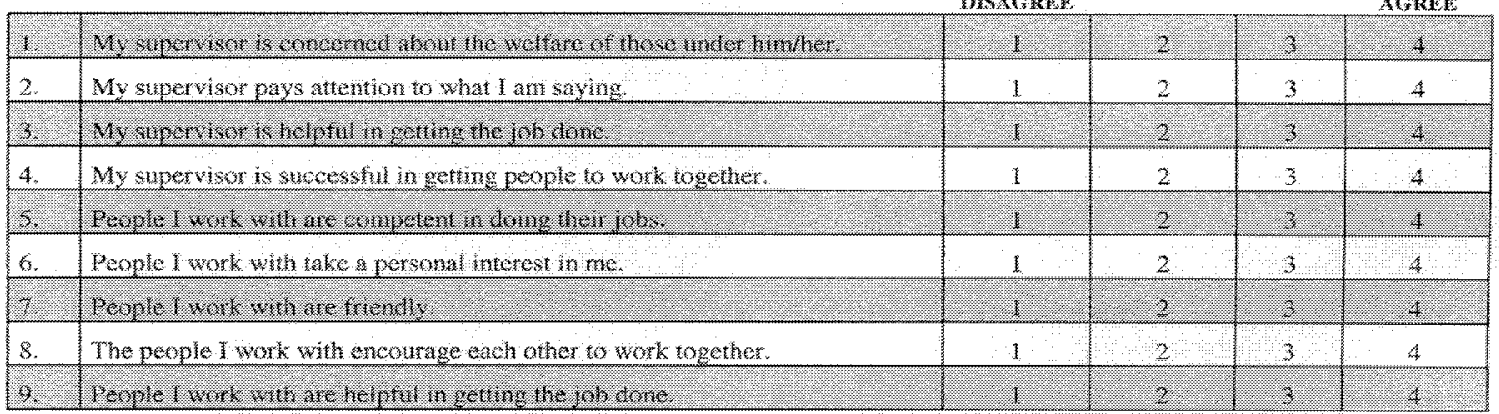

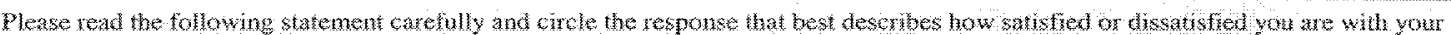
straent job sthetik

(Overall Job Safisfaetion Single Ifen PIIC)

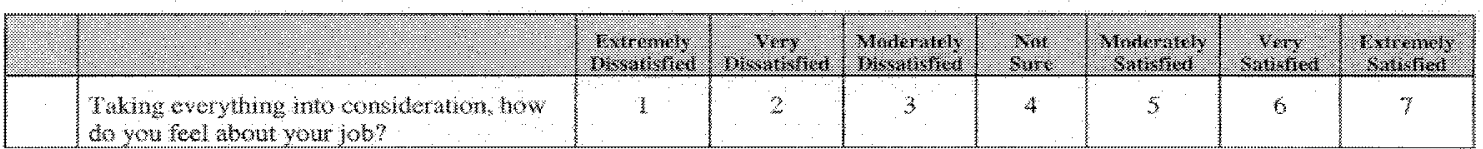

\section{Thank you for completing the survey!}




\section{APPENDIX B: GOVERNMENT AGENCY SAMPLE SURVEY}

Below are statenents about life that people often feel differently about. Crole a ramber to show how you teel about each one. Read the items carefully and indicate how much you think each one is true in general.

\begin{tabular}{|c|c|c|c|c|c|}
\hline \multicolumn{6}{|c|}{ (Dispositional ResiliencedMarliness-DRS) } \\
\hline & $\begin{array}{l}\text { Circle a nomber m show how you freel ahout ereh } \\
\text { statement: }\end{array}$ & 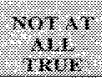 & 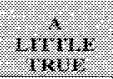 & Writit & 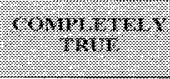 \\
\hline 1. & Most of my life gets spent doing things tixat are worthwhile. & 0 & 1 & 2 & 3 \\
\hline 2. & Planning thesd crn help avoid most future problems. & 0 & 1 & 2 & 3 \\
\hline 3. & $\begin{array}{l}\text { No matter how hard I try, my efforts ustatly accomplish } \\
\text { nothing. }\end{array}$ & 0 & 1 & 2 & 3 \\
\hline 4. & I don't lake to make changes in my everyday schedule & 0 & 1 & 2 & 3 \\
\hline 5. & The "ried and true" ways are always best. & 0 & 1 & 2 & 3 \\
\hline 6. & Working hate doesnt matter, since on y the bosses profit by it. & 0 & 1 & 2 & 3 \\
\hline 7. & By working hard you can always achieve your goals. & 0 & 1 & 2 & 3 \\
\hline 8. & Most of what havpens in life is just meant to be. & 0 & 1 & 2 & 3 \\
\hline 9. & When I make plans, Tm certain I can make them work. & 0 & 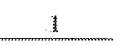 & 2 & 3 \\
\hline 10 & Hex exciting to leam something about myself & 0 & 1 & 2 & 3 \\
\hline 11. & I really look torward to my work. & 0 & 1 & 2 & 3 \\
\hline 12. & 1) Im working on a difucult task, I know when to seek loelp. & 0 & 1 & 2 & 3 \\
\hline 13. & I wonl answer a guestion antel Im really sure landerstand it. & 0 & 1 & 2 & 3 \\
\hline 14. & Ihke a lot of variety in my work. & 0 & 1 & 2 & 3 \\
\hline 15. & Most of the time people listen catrefulty to what I say. & 0 & 1 & 2 & 3 \\
\hline 16. & Thinking of yoursele as a free person just leads to frustration. & 0 & 1 & 2 & 3 \\
\hline 17. & Tryig you best at work really pays of in the exd. & 0 & 1 & 2 & 3 \\
\hline 18. & My mistakes are ustally very difficult to correct. & 0 & 1 & 2 & 3 \\
\hline 19. & It bothers me when my daty routine gets interumpled. & 0 & 1 & 2 & 3 \\
\hline 20. & Most yood athletes and leaders are born, not made. & 0 & 1 & 2 & 3 \\
\hline 21. & Hoften wake up eater to take up my life wherever it left of & 0 & 1 & 2 & 3 \\
\hline 22. & Lots of times. don t really know my own mind. & 0 & 1 & 2 & 3 \\
\hline 23. & I tespect rules beause they guide the. & 0 & 1 & 2 & 3 \\
\hline 24. & 11ke it when things are urcertain ar unptedictable. & 0 & 1 & 2 & 3 \\
\hline 25. & I caul do much to prevent it if someone wants to hasm me. & 0 & 1 & 2 & 3 \\
\hline 26. & Changes in routine are interesting to the. & 0 & 1 & 2 & 3 \\
\hline 27. & Most ays bife is reatly interesting and excitiny for me. & 0 & 1 & 2. & 3 \\
\hline 28. & It's latrd to imagine anyone getting exeited about working & 0 & 1 & 2 & 3 \\
\hline 29. & What happens to me tomonow depends on what I do today. & 0 & 1 & 2 & 3 \\
\hline 30 & Ordinary work is just too boring to be worth doing. & 0 & 1 & 2 & 3 \\
\hline
\end{tabular}


The next few items are concerned with stress at work. Read each item and then circle the appropriate number that indicates how often you have experienced the following at work during the last montu:

\begin{tabular}{|c|c|c|c|c|c|c|}
\hline \multicolumn{7}{|c|}{ (Work Stress) } \\
\hline & 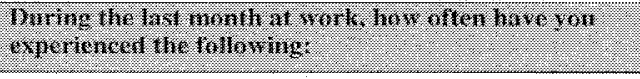 & MTror & 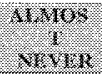 & 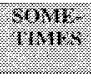 & 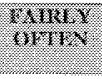 & 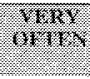 \\
\hline 1. & Felt you had too wuch stress at work. & $\underline{3}$ & 2 & 3 & 4 & 5 \\
\hline 2 & $\begin{array}{l}\text { Been apset because of something that happened } \\
\text { whe pectedy ar work. }\end{array}$ & i & 2 & 3 & 4 & $s$ \\
\hline 3. & Felt that hings were going your way at work. & 1 & 2 & 3 & 4 & $s$ \\
\hline 4. & 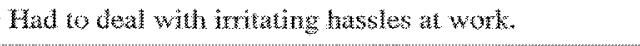 & 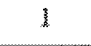 & 2 & 3 & 4 & $\$$ \\
\hline 5. & Tele nervous or "stressed out" at work & 1 & 2 & 3 & 4 & 5 \\
\hline 6. & Had to deal with stressful events at work. & 1 & 2 & 3 & 4 & 5 \\
\hline 7. & $\begin{array}{l}\text { Had to deat with ongoing problens at work that just } \\
\text { never seen to go at way. }\end{array}$ & 1 & 2 & 3 & 4 & 5 \\
\hline
\end{tabular}

Please nad the following statements carefully and circle the response that best describes your job situation.

(Supervisor Support $1-4$ \& Coworker Support $45-9)$

\begin{tabular}{|c|c|c|c|c|c|}
\hline & 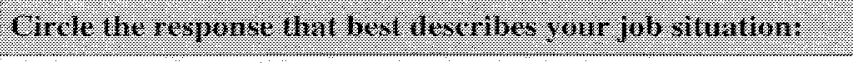 & 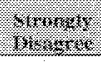 & noият: & Am:s: & Tritrist \\
\hline 1. & 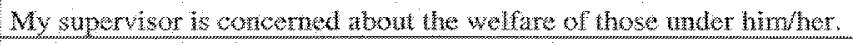 & 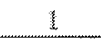 & 2 & 3 & 4 \\
\hline 2. & My strpervisor tyays attention to what l ath sayng & 1 & 2 & 3 & 4 \\
\hline 3. & My supervisor is helotul in getting the job done. & 1 & 2 & 3 & 4 \\
\hline 4. & My sumervisor ss stecesstul in getting people to work together. & 1 & 2 & 3 & 4 \\
\hline 5. & Geople 1 wotk will are conpetent in doing their jobs. & 1 & 2 & 3 & 4 \\
\hline 6. & feople work with take a personal interest in me. & 1 & 2 & 3 & 4 \\
\hline 7. & People 1 work with are friemuty. & 1 & 2 & 3 & 4 \\
\hline 8. & The people I work with oncourage each other to work together. & 1 & 2 & 3 & 4 \\
\hline 9. & People r work with are helofut in getting the job done. & 1 & 2 & 3 & 4 \\
\hline
\end{tabular}

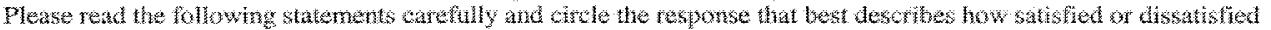

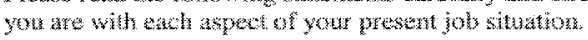

(Total Job Satisfaction 1 -15 \& Overall Job Satisfaction 16 )

\begin{tabular}{|c|c|c|c|c|c|c|c|c|}
\hline & 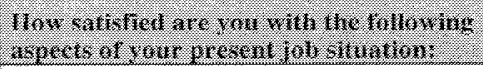 & 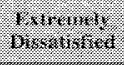 & 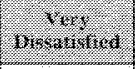 & 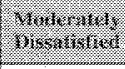 & rive & 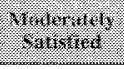 & 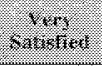 & 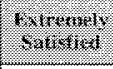 \\
\hline 1. & The physical work conditions. & 1 & 2 & 3 & 4 & 5 & 6 & 7 \\
\hline 2 & $\begin{array}{l}\text { The freadon to choose your own } \\
\text { nuthod of working. }\end{array}$ & 1 & 2 & 3 & 4 & 5 & 6 & 7 \\
\hline
\end{tabular}




\begin{tabular}{|c|c|c|c|c|c|c|c|c|}
\hline 3 & Your le low workers. & 1 & 2 & 3 & 4 & 5 & 6 & 7 \\
\hline 4 & The recogenition you get for good work. & 1 & 2 & 3 & 4 & 5 & 6 & $T$ \\
\hline 5 & Your immediate boss & 1 & 2 & 3 & 4 & 5 & 6 & 7 \\
\hline \multirow[t]{2}{*}{6} & $\begin{array}{l}\text { Whe mount of responsibility you gre } \\
\text { given. }\end{array}$ & 1 & 2 & 3 & 4 & 5 & 6 & 7 \\
\hline & 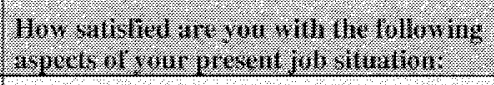 & 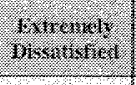 & mistarimath & Mrigritel & ringen & 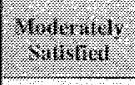 & 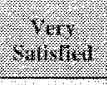 & 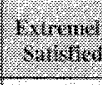 \\
\hline 4 & Your arte or nay & 1 & 2 & 3 & 4 & 5 & 6 & 9 \\
\hline 8. & Your oppormunity to use your abintites & 1 & 2 & 3 & 4 & 3 & 6 & 7 \\
\hline 19. & $\begin{array}{l}\text { Work retationstip between } \\
\text { management and workers in yout } \\
\text { organzation. }\end{array}$ & 1 & 2 & 3 & 4 & 5 & 6 & 7 \\
\hline 10 & Your cliance af monnotion & 1 & 2 & 3 & 1 & 5 & 6 & 7 \\
\hline 11 & The way y you o rganuzation is mankged & 1 & 2 & 3 & 4 & 5 & 6 & 7 \\
\hline 12 & $\begin{array}{l}\text { The attention pad to suggestions you } \\
\text { make. }\end{array}$ & 1 & 2 & 3 & 4 & 5 & 6 & 7 \\
\hline 13. & Xour hours of york & 1 & 2 & 3 & 4 & 5 & 6 & 3 \\
\hline 14 & The arnotme of weriety in your job. & 1 & 2 & 3 & 4 & $S$ & 6 & 2 \\
\hline 15. & Your wob securnty & 1 & 2 & 3 & 4 & 3 & 6 & 7 \\
\hline 16. & $\begin{array}{l}\text { Now, ching overy hing nto } \\
\text { consideraton, how do you reel about } \\
\text { you bo as a whole? }\end{array}$ & 1 & 2 & 3 & 1 & 5 & 6 & 7 \\
\hline
\end{tabular}

This scale cousists of a mmber of words that deseribe differeat feelngs and enotions Read bach tem

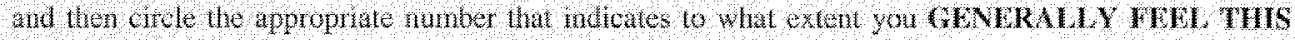
WAY.

(Negatiye Affect

\begin{tabular}{|c|c|c|c|c|c|c|}
\hline . & 1 genervily fi.els & ming wh & I. & momeritito & gim in min & mars wiretis? \\
\hline 1. & Distessed & 1 & 2 & 3 & 4 & 8 \\
\hline 2 & Upset & 1 & 2 & 3 & 4 & 5 \\
\hline 3 & Cuiny & 1 & 2 & 3 & 4 & 5 \\
\hline 4 & Scared & 1 & 2 & 3 & 4 & 5 \\
\hline s. & Mostile & 1 & 2 & 3 & 4 & 5 \\
\hline 6 & minlable & 1 & 2 & 3 & 4 & 5 \\
\hline 7 & Ashomed & 1 & 2 & 3 & 4 & 5 \\
\hline 8. & Nervous & 1 & 2 & 3 & 4 & 5 \\
\hline 9. & Jutry & 1 & 2 & 3 & 4 & 5 \\
\hline 10 & Arand & 1 & 2 & 3 & 4 & 5 \\
\hline
\end{tabular}


The questions below ask about your feelings regarding working at the Department of Human Services. Your individual responses will be strictly confidential and will not be shared with your employer except in group torm.

1. Aro you thiming about leaving Dels enoloynent? Yes No (f no, skip to geation 5 )

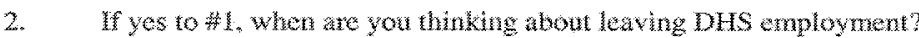
within 6 momthes $x$ a

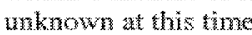
1.2 yaars or greaker other (vease wown

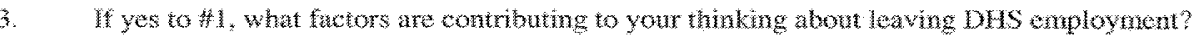

solsary structute

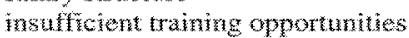

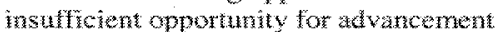

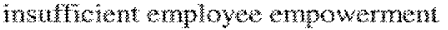

working enwroment

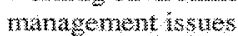

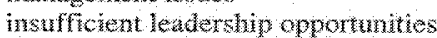
other (renese sedf)

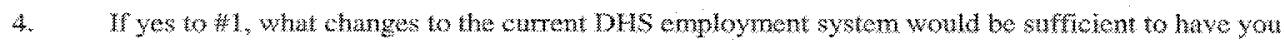
conntue smploymont a DAs?

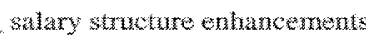

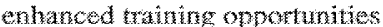
enhanced atrancement opportunitus enhunced enployecem empowerment improventens in the workplace envimonment

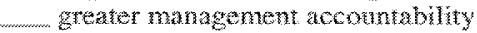

entanced levdership oppomantates oner (platase explatin)

5. In your ophon, what are the most common reasons peope leave DHs employmenty

salum structure

insufficient trining oporumites

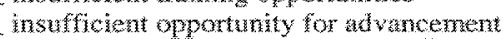
insufficient enployes empowement working enviromment manatement is

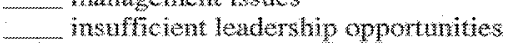
other (please sporify)

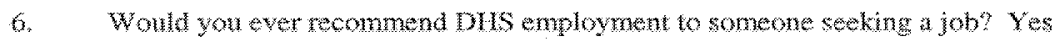
Mo

Why (please explärit artuer response)

\section{THANK YOU VERY MUCH!!}




\section{APPENDix C: High TECH CONSENT LeTter}

\section{APPLIED MATTELAES}

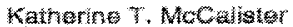

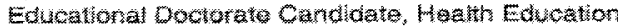

Folvary 3. 2002

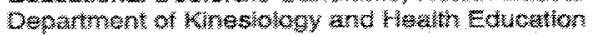

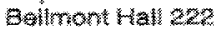

Tha Univerasty of Texas at Ausum

A

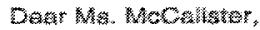

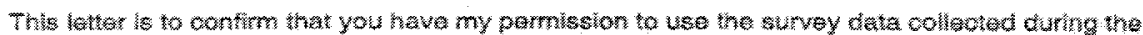
"F⿸尸匕

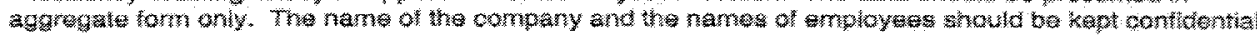

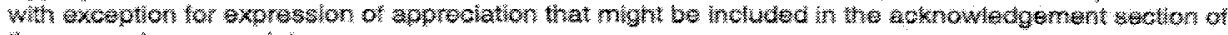

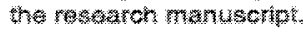

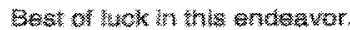

Sinteray

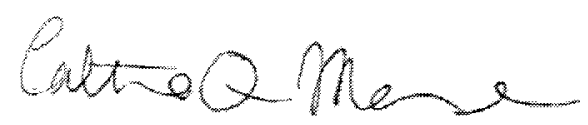

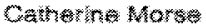

Comorate Axom

Apolined whaterialy

\%

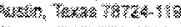

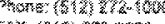

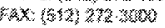




\section{APPENDIX D: GOVERNMENT AGENCY CONSENT LETTER}

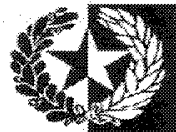

Dr. Mary sromara

molesw

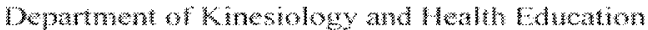

Gellanch Hall 222

Intiversity of Tewax

Ansin. $T \times 7872$

Dear Dr. Steinhard:

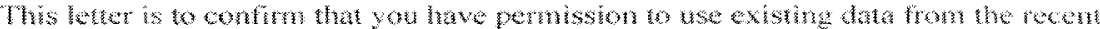

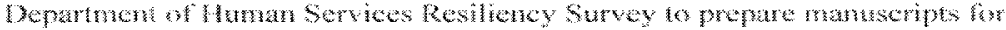

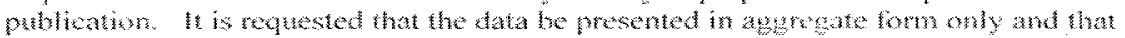

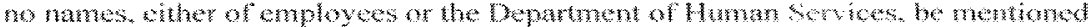
in the manuserigt.

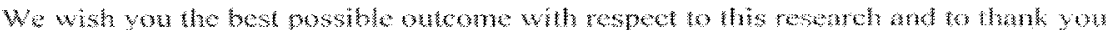

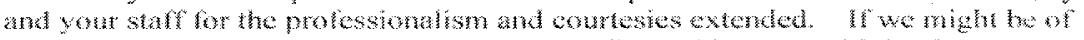

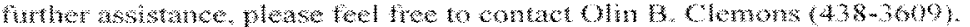

kespecturty.

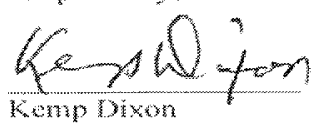

Director. Human Ressukrce Services 
APPENDIX E: JoB SATISFACTION SINGLE AND 15-ITEM CORRELATION

\section{Government agency sample}

Variable

Range

Job Satisfaction (single item)

Job Satisfaction (15-item)

\begin{abstract}
Possible
\end{abstract}
$7-105$

$1-7$
$\mathbf{M}$

SD

Job Sat (15-item)

${ }^{*} \underline{p}<.05$, two-tailed, ${ }^{* *}{ }^{*}<.01$, two-tailed.

Job satisfaction was assessed in this study using a common single-item overall job satisfaction measure in both the high tech and government agency samples. This single-item measure was chosen from the 16-item subscale due to its ability to measure overall job satisfaction and due to space limitations on the company surveys. Participants were asked to answer the question "Taking everything into consideration, how do you feel about your job as a whole?" indicating their degree of satisfaction with their present job.

Job satisfaction was measured in the government sample using both the single-item scale and a longer (15-item) scale. The 15-item scale measures total job satisfaction from many different facets, using two sub-scales: intrinsic job satisfaction and extrinsic job satisfaction. Participants were asked to answer questions such as "How satisfied are you with the physical conditions of your present job?" and "How satisfied are you with the amount of responsibility you are given in your present job?" The participants' responses to these questions indicate their degree of satisfaction with the various aspects of their present job. As expected the predictors accounted for a greater amount of variance in the model using the15-item scale than the singleitem job satisfaction measure in the current study. 
Although, well constructed multiple items scales are typically applied when possible, support exists for use of a single-item job satisfaction measure as an effective tool for assessing overall job satisfaction (Nagy, 2002; Scarpello \& Campbell, 1983; Wanous et al., 1997). Results of these three studies (including a 1997 meta-analysis) indicate that a single-item job satisfaction measure compares favorably to several published multiple-item general job satisfaction scales. The significant, strong correlation between the single-item and 15-item scales for job satisfaction $(r=.82)$ indicates a high level of convergent validity and lends additional support to the use of the shorter scale in this study.

In the current study, the use of a single-item overall job satisfaction scale was preferable. Given that the research question in the current study investigated the variables that predict job satisfaction, focusing on overall job satisfaction, not specific facets of job satisfaction, the use of the single-item scale across both samples was the best study measure. Practical limitations such as survey length and cost of employee time required to complete the survey were also taken in consideration when choosing the measure. The findings from this study support previous research indicating that the use of a single-item measure is appropriate in some studies where the research question and the research situation suggest the use of a single-item scale for job satisfaction (Wanous et al., 1997). 


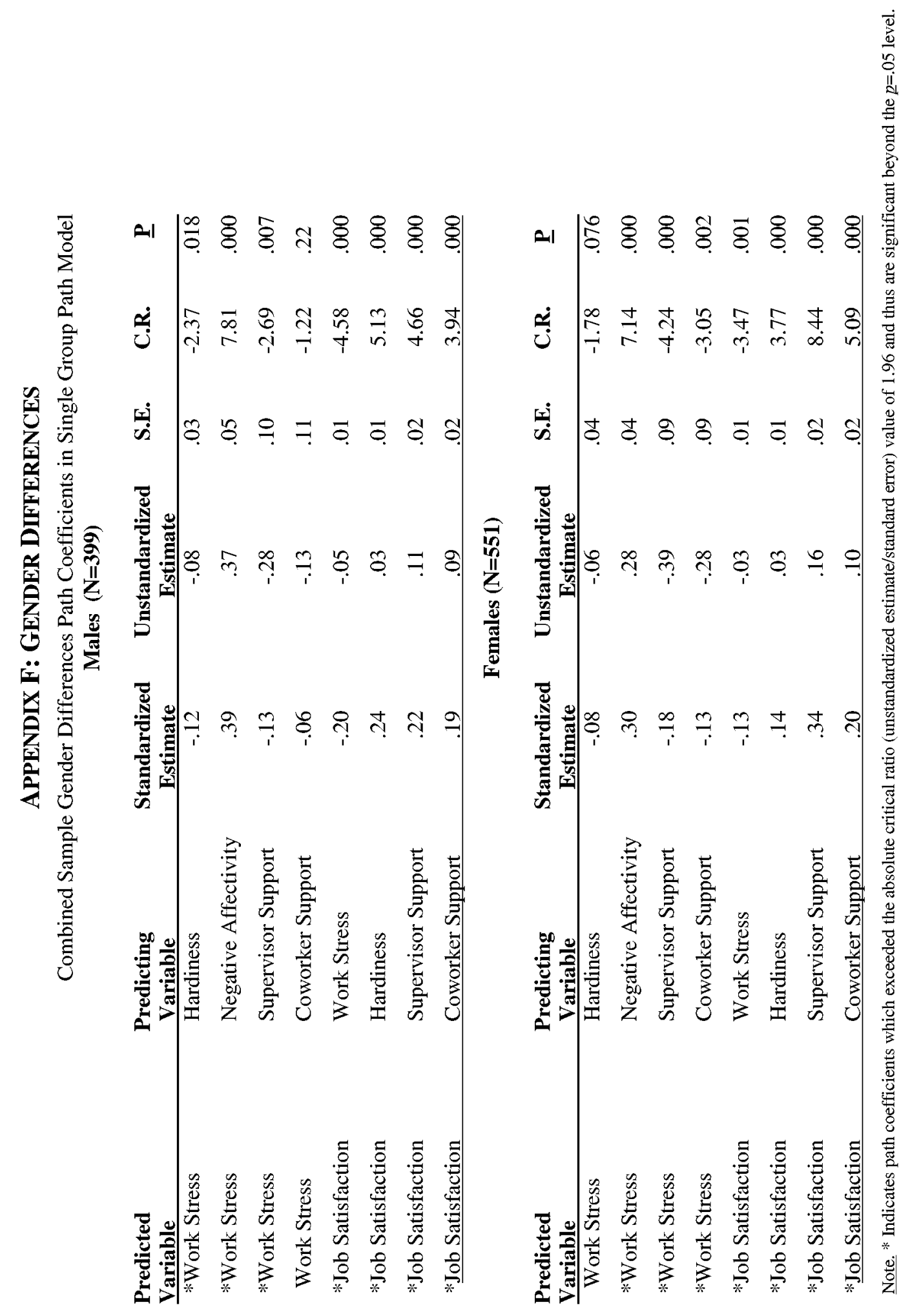

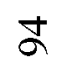




\section{References}

Abdel-Halim, A.A. (1982). Social support and managerial affective responses to job stress. Journal of Occupational Behaviour, 3, 281-295.

Arbuckle, J. (1995). Analysis of moment structures (AMOS). Version 4.0. [computer software]. Chicago, Illinois: Smallwaters Corp.

Babin, B.J., \& Boles, J.S. (1996). The effects of perceived co-worker involvement and supervisor support on service provider role stress, performance, and job satisfaction. Journal of Retailing, 72, 57-75.

Bartkus KR, Howell RD, Parent CR, et al. (1997). Managerial antecedents and individual consequences of group cohesiveness in travel service selling. Journal of Travel Resources, 35, 56-63.

Bartone, P.T., Ursano, R.J., Wright, K.M., \& Ingraham, L.H. (1989). The impact of a military air disaster on the health of assistance workers: a prospective study. Journal of Nervous and Mental Disease, 177, 317-328.

Bateman, T.S., \& Strasser, S. (1983). A cross-lagged regression test of the relationships between job tension and employee satisfaction. Journal of Applied Psychology, 68, 439-445.

Beardslee, N.Q., White, N., \& Richter, J. (1995). Strategies to decrease stress and enhance job satisfaction among nursing faculty. College Student Journal, 29, 511-517.

Beehr, T.A., Jex, S.M., Stacy, B.A., \& Murray, M.A. (2000). Work stressors and coworker support as predictors of individual strain and job performance. Journal of Organizational Behavior, 21, 391-405.

Beehr, T.A., King, L.A., \& King, D.W. (1990). Social support and occupational stress: talking to supervisors. Journal of Vocational Behavior, 36, 61-81.

Bentler, P.M., \& Bonett, D.G. (1980). Significance tests and goodness of fit in the analysis of covariance structures. Psychological Bulletin, 88, 588-606.

Bentler, P.M., \& Chou, C. (1987). Practical issues in structural modeling. Sociological Methods \& Research, 16, 78-117. 
Berwick, K.R. (1992) Stress among student affairs administrators: the relationship of personal characteristics and organizational variables to work-related stress. Journal of College Student Development, 33, 11-25.

Blau, P.M. (1964). Exchange and power in social life. New York: Wiley.

Brief, A.P., Burke, M.J., George, J.M., Robinson, J.S., \& Webster, J. (1988). Should negative affectivity remain an unmeasured variable in the study of job stress? Journal of Applied Psychology, 73, 193-198.

Carver, C.S. (1998). Resilience and thriving: issues, models, and linkages. Journal of Social Issues, 54, 245-262.

Chu, C., \& Dwyer, S. (2002). Employer role in integrative workplace health management: a new model in progress. Disease Management Health Outcomes, 10, 175-186.

Cohen, J. (1992). A power primer. Psychological Bulletin, 112, 155-159.

Cohen, S., Kamarck, T., \& Mermelstein, R. (1983). A global measure of perceived stress. Journal of Health and Social Behavior, 24, 385-396.

Cohen, S., \& Williamson, G.M. (1988). Perceived stress in a probability sample of the United States. In S. Spacepan, \& S. Oskamp, (Eds.), The Social Psychology of Health. (pp. 31-65). Newbury, Ca: Sage.

Collins, M. (1996). The relation of work stress, hardiness, and burnout among full-time hospital staff nurses. Journal of Nursing Staff Development, 12, 81-85.

Cooper, C.L., Rout, U., \& Faragher, B. (1989). Mental health, job satisfaction and job stress among general practitioners. British Medical Journal, 298, 366370.

Cummins, R.C. (1989). Locus of control and social support: Clarifiers of the relationship between job stress and job satisfaction. Journal of Applied Social Psychology, 19, 772-788.

Cummins, R.C. (1990). Job stress and the buffering effect of supervisory support. Group \& Organization Studies, 15, 92-104. 
Davis-Sacks, M.L., Jayarane, S., \& Chess, W.A. (1985). A comparison of the effects of social support on the incidence of burnout. Social Work, 30, 240-244.

Dormann, C., \& Zapf, D. (1999). Social support, social stressors at work, and depressive symptoms: testing for main and moderating effects with structural equations in a three-wave longitudinal study. Journal of Applied Psychology, 84, 874-884.

Ducharme, L.J., \& Martin, J.K. (2000). Unrewarding work, coworker support, and job satisfaction. Work and Occupations, 27, 223-243.

Eisenberger, R., Cummings, J., Armeli, S., \& Lynch, P. (1997). Percieved organizational support, discretionary treatment, and job satisfaction. Journal of Applied Psychology, 82, 812-820.

Evans, D.R., Pellizzari, J.R., Culbert, B.J., \& Metzen, M.E. (1993). Personality, marital, and occupational factors associated with quality of life. Journal of Clinical Psychology, 49, 477-485.

Fisher, C.D. (1985). Social support and adjustment to work: a longitudinal study. Journal of Management, 11, 39-53.

Fisher, C.D. (2000). Mood and emotions while working: missing pieces of job satisfaction? Journal of Organizational Behavior, 21, 185-202.

French, J.R. Jr., Caplan, R.D., \& Harrison, R.V. (1982). The mechanisms of job stress and strain. Chichester: Wiley.

Gallup News Service. (2001). American workers most satisfied with workplace safety, relations with co-workers. The Gallup Organization. (Ed.)

Retrieved November 19, 2001. Retrieved from http://www.gallup.com/poll/releases/pr010907.asp

Gallup News Service. (1999). American workers generally satisfied but indicate their jobs leave much to be desired. The Gallup Organization. (Ed.)

Retrieved November 9, 2001. Retrieved from http://www.gallup.com/poll/releases/pr990903.asp

Goetzel, R.A., Anderson, D.R., Whitmer, R.W., Ozminkowski, R.J., Dunn, R.L., Wasserman, J., et al. (1998). The relationship between modifiable health risks and healthcare expenditures. Journal of Occupational and Environmental Medicine, 40, 843-854. 
Hackett, R. D. (1989). Work attitudes and employee absenteeism: a synthesis of literature. Journal of Occupational Psychology, 62, 235-248.

Hackett, R. D., \& Guion, R.M. (1985). A re-evaluation of the absenteeism-job satisfaction relationship. Organizational Behavior \& Human Decision Processing, 35, 340-381.

Heaney, C.A., \& Israel, B.A. (1990). Social networks and Social Support, In K. Glanz, F.M. Lewis \& B.K. Rimer (Eds.), Health Behaviour and Health Education: Theory, Research and Practice (pp.179-205). San Francisco: Joney-Bass.

Henne, D., \& Locke, E.A. (1985). Job dissatisfaction: what are the consequences? International Journal of Psychology, 20, 221-240.

Hills, H., \& Norvell, N. (1991). An examination of hardiness and neuroticism as potential moderators of stress outcomes. Behavioral Medicine, 17, 31-38.

Himle, D.P., Jayaratne, S., \& Thyness, P.A. (1989). The effects of emotional support on burnout, work stress and mental health among Norwegian and American social workers. Journal of Social Service Research, 13, 27-45.

Holahan, C., \& Moos, R. (1990). Life stressors, resistance factors, and improved psychological functioning: a extension of the stress resistance paradigm. Journal of Personality and Social Psychology, 58, 909-917.

House, J. S. (1981) Work Stress and Social Support. Massachusetts: AddisonWesley Publishing Company.

Hoyle, R.H. (1995). Structural Equation Modeling. California: Sage Publications, Inc.

Hurrell, J.J., \& McLaney, M.A. (1988). Exposure to job stress- A new psychometric instrument. Scandanavian Journal of Work Environment and Health, 68, 3-19.

Jackson, S., \& Schuler, R. (1985). A meta-analysis and conceptual critique of research on role ambiguity and role conflict in work settings. Organizational Behavior and Decision Processes, 36, 16-78.

James, L.A., \& James, L.R. (1989). Integrating work environment perceptions: explorations into the measurement of meaning. Journal of Applied Psychology, 74, 739-751. 
Janssen, O. (2000). Job demands, perceptions of effort-reward fairness and innovative work behavior. Journal of Occupational and Organizational Psychology, 73, 287-302.

Judge, T.A., \& Watanabe, S. (1993). Another look at the job satisfaction-life satisfaction relationship. Journal of Applied Psychology, 78, 939-948.

Judge, T.A., Locke, E.A., Durham, C.C., \& Kluger, A.N. (1998). Dispositional effects on job and life satisfaction: the role of core evaluations. Journal of Applied Psychology, 83, 17-34.

Kahn, R.L., Wolfe, E.M., Quinn, R.P., Snoek, J.D., \& Rosenthal, P. (1964). Organizational Stress: Studies in role conflict and ambiguity. New York: Wiley.

Karasek, R.A., \& Theorell, T. (1990). Healthy Work. Stress, Productivity, and the Reconstruction of Working Life. Basic Books: New York.

Karasek, R.A., Triantus, K., \& Chaudry, S. (1982). Coworker and supervisor support as moderators of associations between task characteristics and mental strain. Journal of Occupational Behavior, 3, 147-160.

Kobasa, S.C. (1982). Commitment and coping in stress resistance among lawyers. Journal of Personality and Social Psychology, 42, 707-717.

Kobasa, S.C., Maddi, \& Kahn (1982). Hardiness and health: A prospective study. Journal of Personality and Social Psychology, 42, 168-177.

Kompier, M.A., Geurts, S.A., Grudemann, R.W., Vink, P., \& Smulders, P.G. (1998). Cases in stress prevention: the success of a participative and stepwise approach. Stress Medicine, 14, 155-168.

Lambert, Jr, C.E., \& Lambert, V.A. (1999). Psychological hardiness: state of science. Holistic Nursing Practice, 13, 11-19.

Langemo, D.K. (1990). Impact of work stress on female nurse educators. IMAGE: Journal of Nursing Scholarship, 22, 159-162.

Lazarus, R.S., \& Folkman, S. (1984). Stress, Appraisal, and Coping. New York: Springer.

Lazarus, R.S. (1966). Psychological Stress and the Coping Process. New York: McGraw-Hill. 
Levin, I., \& Stokes, J.P. (1989). Dispositional approach to job satisfaction: role of negative affectivity. Journal of Applied Psychology, 74, 752-758.

Locke, E.A. (1992). The nature and causes of job satisfaction, in M.D. Dunnette (Ed.), Handbook of Industrial and Organizational Psychology. Chicago: Rand McNally.

Mackie, K.S., Holahan, C.K. \& Gottlieb, N.H. (2001). Employee involvement practices and mental health in male and female employees of a human services residential facility. Human Relations, 54(8), 1065-1092.

Maddi, S.R., \& Kobasa, S.C. (1984). The hardy executive: Healthy under stress. Homewood, Illinois: Dow Jones-Irwin.

Mak, A.S., \& Mueller, J. (2000). Job insecurity, coping resources and personality dispositions in occupational strain. Work \& Stress, 14, 312-328.

Mannheim, B., Baruch, Y., \& Tal, J. (1997). Alternative models for antecedents and outcomes of work centrality and job satisfaction of high-tech personnel. Human Relations, 50, 1537-1562.

Manning, M.R., Willaims, R.F., \& Wolfe, D.M. (1988). Hardiness and the relationship between stressors and outcomes. Work \& Stress, 2, 205-216.

Martin, T.N., \& Hunt, J.G. (1980). Social influence and intent to leave a pathanalytic process model. Personnel Psychology, 33, 505-527.

Mobley, W.H. (1977). Intermediate Linkages in the relationship between job satisfaction and employee turnover. Journal of Applied Pyschology, 562, 237-240.

Moyle, P. (1998). Longitudinal influences of managerial support on employee well-being. Work \& Stress, 12, 29-49.

Murphy, L.R. (2002). Stress management. In: O’Donnell, M.P.(Ed.), Health promotion in the workplace. (pp.389-414). Albany, NY: Delmar.

Nagy, M.S. (2002). Using a single-item approach to measure facet job satisfaction. Journal of Occupational and Organizational Psychology, 75, 77-86.

National Institute for Occupational Safety and Health. (1999). Stress at Work. (DHHS NIOSH Publication No. 99-101). Cincinnati, OH: NIOSH. 
Necowitz, L.B., \& Roznowski, M. (1994). Negative affectivity and job satisfaction: cognitive processes underlying the relationship and effects on employee behaviors. Journal of Vocational Behavior, 45, 270-294.

Nie, H.H., Hull, C.H., Jenkins, J.G., Steinbrenner, K., \& Bent, D.H. (1974). Statistical package for the social sciences (SPSS). Version 10.0. [computer software]. New York: McGraw-Hill.

O'donnell, M.P. (Ed.). (2002). Health Promotion in the Workplace. Third edition. Albany, New York: Delmar Thomson Learning.

Poulin, J.E., \& Walter, C.A. (1992). Retention plans and job satisfaction of gerontological social workers. Journal of Gerontological Social Work, 19, 99-114.

Ray, E.B., \& Miller, K I. (1994). Social support, home/work stress, and burnout: who can help? Journal of Applied Behavioral Science, 30, 357-373.

Revicki, D.A., Whitley, T.W., \& Gallery, M.E. (1993). Organizational characteristics, perceived work stress, and depression in emergency medicine residents. Behavioral Medicine, 19, 74-81.

Rosse, J.G., \& Hulin, C.L. (1985). Adaptation to Work: An analysis of employee health, withdrawal, and change. Organizational Behavior and Human Decision Processes, 36, 324-347.

Rout, U. (1999). Gender differences in stress, satisfaction and mental wellbeing among general practitioners in England. Psychology, Health \& Medicine, $4,345-355$.

Rush, M.C., Schoel, W.A., \& Barnard, S.M. (1995). Psychological resiliency in the public sector: "Hardiness" and pressure for change. Journal of Vocational Behavior, 46, 17-39.

Sagie, A. (1998). Employee absenteeism, organizational commitment, and job satisfaction: another look. Journal of Vocational Behavior, 52, 156-171.

Sauter, S.L., \& Murphy, L.R. (Eds.) (1995). Organizational risk factors for job stress. Washington, D.C.: American Psychological Association.

Scarpello, V., \& Campbell, J.P. (1983). Job satisfaction: are all parts there? Personnel Psychology, 36, 557-600. 
Schaefer, J.A., \& Moos, R.H. (1992). Life crises and personal growth. In B.N. Carpenter (Ed.), Personal coping theory, research and applications. (pp.149-170). NewYork: Praeger.

Schaubroeck, J., \& Fink, L.S. (1998). Facilitating and inhabiting effects of job control and social support on stress outcomes and role behavior: a contingency model. Journal of Organizational Behavior, 19, 167-195.

Schirmer, L.L., \& Lopez, F.G. (2001). Probing the social support and work strain relationship among adult workers: Contributions of adult attachment orientations. Journal of Vocational Behavior, 59, 17-33.

Seers, A., McGee, G.W., Serey, T.T., \& Graen, G.B. (1983). The interaction of job stress and social support: a strong inference investigation. Academy of Management Journal. 26, 273-284.

Steinhardt, M.A., Dolbier, C.L., Gottlieb, N.H., \& McCalister, K.T. (In press). The impact of personality and workplace relationships on job stress and job satisfaction. American Journal of Health Promotion.

Terry, D.J., Nielsen, M., \& Perchard, L. (1993). Effects of work stress on psychological well-being and job satisfaction: the stress-buffering role of social support. Australian Journal of Psychology, 45, 168-175.

Thoits, P.A. (1983). Dimensions of life events that influence psychological distress: an evaluation and synthesis of the literature. In. H.B. Kaplan (Ed.), Psychosocial Stress: Trends in theory and research (pp. 33-103). New York, NY: Academic Press.

Turnipseed, D.L. (1999). An exploratory study of the hardy personality at work in the health care industry. Psychological Reports, 85, 1199-1217.

Ulleberg, P., \& Rundmo, T. (1997). Job stress, social support, job satisfaction and absenteeism among offshore oil personal. Work \& Stress, 1, 215-228.

U.S. Department of Labor. (1999a). Occupational employment projections to 2008. Bureau of Labor Statistics, November, 1999. Retrieved from http://www.stats.bls.gov/opub/mlr/1999/11/art5exc.htm

U.S. Department of Labor. (1999b). Occupational stress and time away from work. Bureau of Labor Statistics, October, 1999. Retrieved from http://www.stats.bls.gov/opub/ted/1999/oct/wk3/art03.htm 
Viswesvaran, C., Sanchez, J.I., \& Fisher, J. (1999). The role of social support in the process of work stress: A metanalysis. Journal of Vocational Behavior,54, 314-334.

Wanous, J.P., Reichers, A.E., \& Hudy, M.J. (1997). Overall job satisfaction: how good are single-item measures. Journal of Applied Psychology, 82, 247252.

Warr, P., Cook, J., \& Wall, T. (1979). Scales for the measurement of some work attitudes and aspects of psychological well-being. Journal of Occupational Psychology, 52, 129-148.

Watson, D., Clark, L.A., \& Tellegen, A. (1988). Development and validation of brief measures of positive and negative affect: the PANAS scales. Journal of Personality and Social Psychology, 54, 1063-1070.

Watson, D., \& Pennebaker, J.W. (1989). Health complaints, stress and distress: exploring the central role of negative affectivity. Psychological Review, 96, 234-254.

Williams, L.J., \& Hazer, J.T. (1986). Antecedents and consequences of satisfaction and commitment in turnover models: A reanalysis using latent variable structural equation methods. Journal of Applied Psychology, 71, 219-231.

Winnubst, J.A., Marcelissen, F.H., \& Kleber, R.J. (1982). Effects of social support in the stressor-strain relationship: A dutch sample. Social Science in Medicine, 16, 475-482.

Wong, K.S., Cheuk, W.H., \& Rosen, S. (2000). The influences of job stress and supervisor support on negative affects and job satisfaction in kindergarten principals. Journal of Social Behavior \& Personality, 15, 85-98.

Wright, T.A., Bennett, K.K., \& Dun, T. (1999). Life and job satisfaction. Psychological Reports, 84, 1025-1028. 


\section{Vita}

Katherine Saunders McCalister was born in Brisbane, Australia on October 23, 1970, the daughter of Charles Richard and Donna Kay Saunders. After completing her work at Plano East High School, Plano, Texas, in 1988, she entered The University of Texas at Austin, in Austin Texas. She received the degree of Bachelor of Science in Kinesiology from The University of Texas in May of 1993. During the following year she was employed by Charlton Methodist Hospital of Dallas as a Health Education Coordinator. In August of 1994, she entered the Graduate school of The University of Texas where she was employed as a Teaching Assistant for the following year. In 1995, she began working for Applied Materials, first coordinating then managing corporate employee health and wellness programs. She completed the degree of Master of Art in Health Education at The University of Texas in August, 1996. In January, 1997, she began her doctorate in Health Education, specializing in Business at The University of Texas at Austin.

Permanent address: 3503 Latimer Dr., Austin, Texas, 78732

This dissertation was typed by the author. 